\title{
Electrogenetic cellular insulin release for real-time glycemic control in type 1 diabetic mice
}

\section{Journal Article}

\section{Author(s):}

Krawczyk, Krzysztof; Xue, Shuai; Buchmann, Peter; Charpin-El-Hamri, Ghislaine; Saxena, Pratik; Hussherr, Marie-Didiée; Shao, Jiawei; Ye, Haifeng; Xie, Mingqi; Fussenegger, Martin (D)

Publication date:

2020-05-29

Permanent link:

https://doi.org/10.3929/ethz-b-000418642

Rights / license:

In Copyright - Non-Commercial Use Permitted

Originally published in:

Science 368(6494), https://doi.org/10.1126/science.aau7187

Funding acknowledgement:

785800 - Electrogenetics - Shaping Electrogenetic Interfaces for Closed-Loop Voltage-Controlled Gene Expression (EC) 
Electrogenetic cellular insulin release for real-time glycemic control in type-1 diabetic mice

Krzysztof Krawczyk $^{1,2}$, Shuai Xue ${ }^{1,3}$, Peter Buchmann ${ }^{1}$, Ghislaine Charpin-El-Hamri ${ }^{4}$, Pratik Saxena $^{1}$, Marie-Didiée Hussherr ${ }^{1}$, Jiawei Shao ${ }^{3,5}$, Haifeng Ye ${ }^{3}$, Mingqi Xie ${ }^{1,5}$ and Martin Fussenegger ${ }^{1,6, *}$

${ }^{1}$ Department of Biosystems Science and Engineering, ETH Zurich, Mattenstrasse 26, CH-4058 Basel, Switzerland.

${ }^{2}$ Present Address: Novartis Pharma AG, P.O. Box, CH-4002 Basel, Switzerland.

${ }^{3}$ Shanghai Key Laboratory of Regulatory Biology, Institute of Biomedical Sciences and School of Life Sciences, East China Normal University, Dongchuan Road 500, Shanghai 200241, People's Republic of China

${ }^{4}$ Département Génie Biologique, Institut Universitaire de Technologie Lyon 1, 74 Boulevard Niels Bohr, F-69622 Villeurbanne Cedex, France.

${ }^{5}$ Key Laboratory of Growth Regulation and Transformation Research of Zheijang Province, School of Life Sciences, Westlake University, Shilongshan Road 18, Hangzhou, People's Republic of China.

${ }^{6}$ Faculty of Science, University of Basel, Mattenstrasse 26, CH-4058 Basel, Switzerland

${ }^{*}$ Corresponding author. E-mail: fussenegger@bsse.ethz.ch

Sophisticated devices for remote-controlled medical interventions require an electrogenetic interface that uses digital electronic input to directly program cellular behavior. Here, we present a cofactor-free bioelectronic interface that directly links wireless-powered electrical stimulation of human cells to either synthetic-promoterdriven transgene expression or rapid secretion of constitutively expressed protein therapeutics from vesicular stores. Electrogenetic control was achieved by coupling ectopic expression of L-type voltage-gated channel (Cav1.2) and inwardly rectifying potassium channel $\left(K_{\mathrm{ir}} 2.1\right)$ to the desired output through endogenous calcium signaling. Focusing on type-1 diabetes, we engineered electro-sensitive human $\beta$-cells (Electro $\beta$ ). Wireless electrical stimulation of Electro $\beta$ inside a custom-built bioelectronic device provided real-time control of vesicular insulin release; insulin levels peaked within 10 


\section{minutes. When subcutaneously implanted, this electro-triggered vesicular release system restored normoglycemia in type-1-diabetic mice.}

Electronic insulin expression and electro-stimulated insulin release for next-generation diabetes therapy.

Precise control of dosage is essential for the success of any drug-based therapy (1-4). However, taking pills or administering biopharmaceuticals at regular intervals based on body weight, as is standard medical practice, is far from being precise and does not reflect the dynamics required for sophisticated metabolic interventions (1-4). Cell-based therapies capitalizing on implanted encapsulated designer cells engineered to fine-tune in-situ production and systemic delivery of protein therapeutics in response to chemical and physical cues have shown promising results in proof-of-concept studies $(5,6)$. Since chemical control input is often limited, traceless physical cues such as light (optogenetics) (7-10), heat transmitted by magnetic fields (magnetogenetics) or radio waves (radiogenetics) (11-14) are attractive for achieving rapid remote-control of therapeutic transgene expression, because they avoid the side effects $(15,16)$ and challenges with bioavailability or pharmacodynamics of chemical trigger compounds (17-20). However, available physically triggered gene switches may require a high energy input $(6,7,9)$, often involve complex chemical or inorganic cofactors $(12,21)$, and may require fine-tuning of the transcription of the therapeutic transgenes, which slows down the overall response dynamics $(5,6,9,12,22)$. Thus, direct cofactor-free wireless electrical stimulation of engineered cells to control vesicular secretion of protein therapeutics in a robust, adjustable and repeatable manner would offer substantial advantages for medical applications by enabling direct communication between electronic devices and designer cells.

Although cellular metabolism and human-made electronics share similar operating principles in terms of input sensing, information processing and output production, the core information transfer and processing functions of living and electronic systems are different, which limits their interoperability. Humans employ ion gradients across insulated membranes to simultaneously process slow analog chemical reactions and communicate information in multicellular systems through soluble or gaseous molecular signals. In contrast, electronic systems use multicore central processing units to control the flow of electrons through insulated metal wires with gigahertz frequency and communicate information across networks via wired or wireless connections. Thus, direct electrical stimulation of gene expression or vesicular 
secretion requires a bioelectronic interface that manages electrical conduction between electrodes and electrosensitive designer cells, as well as conversion of electronic information via depolarization to protein production and release.

The first attempts to create an electrogenetic interface were reported over a decade ago $(23,24)$, but that interface was neither direct nor usable under physiological conditions. More recently, a SoxR-based redox system that can control gene expression in Escherichia coli was reported (25), but this was also not direct, and was too toxic for in-vivo application. Thus, despite decades of expertise in converting trigger-inducible bacterial and fungal repressoroperator interactions into synthetic mammalian gene switches, simple translation of bacterial electrogenetics into a mammalian cellular context has been unsuccessful due to the cytotoxicity, limited bioavailability and poor clinical compatibility of electro-sensitive redox compounds (23).

With the advent of optogenetics it became possible to remote-control target gene expression by illumination with light and so to indirectly link electrical stimulation via a light source with cellular transcription control $(6,10)$. This enabled glycemic control of experimental type-2 diabetes by controlling an optogenetic biomedical implant with a smartphone to upload instructions for designer cells to produce and systemically deliver a therapeutic dose of an insulinogenic peptide (6). However, the optogenetic device requires a considerable amount of energy to operate the light source $(6,10)$. The power-efficiency associated with direct electrical stimulation is a major reason why clinically licensed pacemakers can be battery-powered for a lifespan of at least 15 years (26). Other major challenges to the clinical application of optogenetic technology include illumination-based cytotoxicity (27), the use of bacterial components $(6,10,18-20)$, and the need for sophisticated chemical or inorganic cofactors that have side effects (28-30), poor bioavailability or short half-lives in vivo (31). Other traceless physical control technologies based on electro-induced heat transmission such as magneto- and radiogenetics share the same challenges $(12,21,32$, $33)$.

Diabetes is a common, chronic condition, and so is an attractive target for individualized precision treatment. Regulation of blood-glucose levels is a closed-loop homeostatic process. Glucose-stimulated insulin release by pancreatic $\beta$-cells involves uptake and metabolism of glucose, ATP-mediated closure of potassium channels, depolarization of the plasma membrane, and opening of the voltage-gated calcium channels, which results in an intracellular $\mathrm{Ca}^{2+}$ surge and concurrent rapid release of insulin from intracellular storage vesicles (34). For intervention in this process, we aimed to design a bioelectronic interface 
consisting of an implantable platform that combines electronics and electrosensitive designer cells that can release insulin on demand. The implant would incorporate a cell chamber containing semipermeable membranes that permit nutrient supply and product delivery via fibrous connective tissue, while protecting the designer cells from cellular host responses (35, 36) and securely containing them for safety reasons (37). To address this need, we describe here a direct cofactor-free electrogenetic interface to trigger vesicular secretion of insulin by using electrical stimulation to modulate the membrane polarization of human $\beta$-cells (Electro) engineered for ectopic expression of calcium and potassium channels. Furthermore, to validate our approach, we incorporated these electro-sensitive designer cells into a bioelectronics implant and evaluated its performance in a mouse model of type-1 diabetes.

\section{Results}

\section{Membrane depolarization-based transcriptional control in mammalian cells}

L-Type voltage-gated calcium channels consist of $\alpha_{1}, \alpha_{2}, \delta$, and $\beta$ subunits and are essential for the functioning of cardiomyocytes, neurons and endocrine cells (38). These channels open upon membrane depolarization, and the resulting calcium influx regulates muscle contraction, vesicular secretion of hormones, and NFAT (nuclear factor of activated Tcells)-driven induction of target genes (39).

To design a mammalian transcription-control circuit responsive to membrane depolarization, we cotransfected HEK-293T cells with one of the three L-type voltage-gated calcium channels, Cav1.2, Cav1.342A or Cav1.3 ${ }_{\Delta 42}$, encoded by the common $\alpha_{2} / \delta_{1}\left(\mathrm{pCav} \alpha_{2} \delta_{1}\right.$, $\left.\mathrm{P}_{\mathrm{hCMV}}-\alpha_{2} / \delta_{1}-\mathrm{pA}\right)$ and $\beta_{3}\left(\mathrm{pCav} \beta_{3}, \mathrm{P}_{\mathrm{hCMV}}-\beta_{3}-\mathrm{pA}\right)$ subunits and the respective channel-forming subunit $\alpha_{1} \mathrm{C}\left(\mathrm{pCav} 1.2, \mathrm{P}_{\mathrm{hCMV}}-\alpha_{1} \mathrm{C}-\mathrm{pA}\right), \alpha_{1} \mathrm{D}_{42 \mathrm{~A}}\left(\mathrm{pCa} \mathrm{a}_{1}\right.$ 1.32A $\left._{42}, \mathrm{P}_{\mathrm{hCMV}}-\alpha_{1} \mathrm{D}_{42 \mathrm{~A}}-\mathrm{pA}\right)$ or $\alpha_{1} \mathrm{D}_{\Delta 42}$ ( $\left.\mathrm{pCa}_{\mathrm{V}} 1.3_{\Delta 42}, \mathrm{P}_{\mathrm{hCMV}}-\alpha_{1} \mathrm{D}_{\Delta 42}-\mathrm{pA}\right)$, as well as the reporter plasmid pMX57 encoding the human placental secreted alkaline phosphatase (SEAP) driven by the P $_{\mathrm{NFAT3}}$ promoter (pMX57, $\mathrm{P}_{\mathrm{NFAT3}}-\mathrm{SEAP-pA}$ ) (Fig. 1A). Depolarization of channel-transgenic HEK-293T cells with 40 $\mathrm{mM} \mathrm{KCl}$ revealed that ectopic expression of Cav1.2 showed the highest depolarizationtriggered SEAP induction (Fig. 1B).

Coexpression of the inwardly rectifying potassium channel $\mathrm{K}_{\mathrm{ir}} 2.1\left(\mathrm{pK}_{\mathrm{ir}} 2.1, \mathrm{P}_{\mathrm{hCMV}}-\right.$ $\mathrm{K}_{\mathrm{ir}} 2.1-\mathrm{pA}$ ), which has been reported to decrease the resting membrane potential of mammalian cells (40), substantially decreased basal SEAP expression and improved the overall induction profile of the depolarization-triggered Cav1.2-mediated transcription-control device (Fig. 1C). Combinatorial analysis of the importance of Cav1.2's individual components for overall 
depolarization-triggered transcription control revealed that the channel-forming $\alpha_{1} \mathrm{C}$ subunit was essential, whereas $\alpha_{2} / \delta_{1}$ and $\beta_{3}$ were not, although their absence reduced the maximum SEAP expression (Fig. S1). Therefore, we used cells expressing the full Cav1.2 with the $\alpha_{1} \mathrm{C}$, $\alpha_{2} / \delta_{1}$ and $\beta_{3}$ components as well as Kir2.1, referred to as ElectroHEK, in all follow-up experiments. Importantly, ElectroHEK cells are not activated by physiological ion concentrations, not even at life-threatening levels of $\mathrm{KCl}(6.5 \mathrm{mM}(27))$ or at $\mathrm{CaCl}_{2}$ levels representing a medical emergency $(3.5 \mathrm{mM}(28))$ (Fig. S2).

\section{Design and characterization of a synthetic electrogenetic mammalian transcription- control device}

To test whether transgene expression can be directly triggered by electrically stimulated membrane depolarization, we electrostimulated the ElectroHEK cells transfected with the $\mathrm{P}_{\mathrm{NFAT} 3}-$ driven SEAP expression vector (pMX57, P $_{\mathrm{NFAT}}$-SEAP-pA), using voltage-controlled square unipolar pulses with alternate polarization (41-43) (Fig. 2A). Indeed, electric pulse stimulation triggered pMX57-transgenic ElectroHEK cells to produce high levels of SEAP (Fig. 2B-D). The electrostimulated transgene expression could be fine-tuned by voltage (maximum SEAP induction at $50 \mathrm{~V}$ ) (Fig. 2B) as well as adjusted by altering the pulse length (maximum SEAP induction at $2 \mathrm{~ms}$ ) (Fig. 2C). Full activation of the system was reached after 4 hours of stimulation (Fig. 2D). Electrostimulation efficiency did not depend on the pulsing frequency within the range of $0.5-10 \mathrm{~Hz}$ (Fig. 2E). Importantly, the parameter set employed for effective electrostimulation did not decrease cell viability (Fig. S3A-D). Additionally, Cav1.2-deficient HEK-293T cells were insensitive to electrostimulation (Fig. S3E). Kinetic experiments revealed maximum SEAP expression 7 hours after the beginning of stimulation (Fig. S4A) and confirmed the reversibility of the system (Fig. S4B).

\section{Design of the bioelectronic implant}

Translation of electrostimulated gene expression into a clinical proof-of-concept bioelectronic implant required a more compact design for electrodes and electrostimulation. Simple miniaturization of the free-hanging electrodes used in the device described above did not provide efficient electrostimulation. Thus we designed a custom-engineered cell-culture insert containing electrodes on either side of a semipermeable membrane harboring a monolayer of electrosensitive ElectroHEK cells (Fig. 3A). Electrostimulation of pMX57 (P PFAT3SEAP-pA)-transfected ElectroHEKs resulted in peak SEAP levels at 7.5 V (Fig. 3B,C), which is one order of magnitude lower than that of the previous free-hanging electrode arrangement, 
and at shorter pulse length (Fig. 3D,E); both factors are important for high power efficiency of any electrostimulation device.

To enable electrostimulated transgene expression by electrosensitive cells in vivo, we designed a wireless-powered bioelectronic implant. The custom-engineered cell-culture insert equipped with the electrodes was clicked into a 3D-printed FDA-licensed polyamide casing (Fig. 4a,c) containing a sealed electronic switchboard (Fig. S5, S6) that generates the square unipolar pulses for electrostimulation of the encapsulated ElectroHEKs. The implant's electronics is inductively powered and controlled by an extracorporeal field generator that wirelessly communicates with the bioelectronic implant at the ISM (industrial, scientific and medical) frequency (13.56 MHz) (Fig. 4B, S7, S8). The implant generates square pulses, the voltage of which is dependent on the distance to the center of the field generator (Fig. S9). The electronic circuit is insensitive to temperatures between $25{ }^{\circ} \mathrm{C}$ and $50{ }^{\circ} \mathrm{C}$ (Table S1). A control run of the bioelectronic implant validated wireless-controlled electrostimulated SEAP expression of pMX57-transfected ElectroHEK cells (Fig. 4C). We confirmed that the bioelectronic implants are IPX7 waterproof (International Protection Marking, IEC standard 60529) and show no cell leakage in a five-day in vitro experiment (Table S2).

\section{Electro $\beta$ cells providing electrostimulated vesicular secretion}

Since ElectroHEK-based insulin production is transcription-based, it lacks the rapid release dynamics of vesicular secretion characteristic of native pancreatic $\beta$-cells (5). To engineer mammalian cells for electrostimulated vesicular release of insulin (Fig. 5A), we derived a monoclonal population $\mathrm{INS}_{\mathrm{Vesc}}$ from the pancreatic $\beta$-cell line 1.1E7 (44) by selection for deficiency in glucose sensitivity (Fig. 6E,F), but with retention of the vesicular insulin-

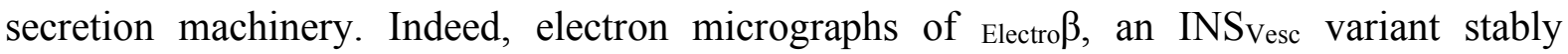
transgenic for constitutive expression of Cav1.2 and $\mathrm{K}_{\mathrm{ir}} 2.1$ channels (pKK66, $\mathrm{P}_{\mathrm{hEF} 1 \alpha^{-}-\alpha_{1} \mathrm{C}-\mathrm{P} 2 \mathrm{~A}-}$ $\left.\mathrm{K}_{\mathrm{ir}} 2.1-\mathrm{pA} ; \mathrm{pMX} 251, \mathrm{P}_{\mathrm{hEF} 1 \alpha^{-}} \alpha_{2} / \delta_{1}-\mathrm{P} 2 \mathrm{~A}-\beta_{3}-\mathrm{pA}\right)$ as well as Proinsulin-NanoLuc, a designer construct engineered to co-secrete insulin and the Oplophorus gracilirostris luciferase (NanoLuc) at an equimolar ratio in endocrine cell types (45) (Fig. 5A), revealed storage vesicles reminiscent of insulin-containing granules of human islet-derived $\beta$-cells (Fig. 5D,E). Additionally, Electro $\beta$ showed well-correlated vesicular insulin and NanoLuc secretion in response to $\mathrm{KCl}$-mediated (Fig. 5B,C) or electrostimulated (Fig. 6A,B) membrane depolarization. The stability and functionality of the Electro $\beta$ cell line were confirmed over at least 30 passages during 3 months in continuous culture (Fig. S10). 
The depolarization-based insulin-release dynamics was profiled by electrostimulating Electro $\beta$ and recording the corresponding NanoLuc-mediated luminescence in the culture supernatant (Fig. 6C). Peak NanoLuc levels were reached within ten minutes following electrostimulation (Fig. 6C), compared to 8 hours for transcription-based insulin production and secretion by ElectroHEK, HEK- $\beta$ (5) and OptoHEK (9) (Fig. S11). When repeatedly electrostimulated, Electro $\beta$ recovered full secretory capacity after four hours (Fig. 6D). Most importantly, Electro $\beta$ did not show any glucose-sensitive insulin production, which ensures exclusive electrostimulation control of vesicular insulin secretion, without interference from blood-glucose levels (Fig. 6E,F). Overall, Electro $\beta$ showed similar electrostimulation parameters to ElectroHEK (Fig. S12A-D). To illustrate the broad applicability of our approach, we also demonstrated electro-stimulated vesicular secretion of glucagon by pancreatic alpha cells, which secrete the insulin counter-regulatory hormone glucagon by calcium-triggered vesicular release (46) (Fig. S13) - this is akin to the $\beta$-cell-mediated insulin secretion.

\section{Wireless electrostimulated vesicular secretion of insulin provides rapid glycemic control in type-1 diabetic mice}

Native pancreatic $\beta$-cells release the insulin stored in granules via a process known as vesicular secretion (34). The immediate release of stored insulin improves the response dynamics and rapidly restores blood-glucose homeostasis in response to postprandial excursions. So far, designer cell-based proof-of-concept strategies to treat experimental diabetes have focused on transcriptional control, which is considered too slow to cope with postprandial blood-glucose surges $(5,6,12,14,21)$. For example, previously reported HEK- $\beta$ cells (5), which rely on transcriptional control and the classical secretory pathway for insulin release, require up to 24 hours to reach physiological blood-insulin levels (Fig. S14). Similar

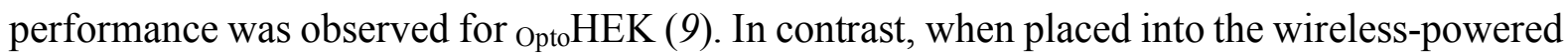
bioelectronic implant (Fig. 4), Electro $\beta$ cells could re-establish postprandial glucose metabolism in insulin-deficient type-1 diabetic mice following a brief electrostimulation without causing hypoglycemic excursions (Fig. 7A), and instantaneously decrease blood-glucose levels to restore normoglycemia following electrostimulation (Fig. 7B). Notably, the results of glucose tolerance tests revealed comparable performance between Electro $\beta$ and human pancreatic islets, which are known to release insulin by vesicular secretion upon glucose sensing (Fig. S7A). Fast vesicular secretion was also confirmed by blood-luminescence quantification (47), which showed a peak signal just 1 hour following electrostimulation, returning to baseline after 2 
hours (Fig. 7C). Glycemia could also be controlled over longer periods of time without any sign of hypoglycemia (Fig. 7D).

\section{Biocompatibility and functional longevity of the bioelectronic implant}

To validate the biocompatibility of the bioelectronic implants, we analyzed treated animals as well as explanted devices at three weeks after implantation, according to ISO 10993 (48), and we observed no material cytotoxicity, systemic kidney or liver toxicity, or alteration of hematologic profile or systemic immune responses; in addition, we saw no local immunecell infiltration or substantial fibrotic tissue formation at the implant-tissue interface. There was no apparent indication of implant-related cytotoxicity (Fig. S15) or systemic toxicity (Table S3), and no apparent difference in hematologic profiles among cell-containing and cellfree bioelectronic implants and biocompatible control implants (Table S4). Likewise, we found no marked difference in the well-vascularized fibrous capsule surrounding the implants (Fig. S16) or in immune-cell infiltration (Fig. S17, Table S5) among cell-containing, cell-free and biocompatible control implants. Mice implanted with Electro $\beta$-cell-containing bioelectronic devices showed no change of body weight compared to untreated animals; also, signs of irritation or inflammation, as well as serum levels of inflammatory cytokines, were similar to or lower than those of animals treated with cell-free or biocompatible reference implants (Fig. S18, Fig. S19). Visual inspection of explanted bioelectronic devices showed no decomposition and no apparent erosion (Fig. S20).

In view of the need for clinical translation towards a lifestyle-compatible therapeutic product, we adapted the bioelectronic implant architecture to allow repetitive exchange of individual cell batches over time (Fig. S20A). Sequential in-situ "refilling" of the implanted bioelectronic device with fresh batches of Electro $\beta$-cells without the need for surgical removal or replacement of the implant will reduce cost as well as implant-associated infections, while increasing patients' convenience and treatment longevity. Insulin levels of type-1-diabetic mice, which had the Electro $\beta$ cells of their bioelectronic implants replaced once a week for a period of three weeks, were restored after remote-controlled electro-stimulated insulin release by Electro $\beta$ cells (Fig. S20B, C). Together, these results suggest that the bioelectronic implant successfully integrates the advantages of electronics-based (49) and cell-based counterparts (5), and represents a promising approach to diabetes treatment. 


\section{Discussion}

In this work, we have eliminated the need to use light as a converter between electronics and genetics, advancing optogenetics into electrogenetics by engineering a direct, co-factorfree electrogenetic interface that enables electronics to directly program gene expression as well as vesicular secretion in human cells. Furthermore, by incorporating electrogenetic designer cells (Electro $\beta$ ) containing this interface into a bioelectronic implant, we have successfully implemented a proof-of-concept device providing rapid electro-stimulated insulin release for the treatment of experimental type-1 diabetes. The overall slow response dynamics associated with transcription-based control systems $(5,6,9,10,12,15,16,18-21)$ highlights the importance of vesicular secretion for the treatment of diabetes, which requires quick vesicular release of insulin to respond rapidly to postprandial blood-glucose surges $(50,51)$. Indeed, we found that wireless electrical stimulation of vesicular insulin release from our engineered Electro $\beta$ cells encapsulated in a bioelectronic implant could attenuate postprandial hyperglycemia in type-1 diabetic mice with comparable performance to transplanted human pancreatic islets.

Taking account of the importance of economical manufacturing, we integrated all components of the bioelectronic implant into a 3D-printed polyamide casing. Although the bioelectronic implant could in principle be powered by batteries (52) (Table S4), for practical reasons, including the limited space for implantation and the intrusiveness of animal experimentation, we chose to power the device inductively at $13.56 \mathrm{MHz}$, an FCC-licensed radio frequency that is reserved internationally for industrial, scientific and medical devices and does not interfere with telecommunications. Due to the power efficiency of the implant, we speculate that wireless-powered control by wearable devices such as smartphones and smartwatches might be feasible in the near future.

However, reaching the full therapeutic potential of electrogenetics will require closedloop control. Whereas classical medical interventions are open-loop, since the dose is largely determined by the physician based upon body weight, closed-loop systems enable feed-back control that coordinates biomarker input to therapeutic output and provides an autonomous and self-sufficient interface with patients' metabolism. For electrogenetic type-1 diabetes control, this would mean using electronic blood-glucose sensors to directly control electro-stimulated insulin release in real time, much like the concepts currently being explored for prototypes of the bionic pancreas (53). However, electronic closed-loop systems operating in the bionic pancreas require frequent calibration, and have a short life-span of only a few days (49). On 
the other hand, incorporation of a microcontroller and/or a glucometer into our bioelectronic implant to achieve closed-loop insulin control should be a straightforward electrical engineering implementation. Most importantly, the delayed resorption of insulin from subcutaneous tissues to which insulin is delivered by the bionic pancreas requires dualhormone control using glucagon to counteract or prevent insulin-mediated hypoglycemia ( 54 , 55). We show here that glucagon can be released from pancreatic $\alpha$-cells by vesicular secretion, just as insulin is from $\beta$-cells, suggesting that a dual-hormone electrogenetic system using two types of engineered cells would be feasible. Nevertheless, dual-hormone control is not expected to be necessary with our electrogenetic system, because, as noted above, the dynamics of electro-stimulated vesicular insulin secretion from Electro $\beta$ cells appear to be comparable with those of human pancreatic islets. Furthermore, the demonstration that our system works in two different types of cells suggests broad potential applicability of electrogenetics for electrostimulated hormone release in future cell-based therapies

As in the case of the bionic pancreas (53), long-term functionality of cellular implants remains a major challenge in designing next-generation encapsulated cell-based therapeutic devices (56). A recent clinical trial using encapsulated pancreatic progenitor cells, the precursor phenotype of insulin-secreting $\beta$-cells (Viacyte's $\mathrm{VC}-01^{\mathrm{TM}}$ ), confirmed the need for further technological development to promote engraftment (57) Long-term functionality of cells inside implants remains among the challenges facing translation of academic proof-of-concept studies into clinical reality. In this context, the first initiatives to improve viability (Beta-O2 Technologies - $\beta A \mathrm{Ar}^{\circledR}$ ) as well as vascularization of encapsulated cells (58) (e.g., Viacyte's PEC Direct $^{\mathrm{TM}}$ or Sernova's Cell Pouch System ${ }^{\mathrm{TM}}$ ) have already begun in industry.

We have shown here that wireless electrical stimulation of insulin release by electrosensitive designer cells inside a bioelectronic implant was able to rapidly restore normoglycemia in type-1 diabetic mice. Wireless electronic devices programming the release of biopharmaceuticals, either via the secretory pathway or vesicular secretion, by means of direct communication between electronic devices and implanted cells is expected to open up many new opportunities for advanced precision healthcare optimized for individuals. 


\section{References and Notes}

1. M. M. Aye, S. L. Atkin, Patient safety and minimizing risk with insulin administration - role of insulin degludec. Drug, healthcare and patient safety 6, 55-67 (2014).

2. A. Goto, O. A. Arah, M. Goto, Y. Terauchi, M. Noda, Severe hypoglycaemia and cardiovascular disease: systematic review and meta-analysis with bias analysis. Bmj 347, f4533 (2013).

3. G. P. Leese et al., Frequency of severe hypoglycemia requiring emergency treatment in type 1 and type 2 diabetes: a population-based study of health service resource use. Diabetes care 26, 1176-1180 (2003).

4. C. Uduku, N. Oliver, Pharmacological aspects of closed loop insulin delivery for type 1 diabetes. Current opinion in pharmacology 36, 29-33 (2017).

5. M. Xie et al., beta-cell-mimetic designer cells provide closed-loop glycemic control. Science 354, 1296-1301 (2016).

6. J. Shao et al., Smartphone-controlled optogenetically engineered cells enable semiautomatic glucose homeostasis in diabetic mice. Science translational medicine $\mathbf{9}$, (2017).

7. T. Kushibiki, S. Okawa, T. Hirasawa, M. Ishihara, Optogenetic control of insulin secretion by pancreatic beta-cells in vitro and in vivo. Gene therapy 22, 553-559 (2015).

8. T. Kim, M. Folcher, M. Doaud-El Baba, M. Fussenegger, A synthetic erectile optogenetic stimulator enabling blue-light-inducible penile erection. Angewandte Chemie 54, 5933-5938 (2015).

9. H. Ye, M. Daoud-El Baba, R. W. Peng, M. Fussenegger, A synthetic optogenetic transcription device enhances blood-glucose homeostasis in mice. Science 332, 1565 $1568(2011)$.

10. M. Folcher et al., Mind-controlled transgene expression by a wireless-powered optogenetic designer cell implant. Nature communications 5, 5392 (2014).

11. H. A. Andersson, Y. S. Kim, B. E. O'Neill, Z. Z. Shi, R. E. Serda, HSP70 promoterdriven activation of gene expression for immunotherapy using gold nanorods and near infrared light. Vaccines 2, 216-227 (2014).

12. V. Ortner et al., Magnetic field-controlled gene expression in encapsulated cells. Journal of controlled release : official journal of the Controlled Release Society $\mathbf{1 5 8}$, 424-432 (2012). 
13. H. Huang, S. Delikanli, H. Zeng, D. M. Ferkey, A. Pralle, Remote control of ion channels and neurons through magnetic-field heating of nanoparticles. Nature nanotechnology 5, 602-606 (2010).

14. S. A. Stanley, J. Sauer, R. S. Kane, J. S. Dordick, J. M. Friedman, Remote regulation of glucose homeostasis in mice using genetically encoded nanoparticles. Nature medicine 21, 92-98 (2015).

15. M. Fussenegger et al., Streptogramin-based gene regulation systems for mammalian cells. Nature biotechnology 18, 1203-1208 (2000).

16. W. Weber et al., Macrolide-based transgene control in mammalian cells and mice. Nature biotechnology 20, 901-907 (2002).

17. B. G. Auner, C. Valenta, J. Hadgraft, Influence of phloretin and 6-ketocholestanol on the skin permeation of sodium-fluorescein. Journal of controlled release : official journal of the Controlled Release Society 89, 321-328 (2003).

18. M. Gitzinger, C. Kemmer, M. D. El-Baba, W. Weber, M. Fussenegger, Controlling transgene expression in subcutaneous implants using a skin lotion containing the apple metabolite phloretin. Proceedings of the National Academy of Sciences of the United States of America 106, 10638-10643 (2009).

19. M. Gitzinger et al., The food additive vanillic acid controls transgene expression in mammalian cells and mice. Nucleic acids research 40, e37 (2012).

20. H. Wang, H. Ye, M. Xie, M. Daoud El-Baba, M. Fussenegger, Cosmetics-triggered percutaneous remote control of transgene expression in mice. Nucleic acids research 43, e91 (2015).

21. S. A. Stanley et al., Radio-wave heating of iron oxide nanoparticles can regulate plasma glucose in mice. Science 336, 604-608 (2012).

22. A. Prindle et al., Rapid and tunable post-translational coupling of genetic circuits. Nature 508, 387-391 (2014).

23. W. Weber et al., A synthetic mammalian electro-genetic transcription circuit. Nucleic acids research 37, e33 (2009).

24. W. Weber et al., Gas-inducible transgene expression in mammalian cells and mice. Nature biotechnology 22, 1440-1444 (2004).

25. T. Tschirhart et al., Electronic control of gene expression and cell behaviour in Escherichia coli through redox signalling. Nature communications 8, 14030 (2017).

26. D. Katz, T. Akiyama, Pacemaker longevity: the world's longest-lasting VVI pacemaker. Ann Noninvasive Electrocardiol 12, 223-226 (2007). 
27. J. H. Stockley et al., Surpassing light-induced cell damage in vitro with novel cell culture media. Scientific reports 7, 849 (2017).

28. T. D. Hinds, Jr. et al., Biliverdin Reductase A Attenuates Hepatic Steatosis by Inhibition of Glycogen Synthase Kinase (GSK) 3beta Phosphorylation of Serine 73 of Peroxisome Proliferator-activated Receptor (PPAR) alpha. The Journal of biological chemistry 291, 25179-25191 (2016).

29. Y. Uda et al., Efficient synthesis of phycocyanobilin in mammalian cells for optogenetic control of cell signaling. Proceedings of the National Academy of Sciences of the United States of America 114, $11962-11967$ (2017).

30. Z. Hu et al., Biliverdin Reductase A (BVRA) Mediates Macrophage Expression of Interleukin-10 in Injured Kidney. International journal of molecular sciences 16, 22621-22635 (2015).

31. H. M. Beyer et al., Red Light-Regulated Reversible Nuclear Localization of Proteins in Mammalian Cells and Zebrafish. ACS Synth Biol 4, 951-958 (2015).

32. G. Jarockyte et al., Accumulation and Toxicity of Superparamagnetic Iron Oxide Nanoparticles in Cells and Experimental Animals. International journal of molecular sciences 17, (2016).

33. B. A. Maher et al., Magnetite pollution nanoparticles in the human brain. Proceedings of the National Academy of Sciences of the United States of America 113, 10797-10801 (2016).

34. F. M. Ashcroft, P. Rorsman, K(ATP) channels and islet hormone secretion: new insights and controversies. Nature reviews. Endocrinology 9, 660-669 (2013).

35. R. Buzzetti, S. Zampetti, E. Maddaloni, Adult-onset autoimmune diabetes: current knowledge and implications for management. Nature reviews. Endocrinology 13, 674686 (2017).

36. D. Jacobs-Tulleneers-Thevissen et al., Sustained function of alginate-encapsulated human islet cell implants in the peritoneal cavity of mice leading to a pilot study in a type 1 diabetic patient. Diabetologia 56, 1605-1614 (2013).

37. T. Desai, L. D. Shea, Advances in islet encapsulation technologies. Nature reviews. Drug discovery 16, 338-350 (2017).

38. G. W. Zamponi, J. Striessnig, A. Koschak, A. C. Dolphin, The Physiology, Pathology, and Pharmacology of Voltage-Gated Calcium Channels and Their Future Therapeutic Potential. Pharmacological reviews 67, 821-870 (2015). 
39. M. D'Arco, A. C. Dolphin, L-type calcium channels: on the fast track to nuclear signaling. Science signaling 5, pe34 (2012).

40. T. Kim et al., The biochemical activation of T-type Ca2+ channels in HEK293 cells stably expressing alpha1G and Kir2.1 subunits. Biochemical and biophysical research communications 324, 401-408 (2004).

41. A. Llucia-Valldeperas et al., Electrical stimulation of cardiac adipose tissue-derived progenitor cells modulates cell phenotype and genetic machinery. Journal of tissue engineering and regenerative medicine 9, E76-83 (2015).

42. M. H. Thelen, W. S. Simonides, C. van Hardeveld, Electrical stimulation of C2C12 myotubes induces contractions and represses thyroid-hormone-dependent transcription of the fast-type sarcoplasmic-reticulum Ca2+-ATPase gene. The Biochemical journal 321 ( Pt 3), 845-848 (1997).

43. Y. Manabe et al., Characterization of an acute muscle contraction model using cultured C2C12 myotubes. PloS one 7, e52592 (2012).

44. J. T. McCluskey et al., Development and functional characterization of insulinreleasing human pancreatic beta cell lines produced by electrofusion. The Journal of biological chemistry 286, 21982-21992 (2011).

45. S. M. Burns et al., High-throughput luminescent reporter of insulin secretion for discovering regulators of pancreatic Beta-cell function. Cell metabolism 21, 126-137 (2015).

46. J. Gromada, P. Chabosseau, G. A. Rutter, The alpha-cell in diabetes mellitus. Nature reviews. Endocrinology 14, 694-704 (2018).

47. H. Yamashita, D. T. Nguyen, E. Chung, Blood-based assay with secreted Gaussia luciferase to monitor tumor metastasis. Methods Mol Biol 1098, 145-151 (2014).

48. B. Rattner, in Host Response to Biomaterials, S. Badylak, Ed. (Academic Press, 2015), chap. 3, pp. 37-51.

49. S. J. Russell et al., Day and night glycaemic control with a bionic pancreas versus conventional insulin pump therapy in preadolescent children with type 1 diabetes: a randomised crossover trial. Lancet Diabetes Endocrinol 4, 233-243 (2016).

50. P. A. Hollander et al., Importance of early insulin secretion: comparison of nateglinide and glyburide in previously diet-treated patients with type 2 diabetes. Diabetes care $\mathbf{2 4}$, 983-988 (2001). 
51. S. E. Kahn et al., Importance of early phase insulin secretion to intravenous glucose tolerance in subjects with type 2 diabetes mellitus. J Clin Endocrinol Metab 86, 58245829 (2001).

52. H. G. Mond, G. Freitag, The cardiac implantable electronic device power source: evolution and revolution. Pacing and clinical electrophysiology : PACE 37, 1728-1745 (2014).

53. S. J. Russell et al., Outpatient glycemic control with a bionic pancreas in type 1 diabetes. $N$ Engl J Med 371, 313-325 (2014).

54. G. Schmelzeisen-Redeker et al., Time Delay of CGM Sensors: Relevance, Causes, and Countermeasures. J Diabetes Sci Technol 9, 1006-1015 (2015).

55. D. B. Keenan, J. J. Mastrototaro, G. Voskanyan, G. M. Steil, Delays in minimally invasive continuous glucose monitoring devices: a review of current technology. $J$ Diabetes Sci Technol 3, 1207-1214 (2009).

56. M. Qi, Transplantation of Encapsulated Pancreatic Islets as a Treatment for Patients with Type 1 Diabetes Mellitus. Adv Med 2014, 429710 (2014).

57. R. R. HENRY et al., Initial Clinical Evaluation of VC-01TM Combination ProductA Stem Cell-Derived Islet Replacement for Type 1 Diabetes (T1D). Diabetes 67, 138OR (2018).

58. Y. Evron et al., Long-term viability and function of transplanted islets macroencapsulated at high density are achieved by enhanced oxygen supply. Scientific reports $\mathbf{8}, 6508$ (2018).

59. H. J. Motulsky, R. E. Brown, Detecting outliers when fitting data with nonlinear regression - a new method based on robust nonlinear regression and the false discovery rate. BMC Bioinformatics 7, 123 (2006)

60. T. D. Helton, W. Xu, D. Lipscombe, Neuronal L-type calcium channels open quickly and are inhibited slowly. The Journal of neuroscience : the official journal of the Society for Neuroscience 25, 10247-10251 (2005).

61. W. $\mathrm{Xu}, \mathrm{D}$. Lipscombe, Neuronal $\mathrm{Ca}(\mathrm{V}) 1.3 \mathrm{alpha}(1)$ L-type channels activate at relatively hyperpolarized membrane potentials and are incompletely inhibited by dihydropyridines. The Journal of neuroscience : the official journal of the Society for Neuroscience 21, 5944-5951 (2001). 
62. Y. Lin, S. I. McDonough, D. Lipscombe, Alternative splicing in the voltage-sensing region of N-Type CaV2.2 channels modulates channel kinetics. Journal of neurophysiology 92, 2820-2830 (2004).

63. Y. Q. Jiang, A. Andrade, D. Lipscombe, Spinal morphine but not ziconotide or gabapentin analgesia is affected by alternative splicing of voltage-gated calcium channel CaV2.2 pre-mRNA. Molecular pain 9, 67 (2013).

64. L. Mates et al., Molecular evolution of a novel hyperactive Sleeping Beauty transposase enables robust stable gene transfer in vertebrates. Nature genetics 41, 753-761 (2009).

65. C. R. Yu et al., Spontaneous neural activity is required for the establishment and maintenance of the olfactory sensory map. Neuron 42, 553-566 (2004).

66. A. Follenzi, G. Sabatino, A. Lombardo, C. Boccaccio, L. Naldini, Efficient gene delivery and targeted expression to hepatocytes in vivo by improved lentiviral vectors. Human gene therapy 13, 243-260 (2002).

67. S. Konermann et al., Genome-scale transcriptional activation by an engineered CRISPR-Cas9 complex. Nature 517, 583-588 (2015).

68. E. Kowarz, D. Loscher, R. Marschalek, Optimized Sleeping Beauty transposons rapidly generate stable transgenic cell lines. Biotechnology journal 10, 647-653 (2015).

69. K. J. Aichberger et al., Low-level expression of proapoptotic Bcl-2-interacting mediator in leukemic cells in patients with chronic myeloid leukemia: role of BCR/ABL, characterization of underlying signaling pathways, and reexpression by novel pharmacologic compounds. Cancer research 65, 9436-9444 (2005). 
Acknowledgments: We would like to thank the Geneva Islet Transplantation Center and Henryk Zulewski for human pancreatic islets, which were obtained through the basic research program of the European Consortium for Islet Transplantation (ECIT) supported by the Juvenile Diabetes Research foundation (JDRF; grant no 31-2008-416). We would like to thank Sebastian Bürgel for help in the initial stage of the project, Andreas Hierlemann for providing pulse generators, Marc Folcher for constructive discussions, Erdem Siringil for support with 3D printing, Brian Lang for advice on statistical analysis, Ana Margarida Palma Teixeira and Gieri Camenisch for preparation of the animal experimentation applications, Alexandra Graff-Meyer and Christel Genoud for taking electron microscopy images, and Haijie Zhao and Nik Franko for their help in assembling implants.

Funding: This work was supported by a European Research Council (ERC) advanced grant (ElectroGene; grant no. 785800) and in part by the Swiss National Science Foundation (SNF) National Centre of Competence in Research (NCCR) for Molecular Systems Engineering.

Author contributions: KK and MF designed the project. KK and PS performed the cell culture experiments and KK designed the implants. KK, SX, GC, MDH, JS and HY performed the animal experiments. PB designed the electronic switchboard. KK, PS, MX and MF designed the experiments and analyzed the results. KK, PS, MX and MF wrote the manuscript. SX, $\mathrm{MDH}, \mathrm{MX}$ and MF designed the modified implants and the in vivo "refill" as well as the insulin kinetics experiments.

Competing interests: The authors declare no competing financial interests.

Data and materials availability: The authors declare that all the data supporting the findings of this study are available within the paper and its supplementary information file. Original plasmids are available upon request. All vector information is provided in Table S7.

\section{Supplementary Content:}

Materials and Methods

Figures S1-S20

Tables S1-S8

References (59-69) 
Figure 1 Design of the electrogenetic circuit in mammalian cells. (a) Schematic representation of the electrogenetic circuit. The inwardly rectifying potassium channel lowers the resting membrane potential of HEK293T cells and electrical pulses depolarize the plasma membrane and open the L-type voltage-gated calcium channel. Calcium influx activates the calmodulin/calcineurin pathway, which leads to dephosphorylation of NFAT and its translocation to the nucleus, where it activates the NFAT-sensitive promoter and triggers transgene expression (b) Comparative performance of three L-type voltage-gated calcium channels. Cells were co-transfected with $\mathrm{P}_{\mathrm{NFAT3}}$-driven SEAP reporter plasmid (pMX57), plasmids encoding, $\alpha_{2} / \delta_{1}\left(\mathrm{pCav} \alpha_{2} \delta_{1}, \mathrm{P}_{\mathrm{hCMV}}-\alpha_{2} / \delta_{1}-\mathrm{pA}\right)$ and, $\beta_{3}\left(\mathrm{pCav} \beta_{3}, \mathrm{P}_{\mathrm{hCMV}}-\beta_{3}-\mathrm{pA}\right)$, and one of the pore-forming subunits: $\alpha_{1} \mathrm{C}$ (pCav1.2, $\left.\mathrm{P}_{\mathrm{hCMV}}-\alpha_{1} \mathrm{C}-\mathrm{pA}\right), \alpha_{1} \mathrm{D}_{42 \mathrm{~A}}\left(\mathrm{pCav} 1.3_{42 \mathrm{~A}}, \mathrm{P}_{\mathrm{hCMV}}-\alpha_{1} \mathrm{D}_{42 \mathrm{~A}^{-}}\right.$ $\mathrm{pA})$ and $\alpha_{1} \mathrm{D}_{\Delta 42}\left(\mathrm{pCav} 1.3_{\Delta 42}, \mathrm{P}_{\mathrm{hCMv}}-\alpha_{1} \mathrm{D}_{\Delta 42}-\mathrm{pA}\right)$, to form Cav1.2, Cav1.342A, and Cav1.3 ${ }_{\Delta 42}$ accordingly. pcDNA3.1(+) was used as a mock plasmid. The cell membrane was depolarized with $40 \mathrm{mM}$ potassium chloride (red bars) and after 24 hours SEAP was quantified in the supernatant. Blue bars show negative controls. (c) Co-expression of L-type voltage-gated calcium channel Cav1.2 and inwardly rectifying potassium channel $\mathrm{K}_{\mathrm{ir}} 2.1$. Cells were cotransfected with pCav1.2 ( $\left.\mathrm{P}_{\mathrm{hCMV}}-\alpha_{1} \mathrm{C}-\mathrm{pA}\right), \mathrm{pCa}_{\mathrm{v}} \alpha_{2} \delta_{1}\left(\mathrm{P}_{\mathrm{hCMV}}-\alpha_{2} / \delta_{1}-\mathrm{pA}\right), \mathrm{pCav} \beta_{3}\left(\mathrm{P}_{\mathrm{hCMV}}-\beta_{3}-\mathrm{pA}\right)$, pKK05 ( $\left.\mathrm{P}_{\mathrm{hCMV}}-\mathrm{K}_{\mathrm{ir}} 2.1-\mathrm{pA}\right)$ and pMX57 ( $\left.\mathrm{P}_{\mathrm{NFAT3}}-\mathrm{SEAP}-\mathrm{pA}\right)$ in the molar proportions 1:1:1:1:3. Cells were depolarized with $40 \mathrm{mM} \mathrm{KCl}$ for 24 hours (red bars) and SEAP was quantified in supernatant samples. Bars represent mean \pm SEM. $\mathrm{n}=3$. $* * \mathrm{p}<0.01, * * * \mathrm{p}<0.001$.

Figure 2 Characterization of the electrogenetic circuit in vitro. (a) Schematic representation of electrical stimulation setup. Cells were stimulated with carbon hanging electrodes (C-dish) using monopolar pulses with alternate polarization. (b-e) Cells were co-transfected with pCav1.2 ( $\left.\mathrm{P}_{\mathrm{hCMV}}-\alpha_{1} \mathrm{C}-\mathrm{pA}\right), \mathrm{pCa}_{\mathrm{v}} \alpha_{2} \delta_{1}\left(\mathrm{P}_{\mathrm{hCMV}}-\alpha_{2} / \delta_{1}-\mathrm{pA}\right), \mathrm{pCa} \beta_{3}\left(\mathrm{P}_{\mathrm{hCMV}}-\beta_{3}-\mathrm{pA}\right), \mathrm{pKK} 05$ ( $\mathrm{P}_{\mathrm{hCMV}}-$ $\mathrm{K}_{\mathrm{ir}}$ 2.1-pA and pMX57 ( $\left.\mathrm{P}_{\mathrm{NFAT3}}-\mathrm{SEAP}-\mathrm{pA}\right)$. SEAP assay was performed 24 hours after the beginning of the electrical stimulation procedure. Blue bars represent unstimulated control, orange bars show electrically stimulated samples, and red bars indicate cells depolarized with $40 \mathrm{mM} \mathrm{KCl}$. (b) Voltage dependence. Electrical stimulation was performed for 1 hour with 2 ms pulses at $10 \mathrm{~Hz}$ frequency and the indicated voltage. (c) Pulse length effect. Electrical stimulation was performed for 1 hour at $50 \mathrm{~V}, 10 \mathrm{~Hz}$ frequency, and the indicated pulse length. (d) Time course. Electrical stimulation was performed for the indicated period of time with 2 ms pulses at $0.5 \mathrm{~Hz}$ and $50 \mathrm{~V}$. (e) Frequency effect. Electrical stimulation was performed for 1 hour with $2 \mathrm{~ms}$ pulses at $50 \mathrm{~V}$ and at the indicated frequency. Bars represent mean \pm SEM. $\mathrm{n}=$ 
3. Statistical significance was calculated versus the negative control. ns - not significant, ${ }^{*} \mathrm{p}<0.05, * * \mathrm{p}<0.01, * * * \mathrm{p}<0.001$.

Figure 3 Design and functionality of the bioelectronic implant in vitro (a) Schematic representation of the stimulation setup in a cell culture insert. Two platinum electrodes (blue) were placed on opposite sides of the porous membrane covered with cells, and electrical pulse stimulation was applied. SEAP was quantified 24 hours after stimulation in the supernatants of the cell-culture insert (above the membrane) and the well of the cell-culture plate (below the membrane), to confirm that the secreted protein diffuses across the membrane of the cellculture insert. (b, c) Voltage-dependent response of electrically stimulated pMX57-transfected ElectroHEK cells grown in a cell culture insert. Cells were stimulated with 2 ms pulses at $1 \mathrm{~Hz}$ frequency for $1 \mathrm{~h}$ (orange bars). SEAP was measured in supernatant samples from the cellculture insert (above the membrane) (b) and from the cell-culture well (below the membrane) (c). Blue bars show the negative control. (d, e) Pulse length-dependence. Cells were stimulated with $7.5 \mathrm{~V}$ pulses at $1 \mathrm{~Hz}$ frequency for $1 \mathrm{~h}$ (orange bars). SEAP was measured from supernatant samples from above (d) and below the cell layer (e). Blue bars show the negative control. Bars represent mean \pm SEM. $n=3$. Statistical significance was calculated versus negative control. ns - not significant, ${ }^{*} \mathrm{p}<0.05,{ }^{*} \mathrm{p}<0.01, * * * \mathrm{p}<0.001$.

Figure 4 Bioelectronic implant in vitro (a) Three-dimensional model of a disassembled bioelectronic implant. A ring containing a porous membrane on one side can be assembled with a 3D-printed polyamide frame to form a cell chamber. The electronic switchboard is placed on the other side of the frame. The active platinum electrode (placed in the cell chamber; invisible in the model) is soldered to a connector on a switchboard. The ground electrode, made out of thin stainless steel mesh, is connected to the second connector on a switchboard. (b) The bioelectronic implant can be placed subcutaneously on the dorsal side of the mouse, with the cell chamber facing down. The field generator provides wireless energy transmission. A red diode enables implant function monitoring. (c) Photograph of two bioelectronic implants with a coin for comparison. (d) Comparison of external generator-powered and implant-powered electrostimulation of pMX57-transfected ElectroHEK cells. SEAP was measured in supernatant samples from above the cell layer. $n=3$. Data points represent mean \pm SEM. Statistical significance was calculated versus negative control. $* * * p<0.001$. 
Figure 5. Electrogenetic engineering of $\boldsymbol{\beta}$-cells. (a) Schematic representation of the electrically inducible insulin secretion pathway. The inwardly rectifying potassium channel $\mathrm{K}_{\mathrm{ir}} 2.1$ lowers the resting membrane potential, which keeps the voltage-gated calcium channel Cav1.2 closed. Electrical pulse stimulation causes membrane depolarization, opening of Cav1.2 and calcium influx, which stimulates vesicle secretion. Vesicles are loaded with preproduced insulin (red dots) and NanoLuc (yellow dots). (b, c) Comparison of insulin secretion by INS $_{\text {Vesc }}$ and Electro $\beta$ cells. Vesicle secretion was quantified by insulin-specific ELISA (b) and luminescence (c) before (blue bars) and after depolarization with $40 \mathrm{mM} \mathrm{KCl}$ (red bars). BDL - below detection limit. (d) Transmission electron microscopy (TEM) pictures of Electro $\beta$ cells. White arrows indicate insulin-containing vesicles. (e) TEM pictures of primary $\beta$-cells from human pancreatic islets. White arrows indicate insulin-containing vesicles. Bars represent mean \pm SEM. $\mathrm{n}=3 .{ }^{* * *} \mathrm{p}<0.001$.

Figure 6 Functionality of Electro $\beta$ cells in vitro. $(\mathbf{a}, \mathbf{b})$ Electrostimulation of Electro $\beta$ cells. Cells were seeded into cell culture inserts, and 24 hours later they were stimulated with electrical pulses (orange bars) or with $40 \mathrm{mM} \mathrm{KCl}$ (red bars). Blue bars show the negative control. $\mathrm{n}=$ 3. (a) Insulin content in the supernatant from inside the insert (above the cell layer) was measured by ELISA. (b) Luminescence measured in supernatant samples taken from inside the insert (above the cell layer). $n=3$. (c) Secretion kinetics. Electro $\beta$ cells were seeded into cell culture inserts and stimulated with electrical pulses (red frame). Luminescence was measured in supernatant samples every $10 \mathrm{~min} . \mathrm{n}=4$ (d) Reversibility assay. Electro $\beta$ cells were electrostimulated for 15 min twice, with $4 \mathrm{~h}$ time intervals between the first and second electrostimulation. $n=4$ (e) Glucose-induced insulin release. Electro $\beta$ cells were incubated with various concentration of glucose for 15 minutes (blue bar $-2.8 \mathrm{mM}$ glucose; orange bars elevated glucose; red bar - $2.8 \mathrm{mM}$ glucose with $40 \mathrm{mM} \mathrm{KCl}$ ). Luminescence was measured in supernatant samples. $n=3$. (f) Glucose-induced insulin release. $I N S_{\text {Vesc }}$ cells were incubated with various concentration of glucose for 60 minutes (blue bar $-2.8 \mathrm{mM}$ glucose; orange bars - elevated glucose; red bar $-2.8 \mathrm{mM}$ glucose with $40 \mathrm{mM} \mathrm{KCl}$ ). Insulin content was quantified in supernatant samples. $\mathrm{n}=3$. Bars and dots represent mean \pm SEM. Statistical significance was calculated versus negative control. ns - not significant, ${ }^{*} p<0.05,{ }^{*} \mathrm{p}<0.01,{ }^{* * *} \mathrm{p}<0.001$. 
Figure 7. Comparative analyses of Electro $\beta$-containing bioelectronic implants in type-I

diabetic mice. Type-1-diabetic mice implanted on the back with Electro-containing bioelectronic devices were profiled for blood-glucose dynamics. (a) Glucose tolerance test. At 48 hours after implantation, the Electro $\beta$ cells inside the bioelectronic implant were electrostimulated for $60 \mathrm{~min}$ (red line), then the animals were given intraperitoneal glucose injections and their blood-glucose levels were monitored. All groups received intraperitoneal glucose injection ( $2 \mathrm{~g}$ per kilogram of body weight). Wild type $(\mathrm{n}=8)$; T1D, implant electrostimulated (type I diabetes, activated implant, $\mathrm{n}=6$ ); T1D, empty implant (type-I diabetes, implant without cells, $n=10$ ), islets (human pancreatic beta islets, $n=3$ ). The statistical significance of differences between the electrostimulated and the mock group was calculated. (b) Real-time glycemia measurement. Fasted type-1-diabetic mice implanted with Electro $\beta$-containing bioelectronic implants were electro-stimulated for 30 minutes and their glycemic profile was recorded. $\mathrm{n}=6$ for the non-stimulated control (T1D, implanted mice), $\mathrm{n}=7$ for the stimulated group (T1D, implanted mice) and $n=6$ for wild-type control. The green frame indicates the normoglycemic range (4.4- $7.2 \mathrm{mM})$. The statistical significance was calculated between the electrostimulated and the non-stimulated control. (c) Blood-luciferase kinetics of animals implanted with Electro $\beta$-cell-containing implants electro-stimulated for $30 \mathrm{~min}$ (red line; $\mathrm{n}=6$ ). NanoLuc was quantified from microliter-scale blood samples every 30 minutes. The blue line indicates the non-electro-stimulated negative control $(n=5)$. The statistical significance of differences versus time point 0 was calculated with a paired t-test. (d) Fasting glycemia. Type1 -diabetic mice were implanted with Electro $\beta$-containing bioelectronic implants and fasting glycemia was recorded for over a week. Orange line indicates the initial level of average glycemia. The statistical significance of differences versus time point 0 was calculated with a paired t-test. Red frames indicate electrostimulation time. ns - not significant, ${ }^{*} \mathrm{p}<0.05$, $* * \mathrm{p}<0.01, * * * \mathrm{p}<0.001$. 


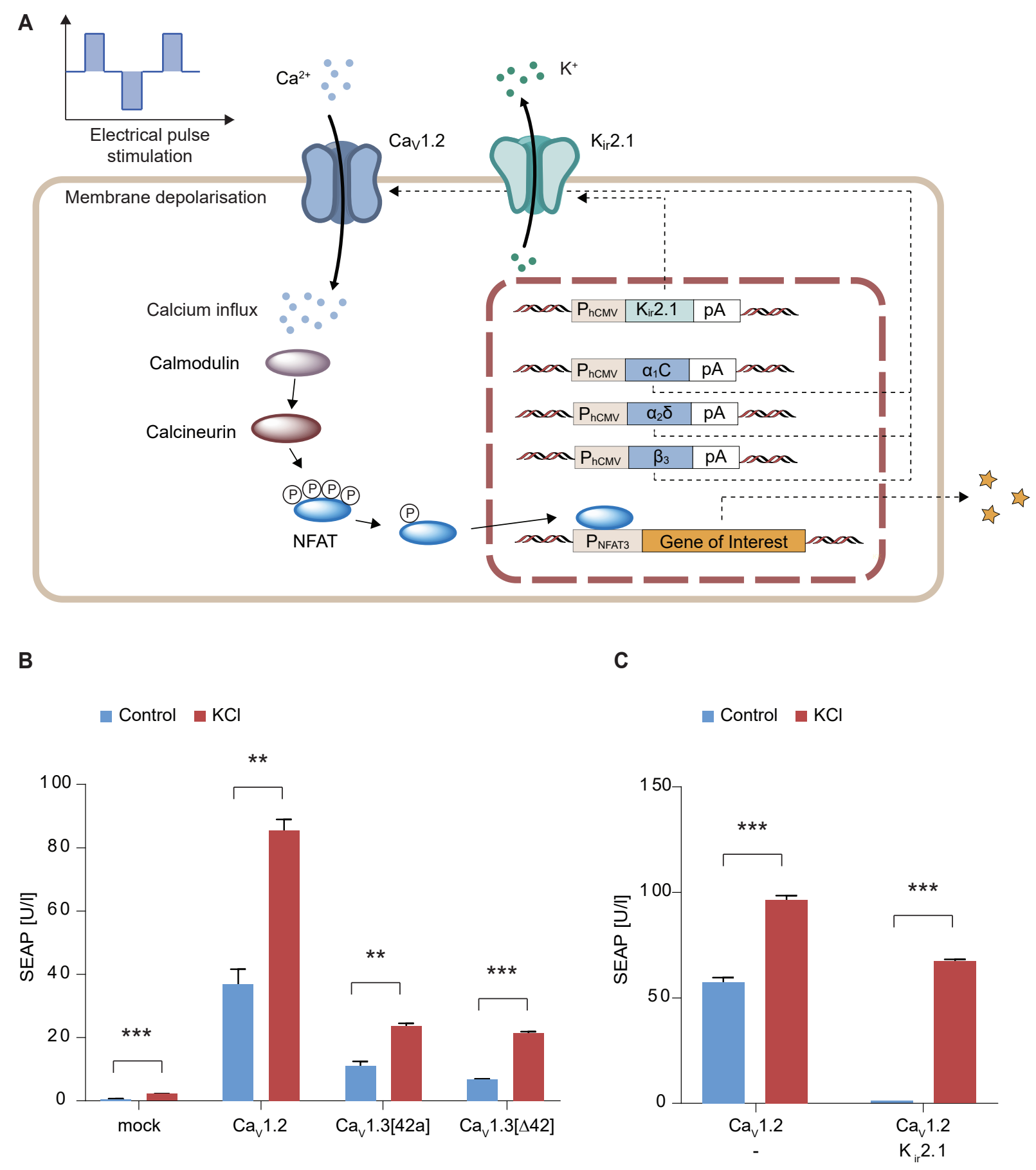

Figure 1 
A

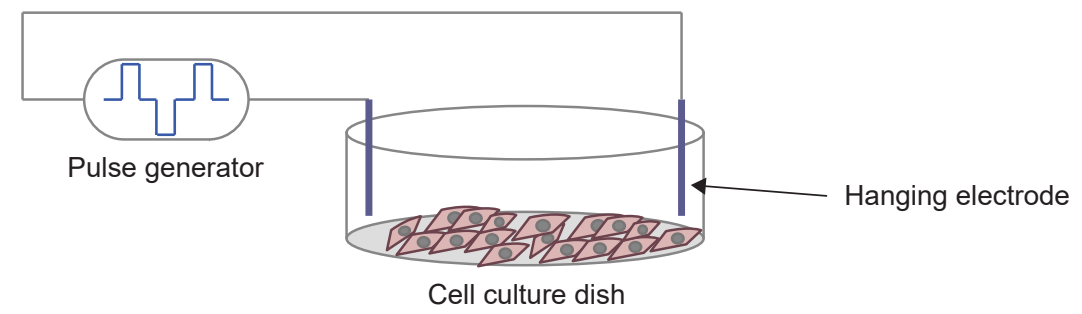

B

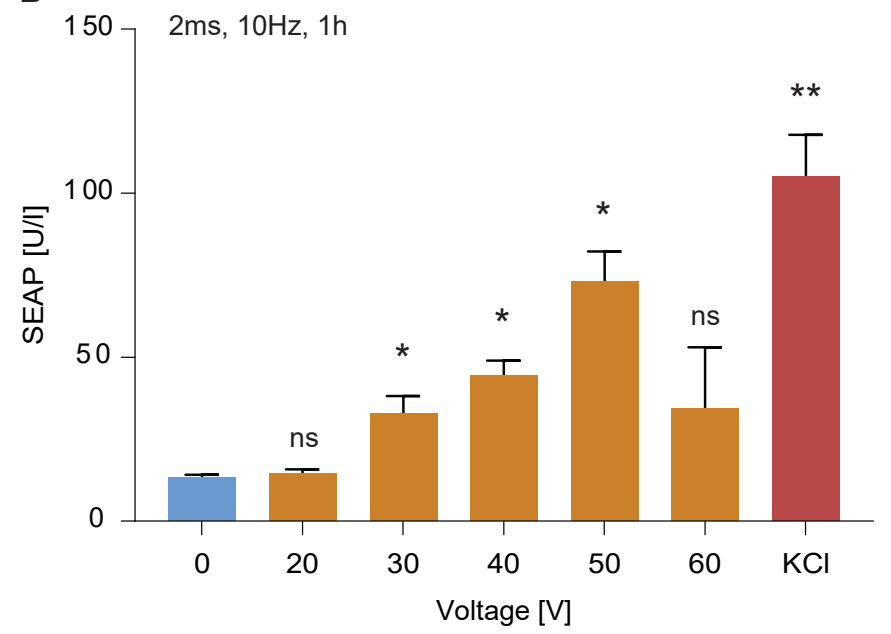

D

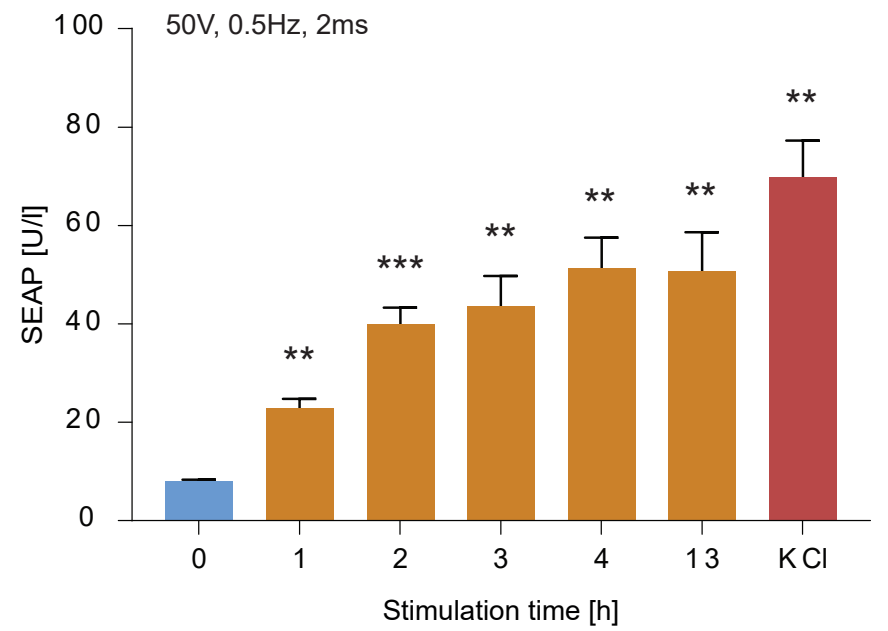

C

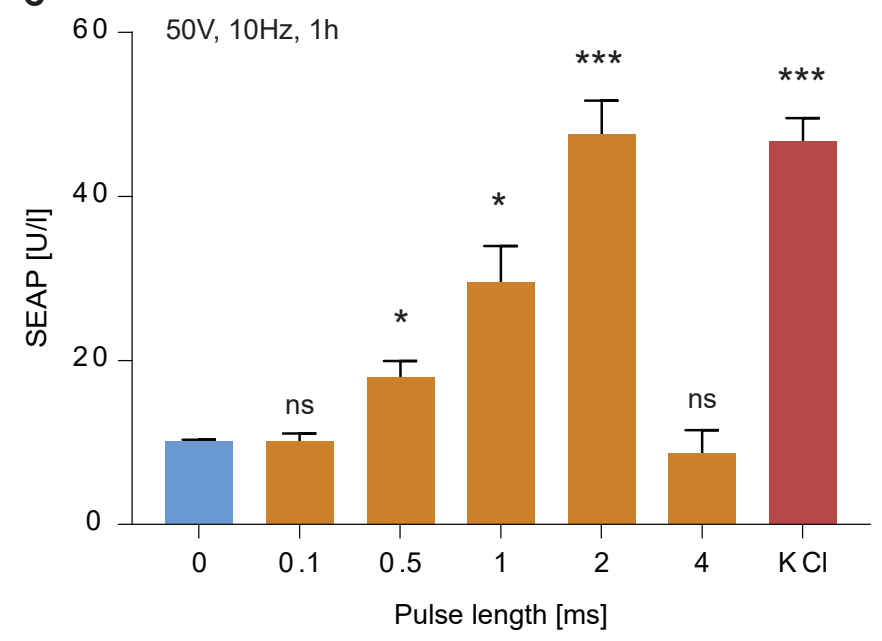

E

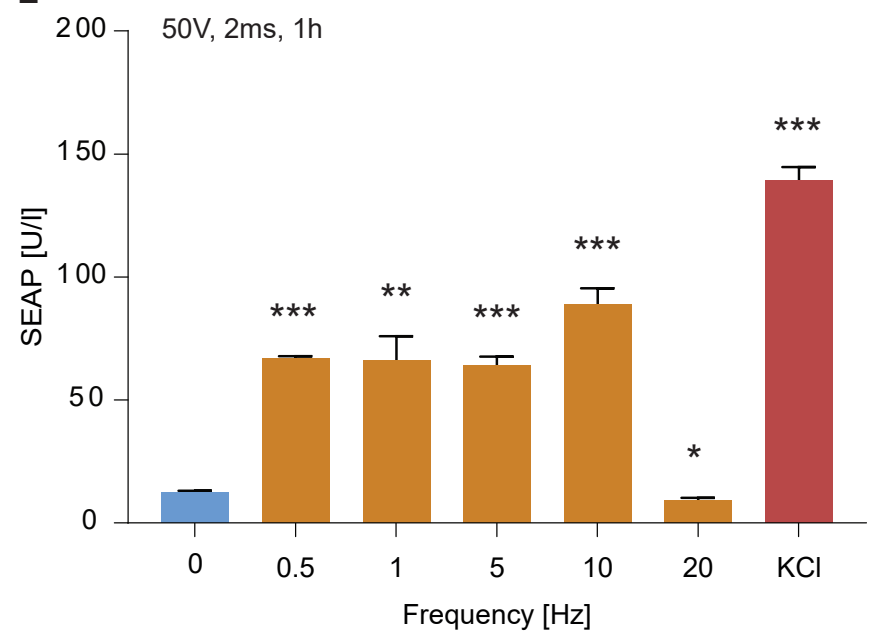

Figure 2 
A
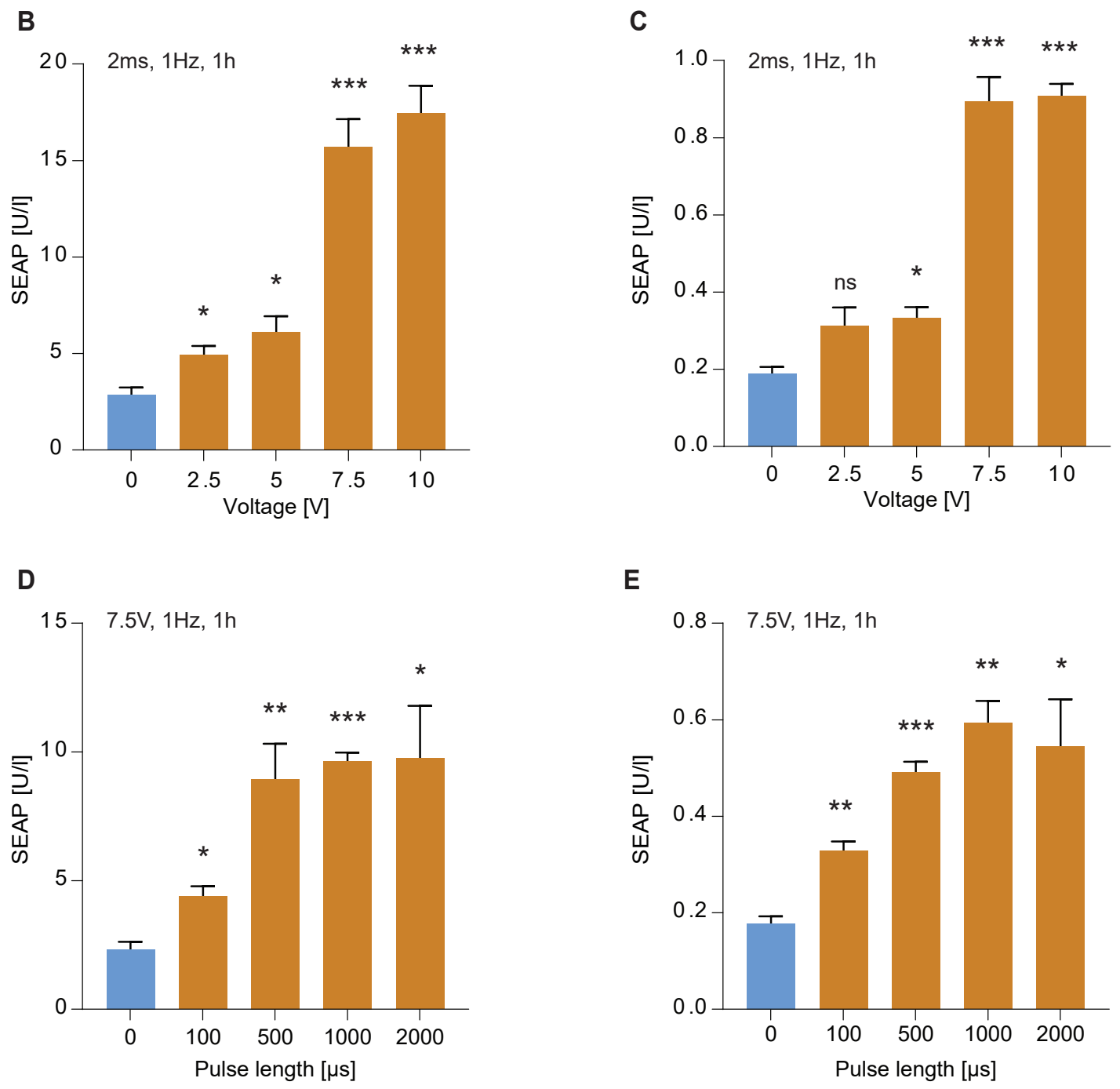

Figure 3 


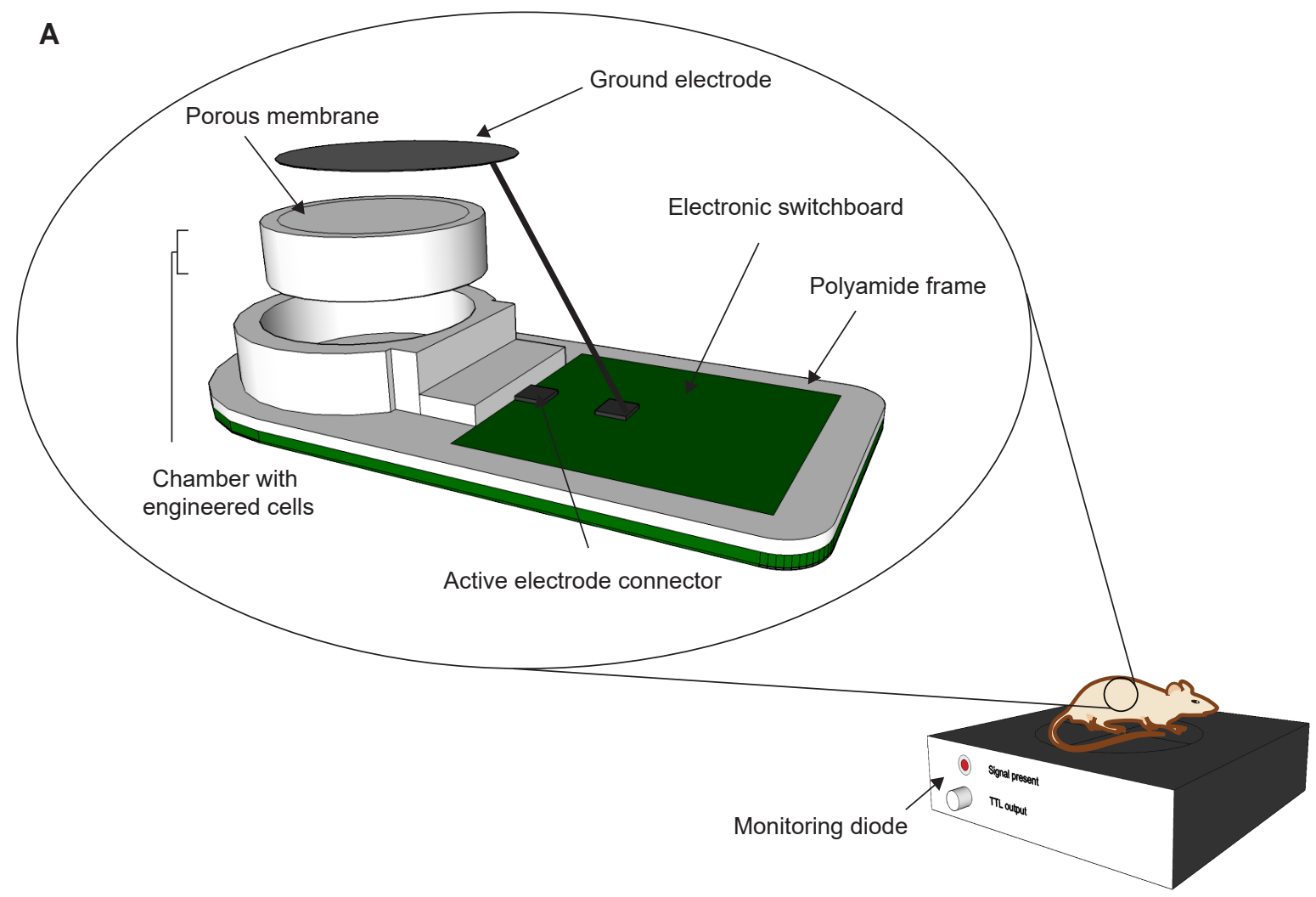

Field generator
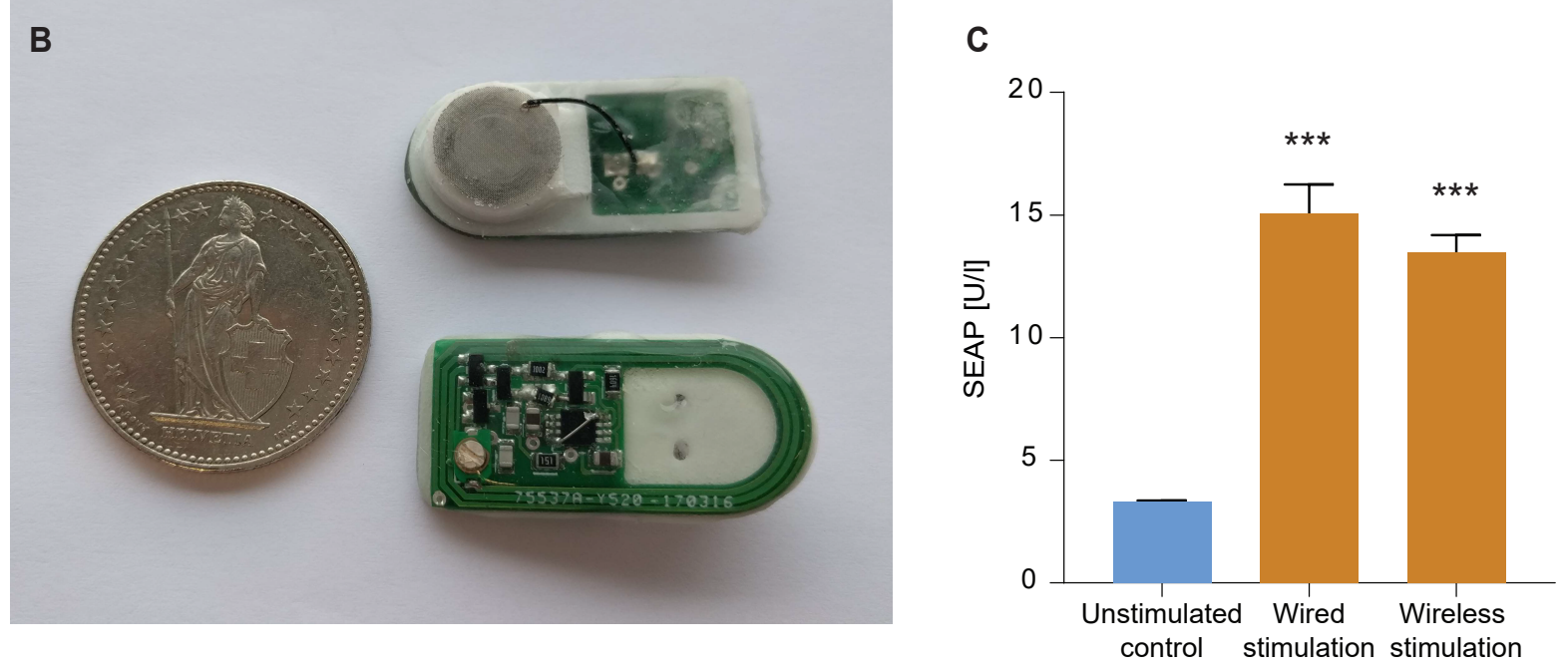

Figure 4 
A

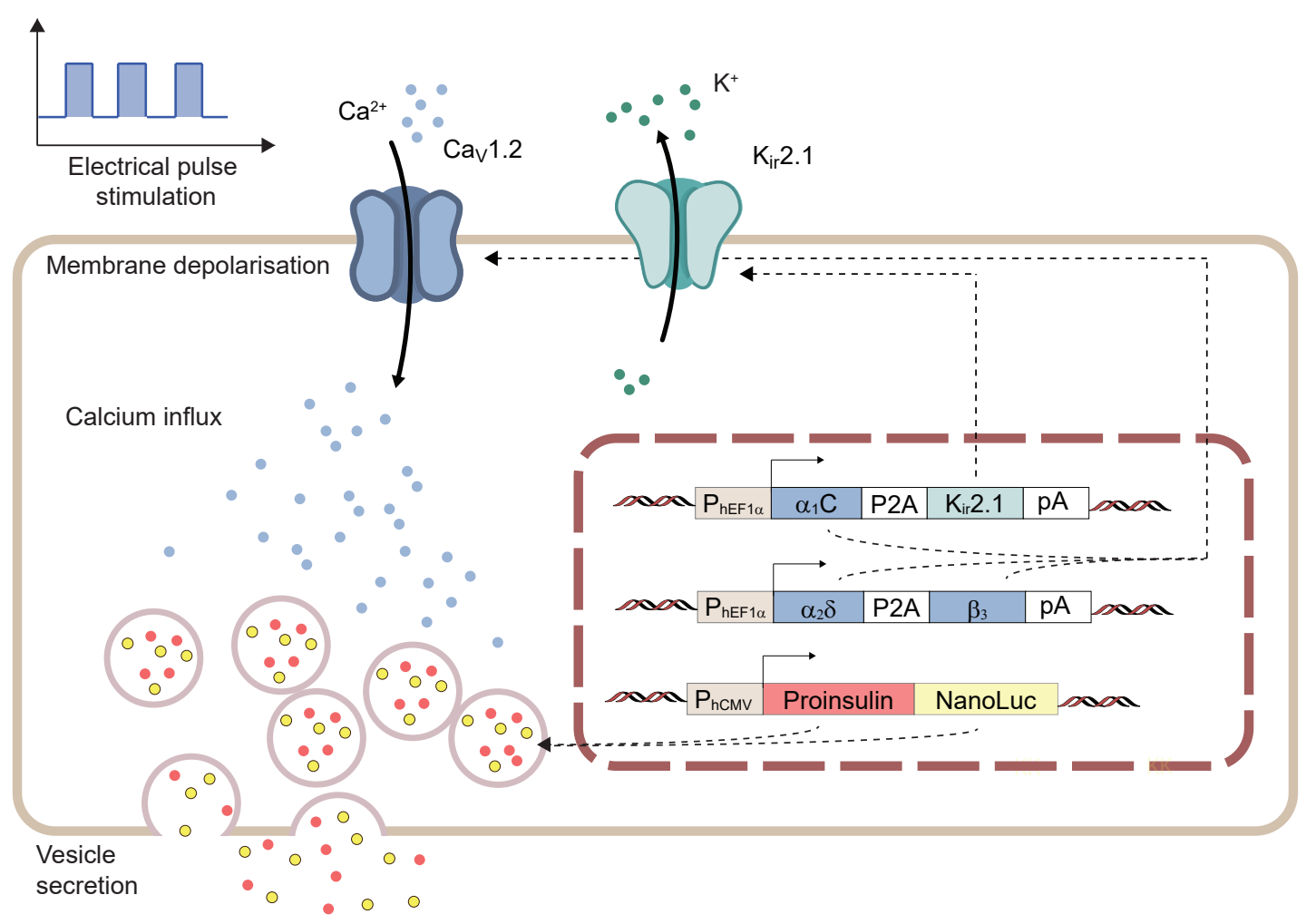

B

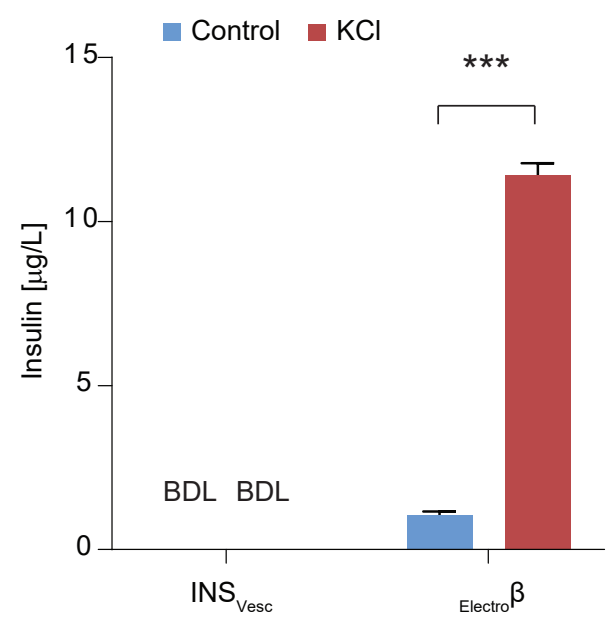

C

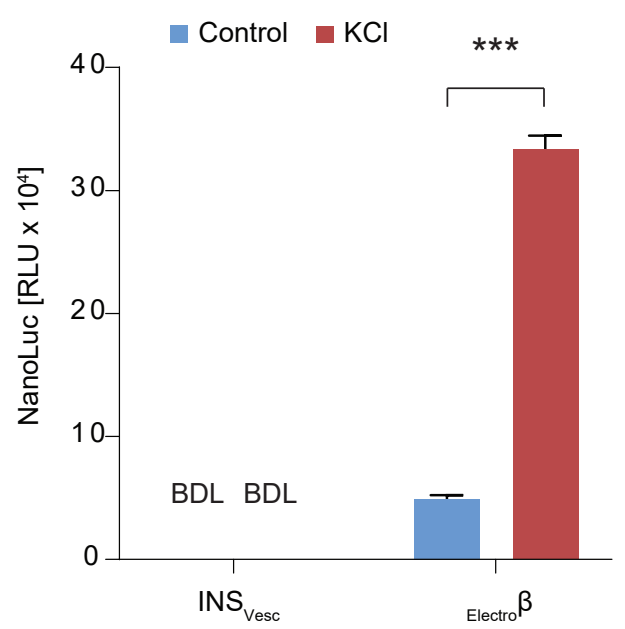

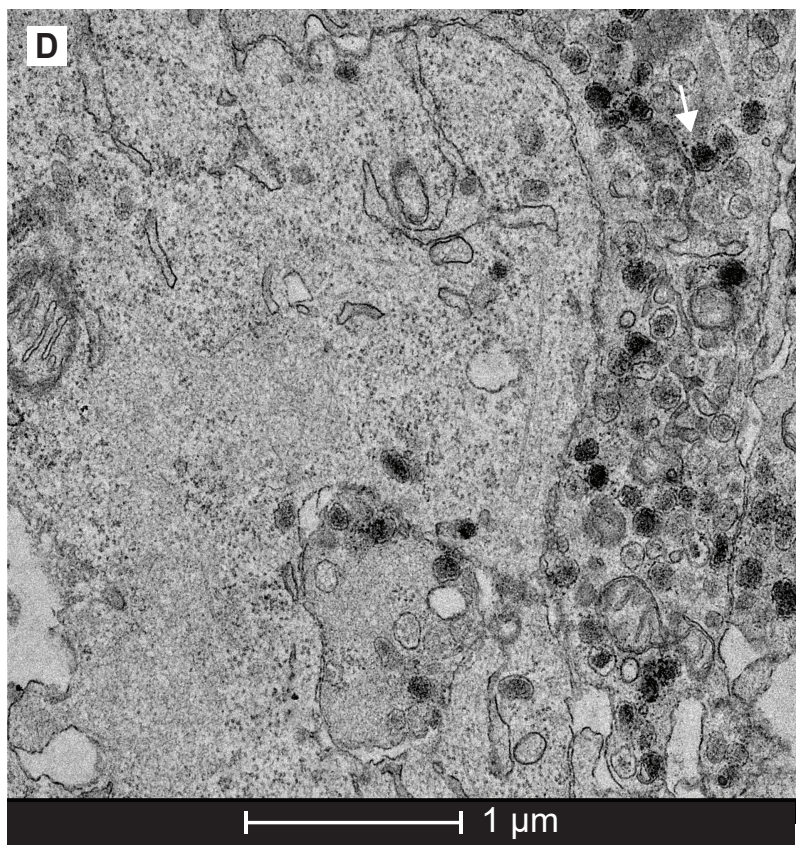

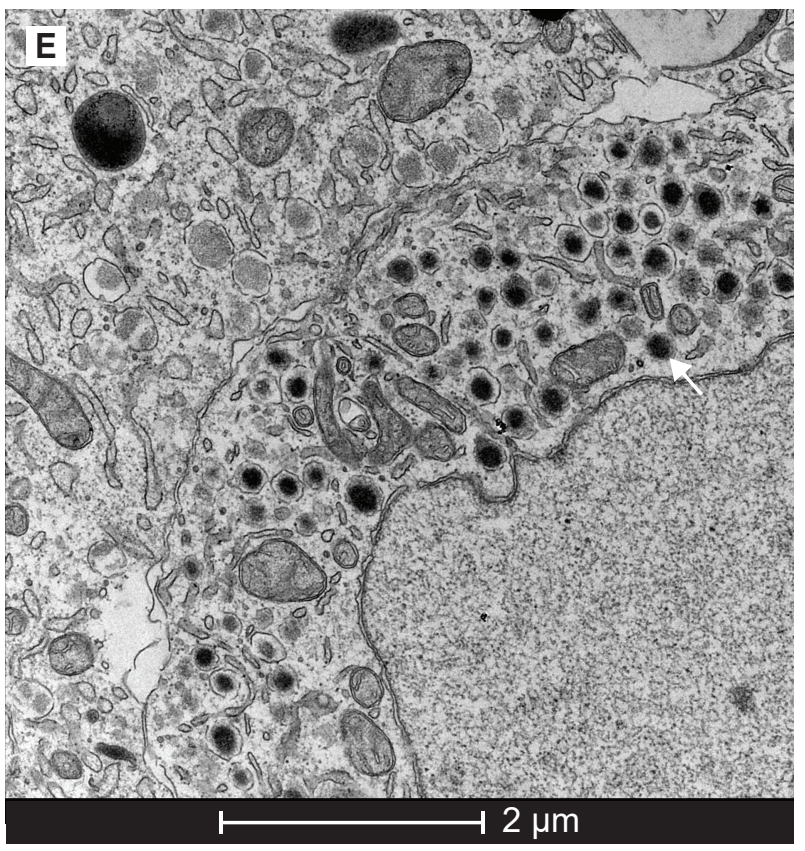

Figure 5 
A

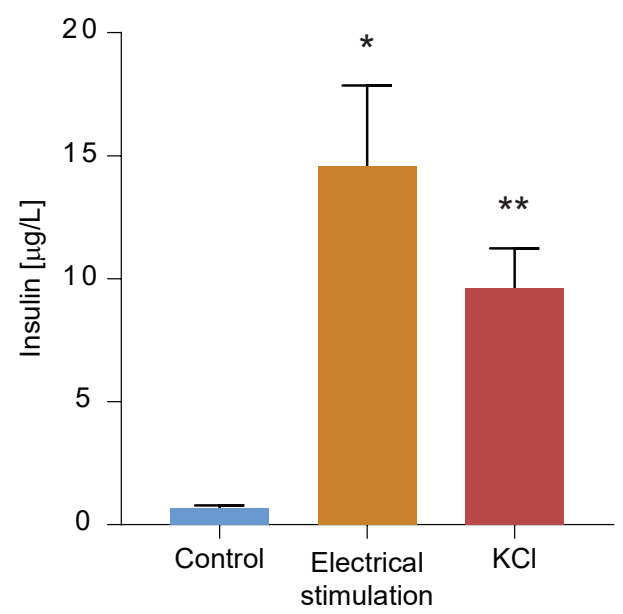

C

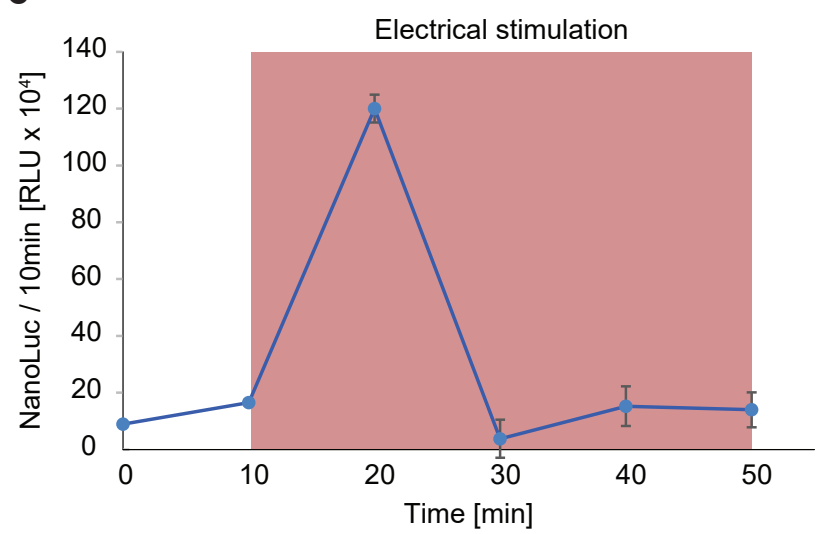

E

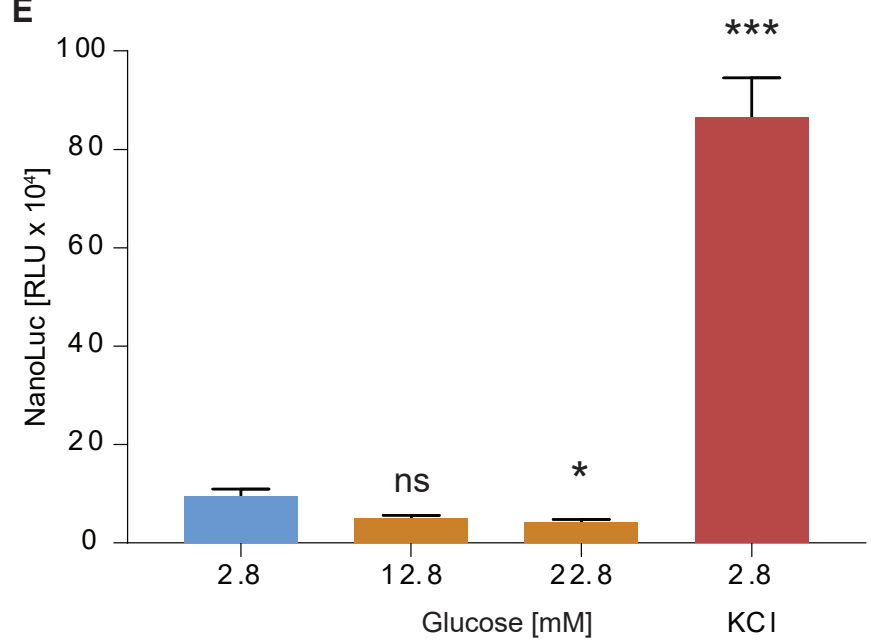

B

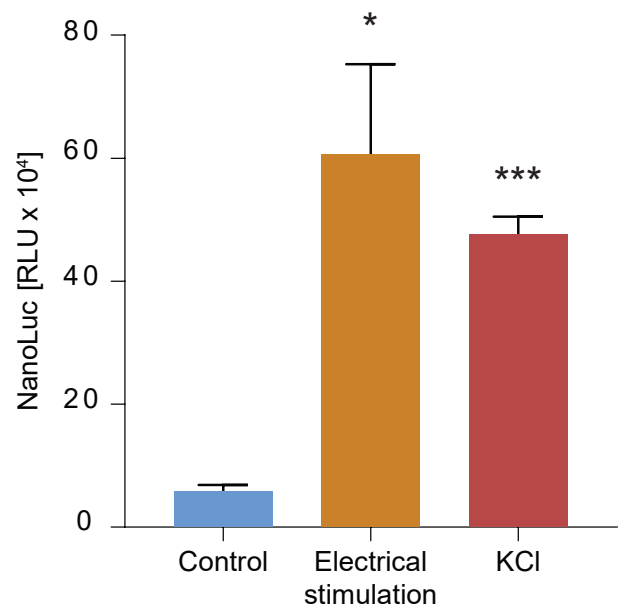

D

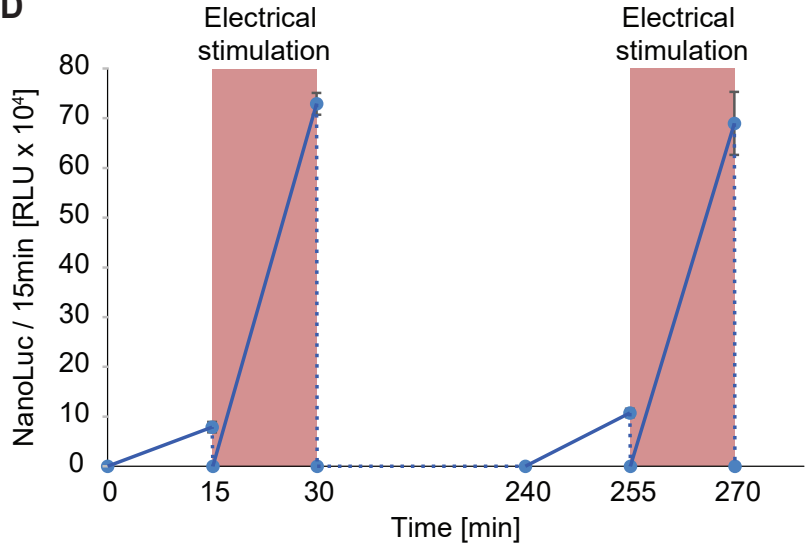

F

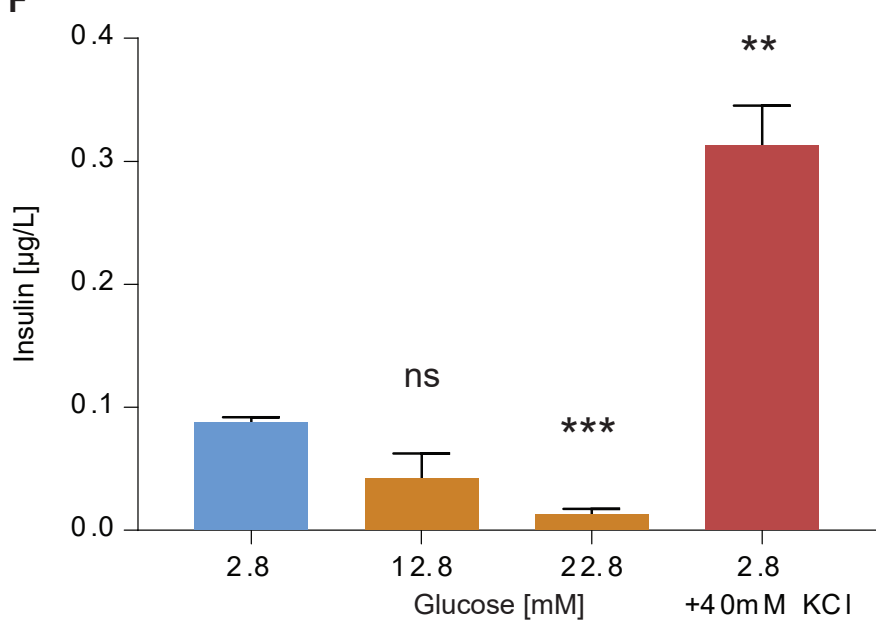


A

Glucose Tolerance Test (GTT)

$$
\rightarrow \text { Wild Type } \neq \text { Islets }
$$

$\rightarrow$-T1D, electrostimulated $\rightarrow$ T1D, empty implant

\section{E lect ro stimul ation}

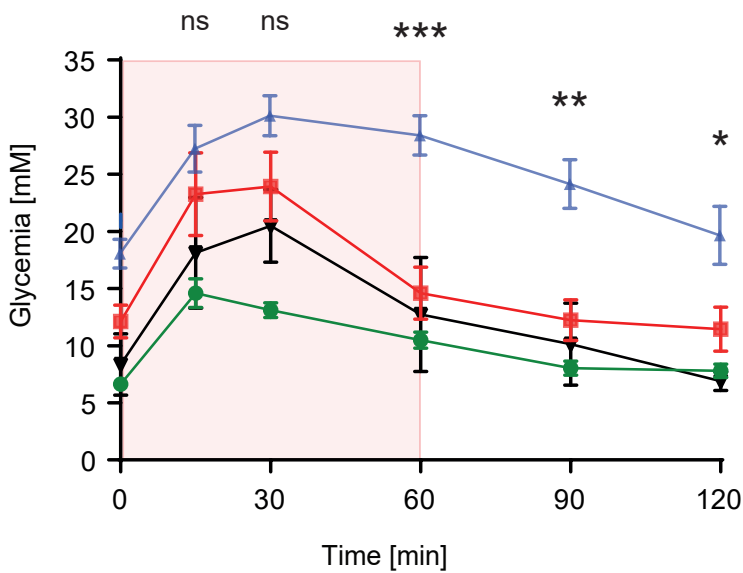

C

$$
\text { In vivo kinetics }
$$

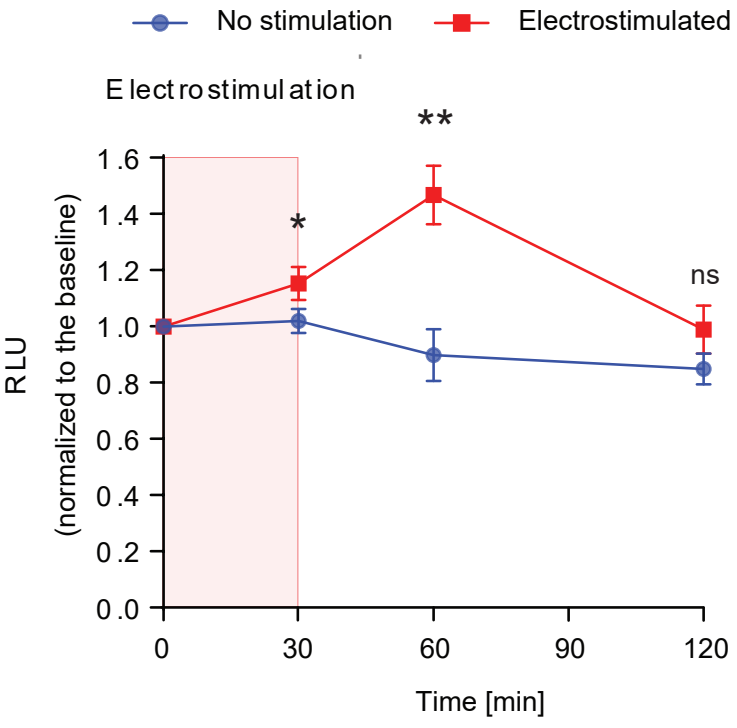

B

Real-time glycemia

$\multimap$ Wild type

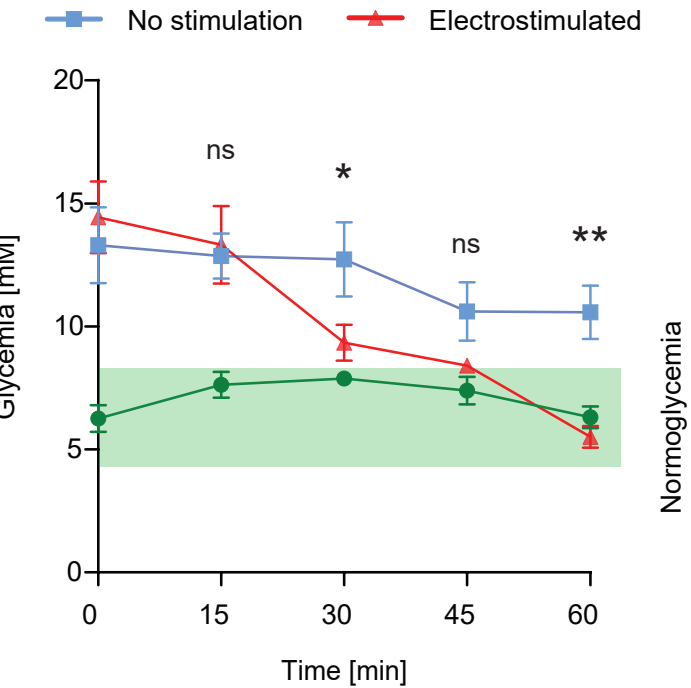

D

Fasting glycemia

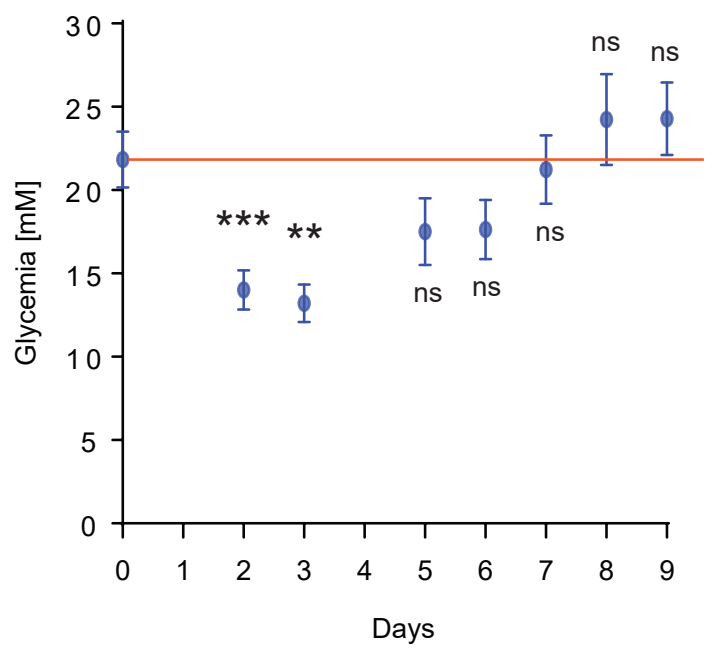

Figure 7 


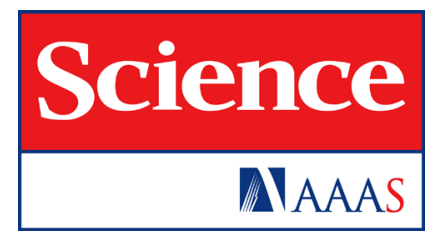

\section{Supplementary Materials for}

\section{Electrogenetic cellular insulin release for real-time glycemic control in type-1} diabetic mice

Krzysztof Krawczyk, Shuai Xue, Peter Buchmann, Ghislaine Charpin-El-Hamri, Pratik Saxena, Marie-Didiée Hussherr, Jiawei Shao, Haifeng Ye, Mingqi Xie and Martin Fussenegger

correspondence to: fussenegger@bsse.ethz.ch

This PDF file includes:

Materials and Methods

Figs. S1 to S20

Tables $\mathrm{S} 1$ to $\mathrm{S} 8$ 


\section{Materials and Methods}

Key plasmids used in this study

Comprehensive design and construction details for all expression vectors are provided in Table S7. Key plasmids include (i) pCa $\alpha_{1} \mathrm{C}\left(\mathrm{P}_{\mathrm{hCMv}}-\alpha_{1} \mathrm{C}-\mathrm{pA}\right), \mathrm{pCav} \alpha_{2} \delta_{1}\left(\mathrm{P}_{\mathrm{hCMv}}-\alpha_{2} / \delta_{1}-\mathrm{pA}\right)$ and $\mathrm{pCav}_{\mathrm{v}} \beta_{3}\left(\mathrm{P}_{\mathrm{hCMv}}-\beta_{3}-\mathrm{pA}\right)$, which enable constitutive expression of subunits $\alpha_{1} \mathrm{C}, \alpha_{2}, \delta_{1}$ and $\beta_{3}$ of the L-type voltage-gated channel Cav1.2, respectively (ii) pMX57, which encodes a $\mathrm{Ca}^{2+}$-responsive $\mathrm{P}_{\mathrm{NFAT3}}$-driven SEAP expression unit (P $\left.\mathrm{P}_{\mathrm{NFAT3}}-\mathrm{SEAP}-\mathrm{pA}\right)$ (5), (iii) pKK66, which harbors a Sleeping Beauty (SB) 100X-specific transposon containing a bicistronic unit for $\mathrm{P}_{\mathrm{hEF} 1 \alpha}$-driven expression of the Cav1.2 $\alpha_{1} \mathrm{C}$ subunit and the inwardly rectifying potassium channel $\mathrm{K}_{\mathrm{ir}} 2.1$, as well as a bicistronic unit for the expression of the blue fluorescent protein (BFP) and the puromycin resistance gene (PuroR) (ITR-P $\mathrm{hEF}_{\alpha} \alpha_{-} \alpha_{1} \mathrm{C}-\mathrm{P} 2 \mathrm{~A}-\mathrm{K}_{\mathrm{ir}} 2.1-\mathrm{pA}-\mathrm{ITR}: \mathrm{P}_{\mathrm{RPBSA}} \mathrm{BFP}-\mathrm{P} 2 \mathrm{~A}-$ PuroR-pA-ITR), (iv) pMX251, which harbors a SB100X-specific transposon containing a constitutive bicistronic unit for the expression of the Cav1.2 $\alpha_{2}, \delta_{1}$ and $\beta_{3}$ subunits, as well as a bicistronic unit for constitutive expression of the red fluorescent protein dTomato and the blasticidin resistance gene (BlastR) (ITR-P $\mathrm{P}_{\mathrm{hEF} 1 \alpha}-\alpha_{2} / \delta_{1}-\mathrm{P} 2 \mathrm{~A}-\beta_{3}-\mathrm{pA}: \mathrm{P}_{\mathrm{RPBSA}}-\mathrm{dT}$ omato-P2A-BlastRpA-ITR) (5), and (v) pProinsulin-NanoLuc (PhCMv-Proinsulin-NanoLuc-pA), a lentiviral expression vector containing a modified proinsulin whose C-peptide has been replaced with Oplophorus gracilirostris luciferase (NanoLuc) (33).

Cell culture and transfection

Human embryonic kidney cells (HEK-293T, ATCC: CRL-11268) were cultivated in Dulbecco's modified Eagle's medium (DMEM; cat. no. 52100-039; Thermo Fischer Scientific, Waltham, MA, USA). 1.1E7 cells (cat. no. 10070101-1VL, Sigma-Aldrich, Saint Louis, MO, USA) were cultivated in Roswell Park Memorial Institute 1640 medium (RPMI; cat. no. 72400021, Thermo Fischer Scientific) supplemented with 10\% fetal bovine serum (FBS; cat. no. F7524, lot no. 022M3395, Sigma-Aldrich), $100 \mathrm{U} / \mathrm{mL}$ penicillin and $100 \mu \mathrm{g} / \mathrm{mL}$ streptomycin (penicillin-streptomycin solution 100x; cat. no. L0022, Biowest, Nuaillé, France). Alpha TC-1 cells (alpha TC-1 Clone 9, ATCC: CRL-2350) were cultivated in DMEM supplemented with 10\% FBS, $15 \mathrm{mM}$ HEPES, $0.1 \mathrm{mM}$ non-essential amino acids, and 0.02\% BSA. Cells were grown at $37^{\circ} \mathrm{C}$, in humidified air containing $5 \% \mathrm{CO}_{2}$. For transfection, 35,000 cells were seeded per $\mathrm{cm}^{2}$ of the cell culture dish, and incubated for $24 \mathrm{~h}$. Then, they were incubated for another 24 h with a 1:3 DNA:PEI (Polyethylenimine MAX; MW 40,000, cat. no. 24765-2; Polysciences Inc., Warrington, PA, USA) solution containing $1.5 \mu \mathrm{g}$ DNA per $\mathrm{cm}^{2}$ of transfected cells.

\section{Production of stably transgenic cell lines}

Electro $\beta$ was produced via the following three-step procedure. (i) First, a 1.1E7-derived cell clone deficient in glucose-sensitive insulin secretion was selected. The resulting cell line, INSVesc, was used for step two. (ii) Second, INS Vesc was transduced with pProinsulin-NanoLuc-derived lentiviral particles, selected in culture medium containing $5 \mu \mathrm{g} / \mathrm{mL}$ blasticidin for 14 days, and cloned by limiting dilution. Monoclonal cell populations were tested for depolarization-triggered NanoLuc secretion. The monoclonal cell line showing the highest induction profile was used for step three. (iii) The proinsulin-NanoLuc-transgenic INS Vesc $_{\text {was }}$ cotransfected with the SB100X expression vector pCMV-T7-SB100 ( $\left.\mathrm{PhCMV}_{\mathrm{SB}} \mathrm{SB} 10 \mathrm{X}-\mathrm{pA}\right)$ and the SB100X-specific transposon

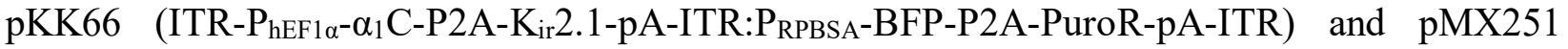
(ITR-P $\left.\mathrm{PEF}_{1}-\alpha_{2} / \delta_{1}-\mathrm{P} 2 \mathrm{~A}-\beta_{3}-\mathrm{pA}: \mathrm{P}_{\mathrm{RPBSA}}-\mathrm{dTomato}-\mathrm{P} 2 \mathrm{~A}-\mathrm{BlastR}-\mathrm{pA}-\mathrm{ITR}\right)$ as described above. After seven days, stably transgenic puromycin-resistant cell populations were selected by FACS- 
mediated single-cell sorting based on the cell's fluorescence relative to parental 1.1E7 (BFP: 405 $\mathrm{nm}$ laser, 450/50 bandpass filter; dTomato: $561 \mathrm{~nm}$ laser, $570 \mathrm{~nm}$ long-pass filter, 586/15 bandpass filter) using a Becton Dickinson LSRII Fortessa flow cytometer (Becton Dickinson, Allschwil, Switzerland).

Lentiviral particle production

pProinsulin-NanoLuc-derived lentiviral particles were produced by cotransfecting HEK$293 \mathrm{~T}$ cells with the lentiviral expression vector pProinsulin-NanoLuc (PhCMV-ProinsulinNanoLuc-pA), as well as the packaging (pSPAX2) and envelope (pMD2.G) vectors at a 4:3:1 ratio, respectively. After $48 \mathrm{~h}$, the lentiviral particles were harvested from the cell culture supernatant and purified by $0.4 \mu \mathrm{m}$ filtration.

Electrostimulation

(a) C-Dish. Cultured cells were electrostimulated using the C-Dish (Ionoptix, Dublin, Ireland), powered by an HP3245A Universal Source function generator (cat. no. 3245A; Hewlett Packard, Palo Alto, CA, USA) connected to a general-purpose linear amplifier (P200, cat. no. P200; FLC Electronics AB, Molndal, Sweden). C-Dish precisely places pairs of carbon electrodes into each well of a standard 6-well cell culture plate containing $35,000 \mathrm{cells} / \mathrm{cm}^{2}$ in 1.4 $\mathrm{mL}$ of cell-specific culture medium. (b) Cell culture chamber. Cell culture chambers with a 0.4 $\mu \mathrm{m}$ transparent PET membrane supporting the growth of monolayer cultures (Falcon ${ }^{\circledR}$ Permeable Support; cat. no 353095, Corning, Corning, NY, USA), fitting individual wells of a standard 24well plate, were equipped with platinum electrodes $(0.5 \mathrm{~mm}$ diameter; cat. no. HXA 050, Cooksongold Ltd., Birmingham, United Kingdom) placed above and below the cell-containing membrane and powered by the amplifier-connected HP3245A Universal Source function generator. The PET membrane of the cell culture chamber was seeded with $35,000 \mathrm{cells} / \mathrm{cm}^{2}$ cultivated in the cell-specific medium $(400 \mu \mathrm{L}$ inside the cell culture chamber, $1.3 \mathrm{~mL}$ inside the 24-well plate).

\section{Analytical assays}

SEAP (human placental secreted alkaline phosphatase) levels were profiled in cell culture supernatants using a colorimetric assay. $100 \mu \mathrm{L} 2$ x SEAP assay buffer (20 mM homoarginine, 1 $\mathrm{mM} \mathrm{MgCl} 2,21 \%$ diethanolamine, $\mathrm{pH} 9.8$ ) was mixed with $80 \mu \mathrm{L}$ heat-inactivated (30 min at $\left.65^{\circ} \mathrm{C}\right)$ cell culture supernatant. After the addition of $20 \mu \mathrm{L}$ substrate solution $(120 \mathrm{mM} \mathrm{p}-$ nitrophenyl phosphate; cat. no. AC128860100, Thermo Fisher Scientific), the absorbance time course was recorded for $45 \mathrm{~min}$ at $405 \mathrm{~nm}$ and $37^{\circ} \mathrm{C}$ using a Tecan Genios PRO plate reader (cat. no. P97084; Tecan Group AG, Maennedorf, Switzerland) and the SEAP levels were determined as described previously (15). Blood SEAP levels were quantified using a chemiluminescencebased assay (cat. no. 11779842001; Roche Diagnostics GmbH, Mannheim, Germany). In brief, serum was isolated from blood samples by centrifugation in Microtainer ${ }^{\circledR}$ serum separation tubes (SST $^{\mathrm{TM}}$, cat. no. 365967; Becton Dickinson) for $5 \mathrm{~min}$ at $10,000 \mathrm{xg}$. $50 \mu \mathrm{L}$ of serum was heatinactivated for $30 \mathrm{~min}$ at $65^{\circ} \mathrm{C}$, centrifuged for $30 \mathrm{~s}$ at $5,000 \mathrm{xg}$, transferred to a well of a 96-well plate containing $50 \mathrm{~mL}$ inactivation buffer, and incubated for $10 \mathrm{~min}$ at $20^{\circ} \mathrm{C} .50 \mu \mathrm{L}$ of substrate reagent was then added to each well and the sample was incubated for $10 \mathrm{~min}$ at $20^{\circ} \mathrm{C}$. The luminescence was quantified using a Tecan Genios PRO plate reader (Tecan Group AG, Maennedorf, Switzerland).

NanoLuc $^{\circledR}$ luciferase was quantified in cell culture supernatants using the Nano-Glo ${ }^{\circledR}$ Luciferase Assay System (cat. no. N1110; Promega, Duebendorf, Switzerland). In brief, $7.5 \mu \mathrm{L}$ of cell culture supernatant was added per well of a black 384 -well plate and mixed with $7.5 \mu \mathrm{L}$ 
substrate-containing assay buffer. Total luminescence was quantified using a Tecan Genios PRO plate reader (Tecan Group AG). Serum NanoLuc ${ }^{\circledR}$ was quantified on an EnVision 2104 Multilabel Reader (PerkinElmer, Waltham, Massachusetts, USA) using the ultrasensitive luminescence program. $5 \mu \mathrm{L}$ of serum was diluted in $10 \mu \mathrm{L}$ of $\mathrm{ddH}_{2} \mathrm{O}$ per well of a black 96-well plate and mixed with $15 \mu \mathrm{L}$ of substrate-containing assay buffer. Aliquots of $15 \mu \mathrm{L}$ of wholeblood samples were diluted in $5 \mu \mathrm{L}$ of $50 \mathrm{mM}$ EDTA and frozen at $-20{ }^{\circ} \mathrm{C}$ until NanoLuc ${ }^{\circledR}$ quantification as described above.

\section{Cell encapsulation}

HEK- $\beta$ cells were encapsulated in coherent alginate-poly-(L-lysine)-alginate beads ( $400 \mu \mathrm{m}$; 500 cells or 1-10 IEQs per capsule) using an Inotech Encapsulator Research Unit IE-50R (EncapBioSystems Inc., Greifensee, Switzerland) set to the following parameters: a 200- $\mu \mathrm{m}$ nozzle with a vibration frequency of $1025 \mathrm{~Hz}$, a $25-\mathrm{mL}$ syringe operated at a flow rate of 410 units, and a voltage of $1.12 \mathrm{kV}$ for bead dispersion.

\section{Cell viability}

Cell viability was quantified by incubating the cells for $2 \mathrm{~h}$ in working solution containing $60 \mu \mathrm{g} / \mathrm{mL}$ resazurin (cat. no. R7017, Sigma-Aldrich, Saint Louis, MO, USA), followed by fluorescence measurement of sample supernatants at 560/9 nm excitation and 590/20 nm emission using a Tecan Infinite 200Pro plate reader (Tecan Group AG, Maennedorf, Switzerland).

\section{Bioelectronic implant for wireless electrostimulation in vivo}

The casing of the bioelectronic implant containing the cell culture chamber and the electronics was 3D-printed using FDA-licensed polyamide and a Formiga P110 3D printer (EOS GmbH, Krailling, Germany; Fabb-It 3D Druckservice, Loerrach, Germany). To fit this casing, the height of the cell culture chamber (Falcon® Permeable Support; Corning, cat. no 353095 or Corning Transwell@; Corning, cat. no. CLS3462-48EA) was cut to $3 \mathrm{~mm}$. The cell culture chamber's $0.4 \mu \mathrm{m}$ membrane enables nutrient supply and product delivery via the vascularized fibrous connective tissue of the host while protecting the electrosensitive designer cells from host-cell responses $(35,36)$. The switchboard, wireless electronics and pulse generator were designed and prototyped by Peter Buchmann, and the final printed circuit board was custommanufactured (ITEAD Intelligent Systems Co. Ltd, Shenzhen, People's Republic of China) (see Supplementary Information). The electrode above the cell culture chamber's membrane containing the electrosensitive designer cells consists of a platinum wire $(0.5 \mathrm{~mm}$ diameter; cat. no. HXA 050, Cooksongold Ltd.) and the electrode below the chamber's membrane was made of a stainless-steel mesh (cat. no. 165; wire diameter $50 \mu \mathrm{m}$, aperture $100 \mu \mathrm{m}$; BOPP AG, Zurich, Switzerland) covering the entire membrane to provide a Faraday-cage effect that would protect the host from any electric shock. The bioelectronic implant was assembled by fitting the electronics into the casing, connecting the electrodes to the electronics, covering the electronic switchboard with insulating tape and sealing it with Epo-Tek 301-2 (cat. no. 301-2; Epoxy Technology Inc., Billerica, MA, USA), fitting the cell culture chamber into the casing, and positioning the electrodes. Bioelectronic implants were sterilized by immersion in $70 \%$ ethanol followed by rinsing in PBS. Each implant was completely filled with $300 \mu \mathrm{L}$ of culture medium containing $2 \times 10^{6}$ Electro $\beta$ suspension cells and $3 \times 10^{6}$ Electro $\beta$ cell aggregates, prepared by cultivation in AggreWell ${ }^{\mathrm{TM}} 400$ (cat. no. 34460, STEMCELL Technologies GmbH, Koeln, Germany) via a dedicated hole, then sealed with PDMS-filled pipette tips (Sylgard 184, cat. no. 184.0001; Suter Kunststoffe AG, Fraubrunnen, Switzerland) and subcutaneously implanted into 
mice after $12 \mathrm{~h}$. To adapt the bioelectronic implant for long-term repetitive in-situ exchange of individual Electro $\beta$-cell batches (Fig. S20), we connected fill-in and exhaust tubes (Venofix ${ }^{\circledR}$ Safety, B. Braun AG, Melsungen, Germany) to the cell culture chamber (Fig. S20A). After implantation, $2 \times 10^{6}$ Electro $\beta$ cells were filled into the culture chamber. For cell replacement, a syringe was connected to the fill-in tube and the cell chamber was flushed several times with a physiological salt solution $(0.9 \% \mathrm{NaCl})$ before the new batches of Electro $\beta$ cells were filled in. Fillin tubes were closed by thermal welding.

Electronic circuitry of the field generator and the bioelectronic implant

The field generator provides wireless power transmission across living tissues using transmitter coils (L2 and L3) producing an alternating electromagnetic field that is detected by the receiver coil (L1) of the bioelectronic implant and converted into electric current to power and control all electronic components of the implant. The field generator also enables detection and functional monitoring of the bioelectronic implant. The field generator consists of four functional elements: the frequency generator, the resonance unit, the filter and edge shaper and the timer (Fig. S7, S8). (a) Frequency generator (Fig. S7A). A crystal-based oscillating circuit (IC2) connected to a negative impedance converter (T4, T6) drives the output transistor (T5) of the frequency generator. (b) Resonance unit (Fig. S7B). The output transistor controls the main transmitter coil (L3) current, which generates an alternating magnetic field. The secondary transmitter coil (L2) with an adjustable capacitor (C8) in parallel forms an oscillating circuit, which amplifies the resonance of the main transmitter coil (L3). (c) Filter and edge shaper (Fig S7C). The current drawn by the main transmitter coil (L3) generates a proportional voltage drop by passing a resistor (R1). This voltage drop is filtered out by an LC network (L1, C4, C5) and amplified by a class A amplifier (T3). A decoupling capacitor (C1) forms a high-pass filter and drives a positive-negative-positive (PNP) transistor (T1). The high gain factor of the PNP transistor produces digital-like behavior of the data output (Data Out) for each fast change of the main transmitter coil current and enables wireless communication between the field generator and the bioelectronics implant. (d) Timer (Fig. S5D). The data output (Data Out) triggers a timer circuit (IC1) that controls an LED, which enables functional monitoring of the bioelectronic implant in real time.

The electronic circuit of the bioelectronic implant consists of three functional elements: The power supply, the time generator and the communication circuit (Fig. S5, Fig. S6). (a) Power supply (Fig. S5A). The receiver coil (L1) and capacitors (C6, C8) connected in parallel form an oscillating circuit that is in resonance with the magnetic field of the transmitter coils of the field generator. To prevent potential impact of the electrical load on the resonance, power is withdrawn from two turns of the receiver coil via current transformation and rectified by two diodes (D4). (b) Time generator (Fig. S5B). Pulses are generated by an integrated time generator. The pulse length and intervals are set by external resistors (R7, R9), a diode (D11) and a capacitor (C14). The timer (IC4) includes an internal voltage divider with three resistors. The potential of the external capacitor and the voltage divider are compared by comparators and used to control the timer output. ON/OFF-states are stored by a flip-flop until the opposite voltage threshold is reached. One output of the flip-flop serves to discharge the capacitor (C14). To reach the required ratio between pulse duration and pulse interval of approximately 1:500, the capacitor is charged through a low-Ohmic resistor (R7) and a diode (D11) and discharged via a highOhmic resistor (R9). (c) Communication circuit (Fig. S5C). Upon detection of a negative pulse edge by a capacitor (C12) and a transistor (T3), the oscillating circuit of the power supply is short-circuited for 15-25 $\mu \mathrm{s}$. This brief overload leads to a breakdown of the resonance in the receiver coil (L1); this results in an abrupt drop of the excitation current in the resonance unit of 
the field generator and produces a voltage increase. This voltage increase is filtered out by the excitation electronics in the field generator and provides digital information on the presence of the bioelectronic implant and the function of the time generator. All electronic components of the bioelectronic implant are listed in Table S8.

\section{Animal experiments}

To establish type-1 diabetes, wild-type 6-week old male Swiss mice (weighing 30-32 g RjOrl:SWISS; Janvier Labs, Le Genest-Saint-Isle, France) were fasted $18 \mathrm{~h}$ per day for two consecutive days and injected with a single dose of freshly diluted alloxan monohydrate (ALX; Sigma-Aldrich; cat. no. A7413, $195 \mathrm{mg} / \mathrm{kg}$ in $300 \mu \mathrm{L}$ PBS) (5). Persistent fasting hyperglycemia was confirmed after $48 \mathrm{~h}$ using a glucometer (Contour ${ }^{\circledR}$ Next, Bayer Healthcare, Leverkusen, Germany). (a) Monitoring of study animals: General well-being of the animals was routinely monitored by animal caretakers by daily visual inspections. Project-specific monitoring was carried out at least five times per week by animal facility staff and animals were euthanized if symptoms of pain and/or distress were observed. Absence of the following applied humane endpoints was defined as asymptomatic disease state: weight loss $>20 \%$, insatiable polydipsia, recurrent dehydration (assessed by skin fold testing), surgical wound complications such as bleedings or inflammation/infection, abnormal breathing pattern, apathy or immobility, closed eyes or self-mutilation, detachment from the group or disinterest to the environment, un-kept appearance e.g. tangled fur and discoloration due to secretions. (b) Bioelectronic implant. At 72 $\mathrm{h}$ after alloxan treatment, the animals received inhalational isoflurane anesthesia and the bioelectronic devices were subcutaneously implanted on the back, with the polyester gauzeprotected mesh electrode facing the ventral side. (c) Glucose tolerance test. Treated animals were fasted for 6 hours and then placed for 60 min below a field generator (see Supplementary Information) to power up the bioelectronic implant and wirelessly stimulate insulin release by Electro $\beta$ cells immediately before the animals were subjected to glucose tolerance tests: blood glucose levels were monitored for indicated period after oral injection of $2 \mathrm{~g} / \mathrm{kg}$ glucose. Mockstimulated implants produced no insulin. (d) Human pancreatic islets implant. Human pancreatic islets were provided by the Geneva Islet transplantation center through the basic research program of European Consortium for Islet Transplantation (ECIT) supported by the Juvenile Diabetes Research foundation (JDRF; grant no 31-2008-416). At $72 \mathrm{~h}$ after alloxan treatment, the animals received anesthesia and the islets-containing chamber (2000 islet equivalents (IEQ) per implant) of a bioelectronic implant was placed as described above. (e) Real-time glycemia. Animals were fasted for 6 hours and glycemia was monitored for the indicated periods of time before and during electrostimulation. (f) In vivo kinetics. Implants were electrostimulated for $30 \mathrm{~min}$ and reporter protein levels were quantified in $15 \mu \mathrm{L}$ blood samples, collected from the tail vein at the indicated time points. (g) Biocompatibility. Mice were subcutaneously implanted on the back with either Electro $\beta$-cell-containing implants, cell-free negative control implants, or biocompatible reference implants serving as positive controls according to ISO 10993. The biocompatible reference implants of identical shape were cast from polydimethylsiloxane (Sylgard 184, cat. no. 184.0001; Suter Kunststoffe AG, Fraubrunnen, Switzerland). They were autoclaved for 20 minutes at $121{ }^{\circ} \mathrm{C}$ prior to implantation. After three weeks, the animals were sacrificed and the bioelectronic implants as well as tissue samples were fixed in 10\% neutral buffered formalin and transferred to AnaPath GmbH (Oberbuchsiten/Liestal, Switzerland), where the biocompatibility assays were performed according to ISO 10993.

Animal experiments were performed according to the directive of the European Community Council (2010/63/EU), approved by the French Republic, and carried out by (i) Ghislaine Charpin-El Hamri (no. 69266309), Marie Daoud-El Baba (no. 69266310) at the Institut 
Universitaire de Technologie of the Université Claude Bernard Lyon 1, F-69622, Villeurbanne Cedex, France (project no. APAFIS \# 16753 - CEEA-55 DR 2018-40v5), (ii) Marie-Didiée Hussherr and Shuai Xue (license number: 2996/30779) at the ETH Zurich in Basel, Switzerland, and by (iii) Jiawei Shao and Shuai Xue (license number: m20190102) in the laboratory of Haifeng Ye at the Institute of Biomedical Sciences and School of Life Sciences, East China Normal University, Shanghai, People's Republic of China.

\section{Histology}

(a) Limited Systemic Toxicity. Two kidneys and two lobes from the liver of each mouse were processed by paraffin embedding, cut into 2-4 $\mu \mathrm{m}$ slices, and stained with hematoxylin and eosin (H\&E) (Fig. S16). (b) Tissue samples. A small portion of the tissue in contact with the semipermeable membrane of a cell chamber was excised, embedded in paraffin, cut into 2-4 $\mu \mathrm{m}$ slices, and stained with H\&E (Fig. S16). (c) Bioelectronic implant sections. Explanted bioelectronic devices, including surrounding tissue, were embedded in methyl methacrylate resin. The cell chamber of each implant was cut into $400 \mu \mathrm{m}$ slices at its central position in the transverse direction using a diamond saw (EXAKT 300 CP System; EXAKT Technologies Inc., Oklahoma City, OK, USA), as shown in Fig. S16. These slices were ground to a thickness of 4060 using the EXAKT $400 \mathrm{CS}$ System (EXAKT Technologies Inc., Oklahoma City, OK, USA) and stained with Paragon (toluidine blue and basic fuchsin). The same procedure was applied to obtain sections at the switchboard's central position (Fig. S16).

\section{$\underline{\text { Immunohistochemistry }(\mathrm{IHC})}$}

IHC was performed using BOND-III Fully Automated IHC and ISH Stainer (Leica Biosystems, Wetzlar, Germany). Rabbit monoclonal anti-CD11b (Ab133357; dilution 1:5000, lot no. GR3209213-2; Abcam, Cambridge, United Kingdom) and rabbit monoclonal anti-CD68 (Ab125212; dilution 1:1000, lot no. GR300618-28; Abcam, Cambridge, United Kingdom) were used. Prior to staining, the samples were incubated in Bon Epitope Retrieval Solution 1 (citratebased buffer, pH: 5.9-6.1; Leica Biosystems, Wetzlar, Germany) at $100{ }^{\circ} \mathrm{C}$ for $20 \mathrm{~min}$.

\section{Histopathology}

Histopathology of the implantation site was analysed at AnaPath $\mathrm{GmbH}$ using a scoring system according to ISO 10993-6:2016(E). Representative images were taken with an Olympus UC30 camera.

\section{$\underline{\text { Image Analysis }}$}

Quantitative analyses of immunohistochemistry sections were performed using the image analysis software QuPath (https://qupath.github.io).

\section{Cytokine Profiling}

Serum samples of each treatment group were mixed and analyzed with a Proteome Profiler Array, Mouse Cytokine Array Panel A (cat. no. ARY 006; R\&D Systems, Inc., Minneapolis, USA), according to the manufacturer's instructions. Chemiluminescence was analysed using an ImageQuant LAS 4000 mini (GE Healthcare Life Sciences, Chicago, Illinois, USA).

\section{Hematology}

Hematological analysis was performed using the scil Vet abc Plus + analyzer (scil animal care company GmbH, Viernheim, Germany). 
$\underline{\text { Sample size determination and statistics }}$

Data are presented as mean values. Error bars show the standard error of the mean. The "n" number refers to biological replicates. Sample size for in vivo experiments was chosen to provide statistical power $(1-\beta) \geq 0.8$ and type I error rate $(\alpha) \leq 0.05$ for a $30 \%$ change of the mean in treated groups, assuming $25 \%$ standard deviation. The p-value was calculated by performing the two-tailed t-test. Outliers were considered by applying the ROUT method (59). 


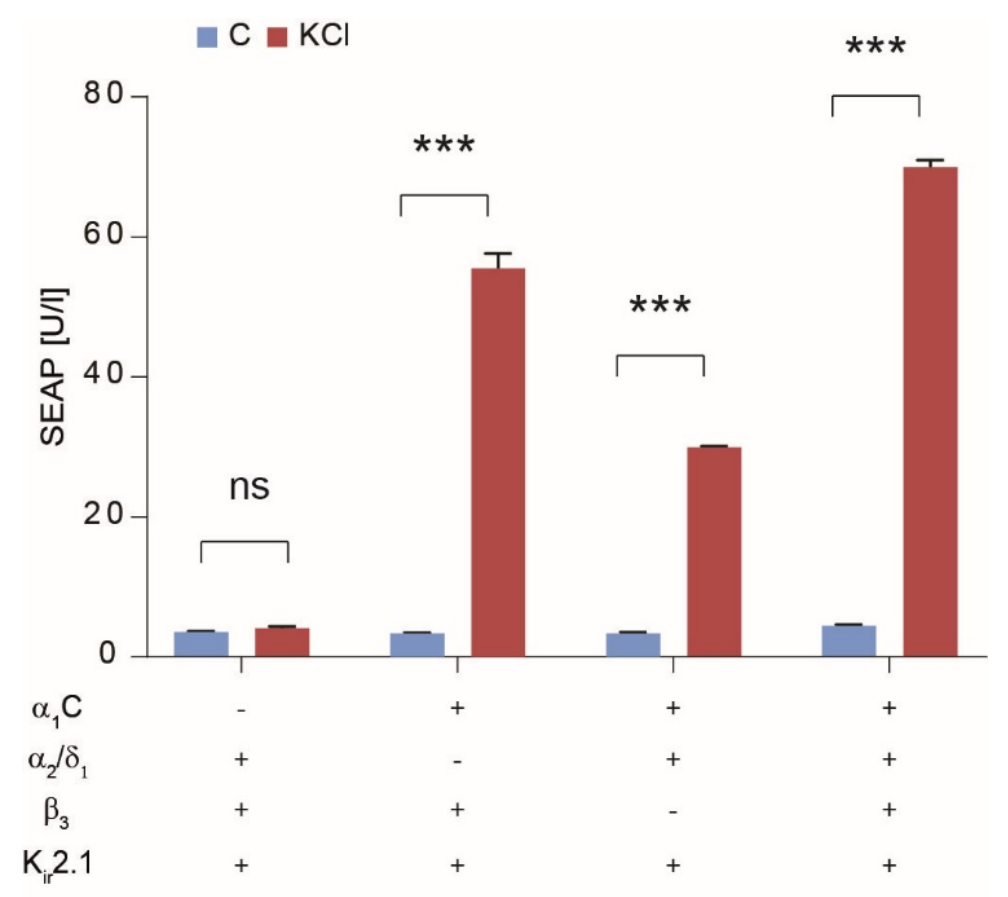

Fig. S1 Validation of system components.

HEK293T cells were co-transfected with plasmids encoding the indicated channel subunits $(+)$ : pCav1.2 ( $\left.\mathrm{P}_{\mathrm{hCMV}}-\alpha_{1} \mathrm{C}-\mathrm{pA}\right), \mathrm{pCa}_{\mathrm{v}} \alpha_{2} \delta_{1}\left(\mathrm{P}_{\mathrm{hCMV}}-\alpha_{2} / \delta_{1}-\mathrm{pA}\right)$ and $\mathrm{pCa}_{\mathrm{v}} \beta_{3} \quad\left(\mathrm{P}_{\mathrm{hCMV}}-\beta_{3}-\mathrm{pA}\right), \mathrm{pKir} 2.1$

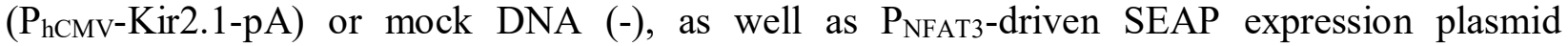
(pMX57). Cell membrane was depolarized with $40 \mathrm{mM} \mathrm{KCl}$ for one hour (red bars) and after 24 hours SEAP production was quantified in supernatant samples. Blue bars represent negative control samples. ns - not significant, $* * * p<0.001$. 

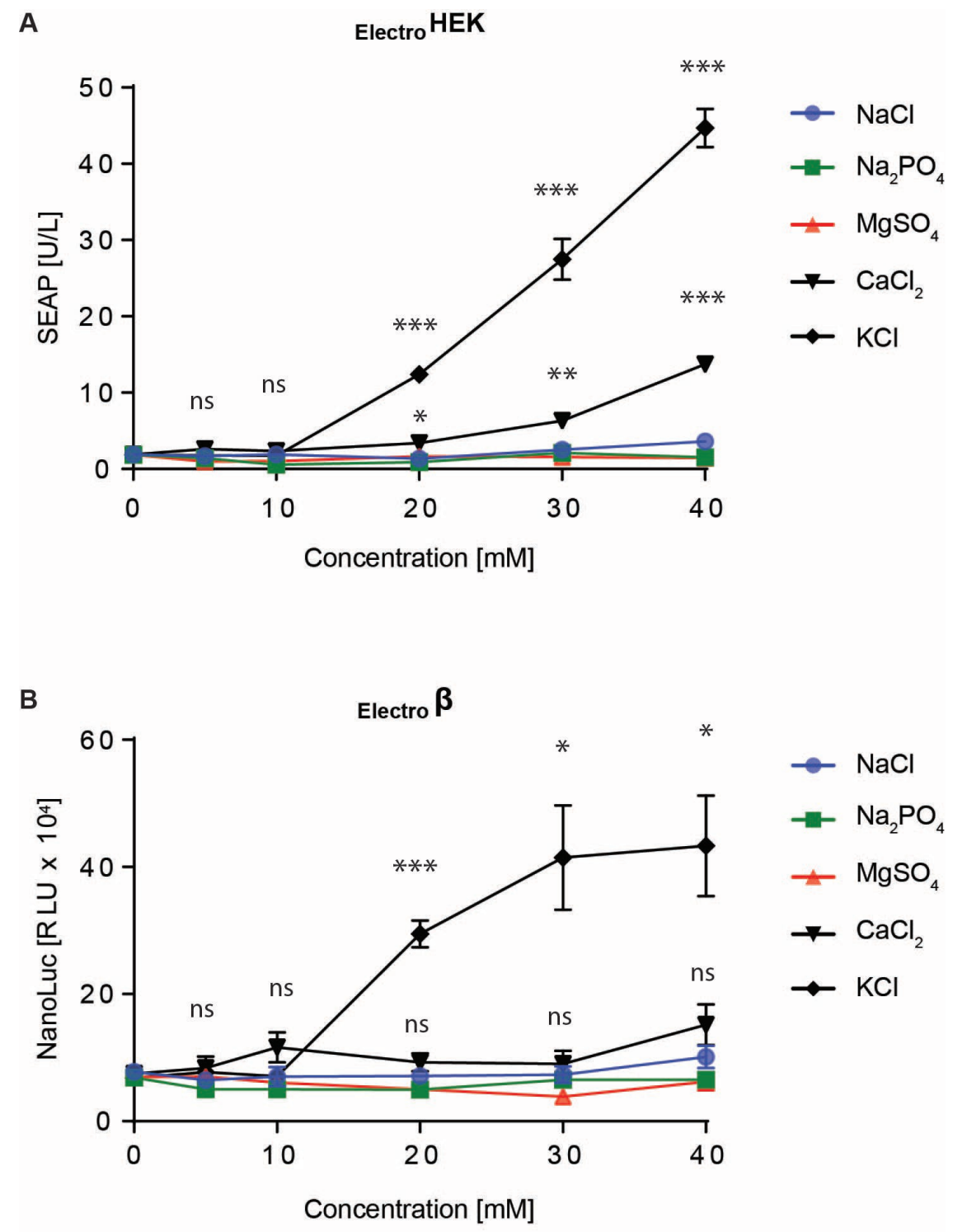

Fig. S2 Impact of salt concentration on the electrogenetic circuit.

(A) ElectroHEK cells were cultivated for 24 hours in medium supplemented with various concentrations of sodium chloride $(\mathrm{NaCl})$, sodium phosphate $\left(\mathrm{Na}_{2} \mathrm{PO}_{4}\right)$, magnesium sulphate $\left(\mathrm{MgSO}_{4}\right)$, calcium chloride $\left(\mathrm{CaCl}_{2}\right)$, or potassium chloride $(\mathrm{KCl})$, and then SEAP was quantified in the culture supernatants. (B) Electro $\beta$ cells were cultivated for 10 min in medium containing various concentrations of $\mathrm{NaCl}, \mathrm{Na}_{2} \mathrm{PO}_{4}, \mathrm{MgSO}_{4}, \mathrm{CaCl}_{2}$ or $\mathrm{KCl}$, and then NanoLuc was quantified in the culture supernatants. Data points represent mean \pm SEM. Statistical significance was calculated versus time $0 . n s-$ not significant, $* \mathrm{p}<0.05,{ }^{* *} \mathrm{p}<0.01, * * * \mathrm{p}<0.001$. 
A

$10 \mathrm{~Hz}, 2 \mathrm{~ms}, 1 \mathrm{~h}$

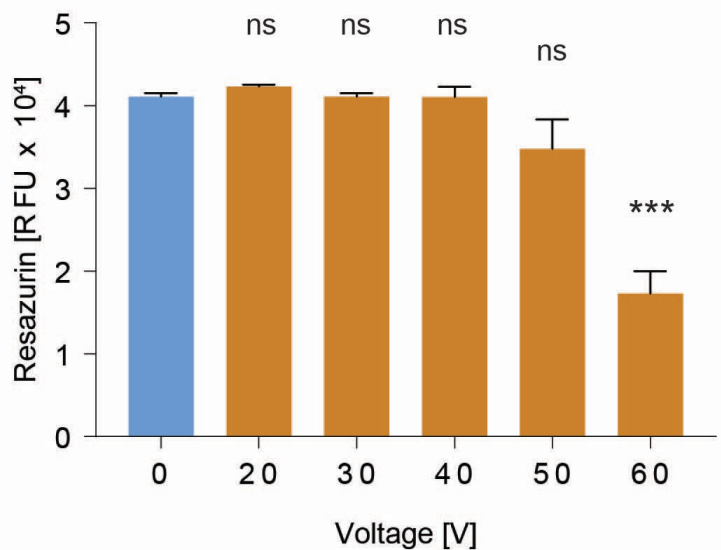

C

$0.5 \mathrm{~Hz}, 2 \mathrm{~ms}, 1 \mathrm{~h}$

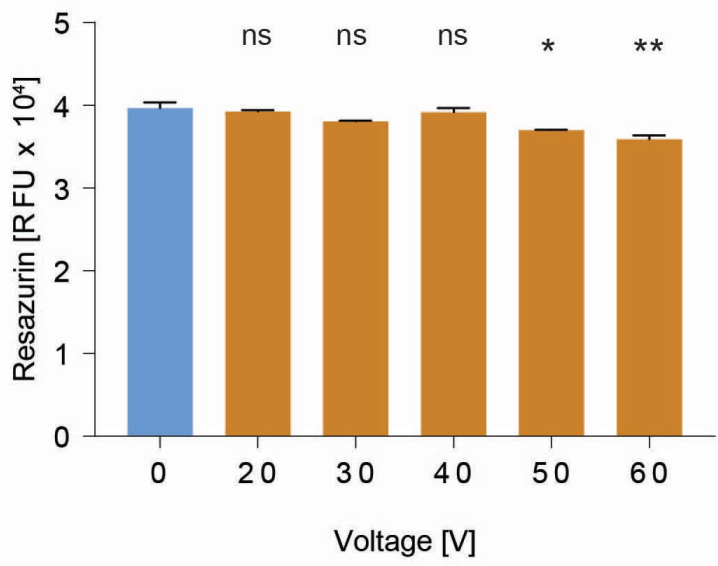

B

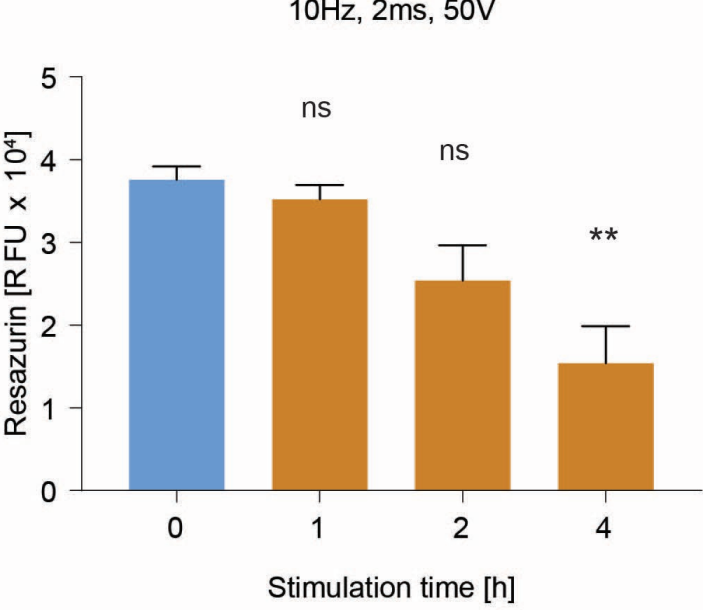

D

$0.5 \mathrm{~Hz}, 2 \mathrm{~ms}, 50 \mathrm{~V}$

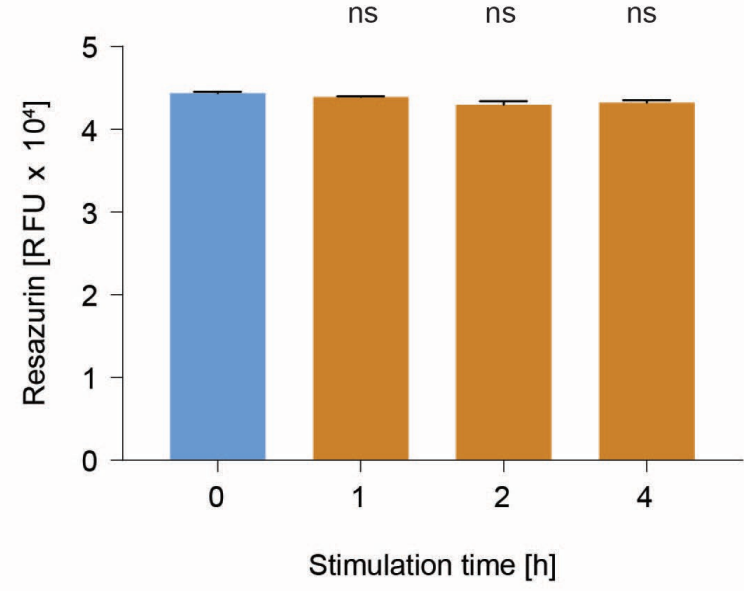

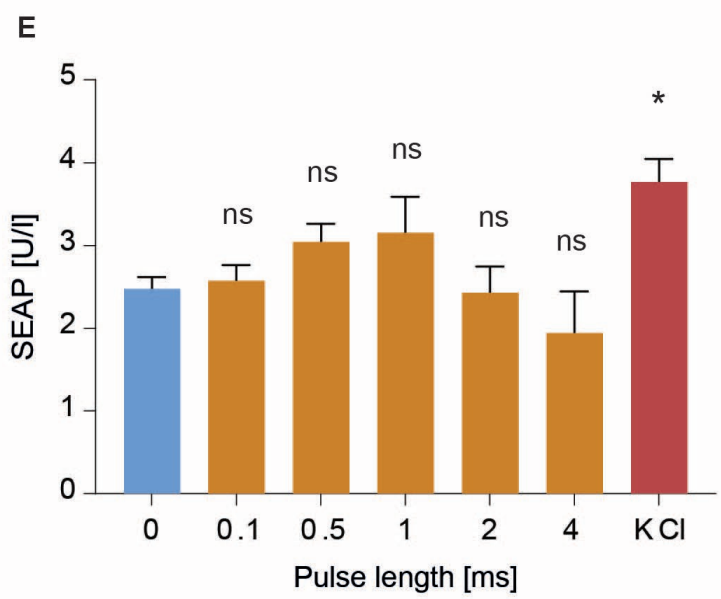

Fig. S3 Electrically inducible gene expression system.

(A-D) Toxicity of electrical stimulation. HEK293T cells were co-transfected with plasmids encoding the L-type voltage-gated calcium channel Cav1.2: pCav1.2, $\left(\mathrm{P}_{\mathrm{hCMv}}-\alpha_{1} \mathrm{C}-\mathrm{pA}\right), \mathrm{pCav} \alpha_{2} \delta_{1}$ 
$\left(\mathrm{P}_{\mathrm{hCMV}}-\alpha_{2} / \delta_{1}-\mathrm{pA}\right), \quad \mathrm{pCav} \beta_{3} \quad\left(\mathrm{P}_{\mathrm{hCMV}}-\beta_{3}-\mathrm{pA}\right), \quad$ Kir2.1: $\quad$ KKir2.1 $\quad\left(\mathrm{P}_{\mathrm{hCMV}}-\mathrm{Kir} 2.1-\mathrm{pA}\right) . \quad$ Electrical stimulation (orange bars) was applied at the indicated voltage $(\mathbf{A}, \mathbf{C})$, or for the indicated period of time (B,D), and 24 hours later cell viability was assessed. (E) Electrical stimulation of cells lacking a voltage-gated calcium channel. HEK293T cells were co-transfected with pCDNA3.1(+) and $\mathrm{P}_{\mathrm{NFAT3}}$-driven SEAP expression plasmid (pMX57). Electrical stimulation $(50 \mathrm{~V}, 1 \mathrm{~Hz}, 1$ hour and pulse length as indicated below the graph; orange bars) was applied and 24 hours later SEAP was quantified in supernatant samples. Depolarization with $40 \mathrm{mM} \mathrm{KCl}$ for 1 hour was used as a positive control (red bar). Blue bars represent unstimulated control. Bars represent mean \pm SEM. $\mathrm{n}=3$. ns - not significant, ${ }^{*} \mathrm{p}<0.05, * * \mathrm{p}<0.01$. 


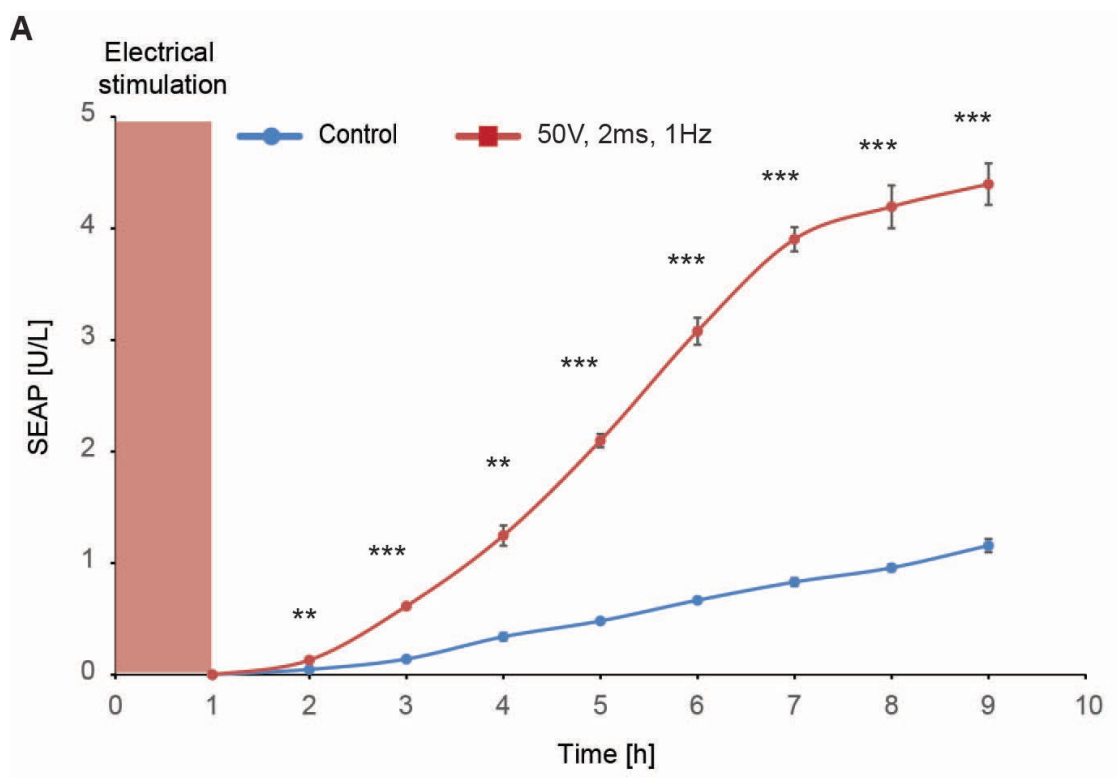

B

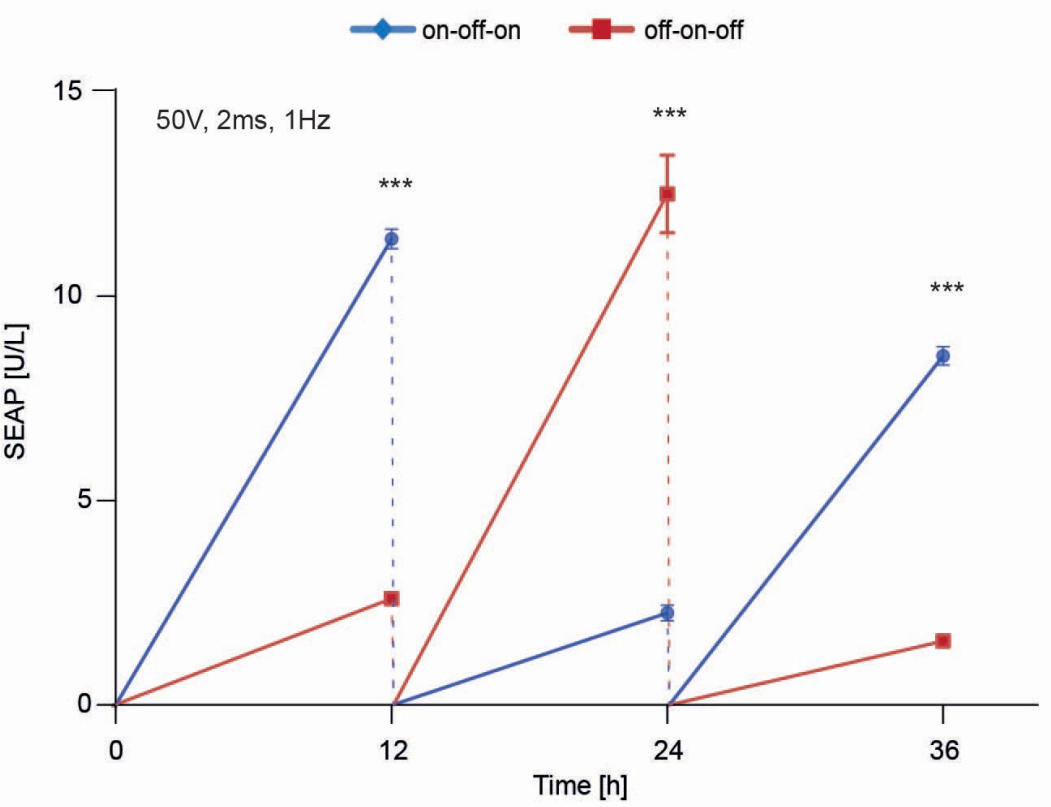

Fig. S4 Electrostimulation kinetics.

HEK293T cells were co-transfected with plasmids encoding pCav1.2 ( $\left.\mathrm{P}_{\mathrm{hCMV}}-\alpha_{1} \mathrm{C}-\mathrm{pA}\right), \mathrm{pCav} \alpha_{2} \delta_{1}$ $\left(\mathrm{P}_{\mathrm{hCMV}}-\alpha_{2} / \delta_{1}-\mathrm{pA}\right)$ and $\mathrm{pCav}_{3} \beta_{3}\left(\mathrm{P}_{\mathrm{hCMV}}-\beta_{3}-\mathrm{pA}\right)$, pKir2.1 ( $\left.\mathrm{P}_{\mathrm{hCMV}}-\mathrm{Kir} 2.1-\mathrm{pA}\right)$ and $\mathrm{P}_{\mathrm{NFAT}}$-driven SEAP and mINS expression plasmid (pKK137). (A) SEAP production kinetics. Cells were electrostimulated with $50 \mathrm{~V}, 2 \mathrm{~ms}$ pulses at $1 \mathrm{~Hz}$ frequency for one hour (red line). SEAP concentration was quantified in supernatant samples every one hour. Blue line represents control samples (not stimulated). (B) Reversibility assay. Cells were electrostimulated at the 0 and $24 \mathrm{~h}$ time points (blue line), or at the $12 \mathrm{~h}$ time point (red line). The culture medium was exchanged every 12 hours and the electrostimulation status was changed (from ON to OFF or from OFF to $\mathrm{ON})$. SEAP was quantified in supernatant samples. Data points represent mean $\pm \mathrm{SEM} . \mathrm{n}=3$. Statistical significance was calculated between on (red dots) and off (blue dots) states for a given time point. ${ }^{*} \mathrm{p}<0.05,{ }^{*} \mathrm{p}<0.01, * * * \mathrm{p}<0.001$. 


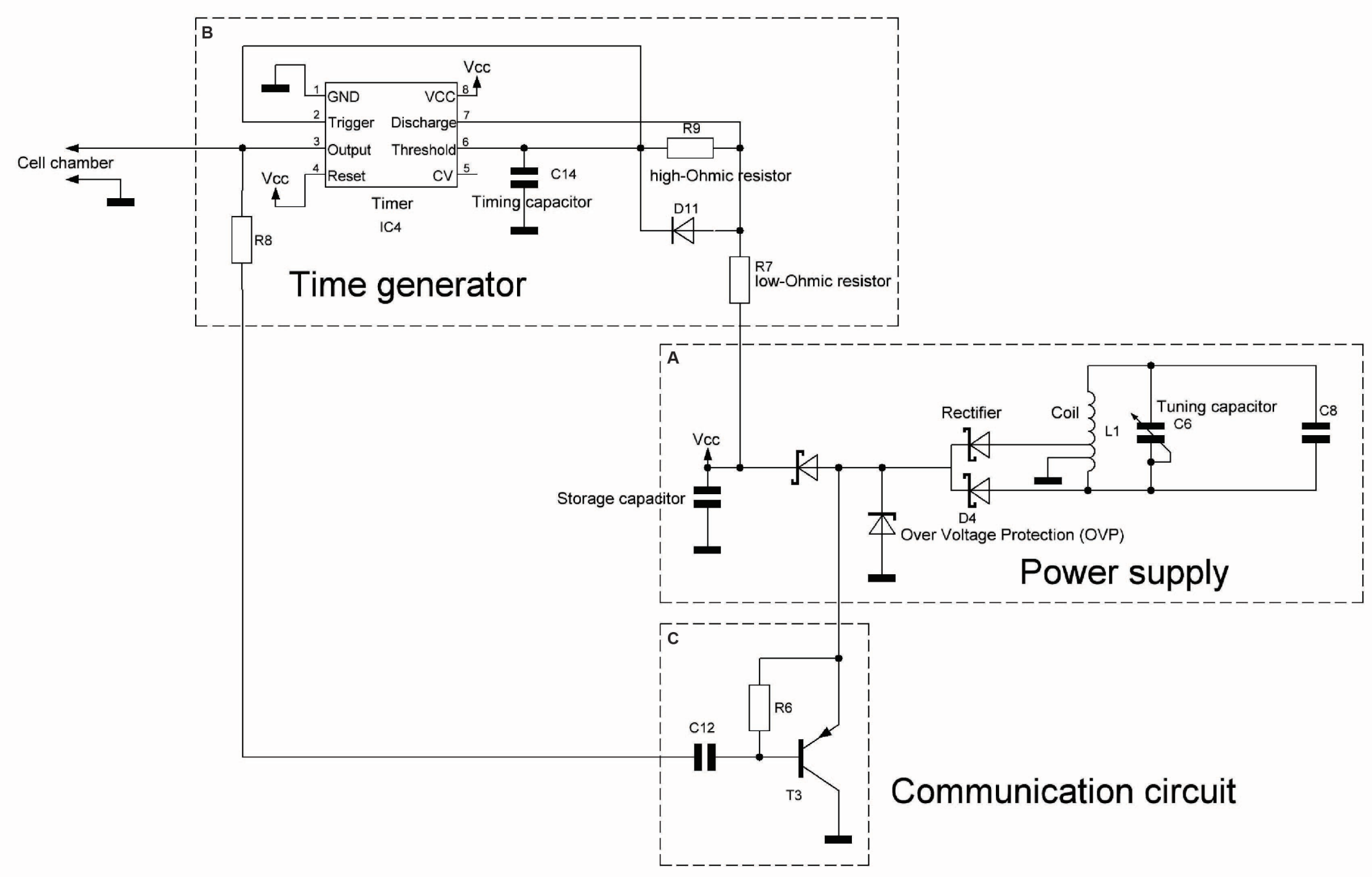


Fig. S5 Electronic circuit of the bioelectronic implant.

The three main functional elements are marked with dashed frames: the power supply (A), the time generator (B) and the communication circuit (C). (A) Power supply. The coil (L1) and capacitors (C6, C8) connected in parallel form an oscillating circuit that is in resonance with the magnetic field of the transmitter coil. To prevent potential impact of the electrical load on the resonance, power is withdrawn from two turns of the receiver coil via current transformation and rectified by two diodes (D4). (B) Time generator. Pulses are generated by an integrated time generator. Pulse length and intervals are set by external resistors (R7, R9), a diode (D11) and a capacitor (C14). The timer (IC4) includes an internal voltage divider with three resistors. The potential of the external capacitor and the voltage divider are compared by comparators and used to control the timer output. ON/OFF-states are stored by a flip-flop until the opposite voltage threshold is reached. One output of the flip-flop serves to discharge the external capacitor (C14). To reach the required ratio between pulse duration and pulse interval of approximately 1:500, the capacitor is charged through a low-Ohmic resistor (R7) and a diode (D11) and discharged via a high-Ohmic resistor (R9). (C) Communication circuit. Upon detection of a negative pulse edge by a capacitor (C12) and a transistor (T3), the oscillating circuit of the power supply is short-circuited for $15-25 \mu \mathrm{s}$. This brief overload leads to a breakdown of the resonance in the receiver coil (L1) and results in an abrupt drop of the excitation current in the transmitter coil and produces a voltage increase. 

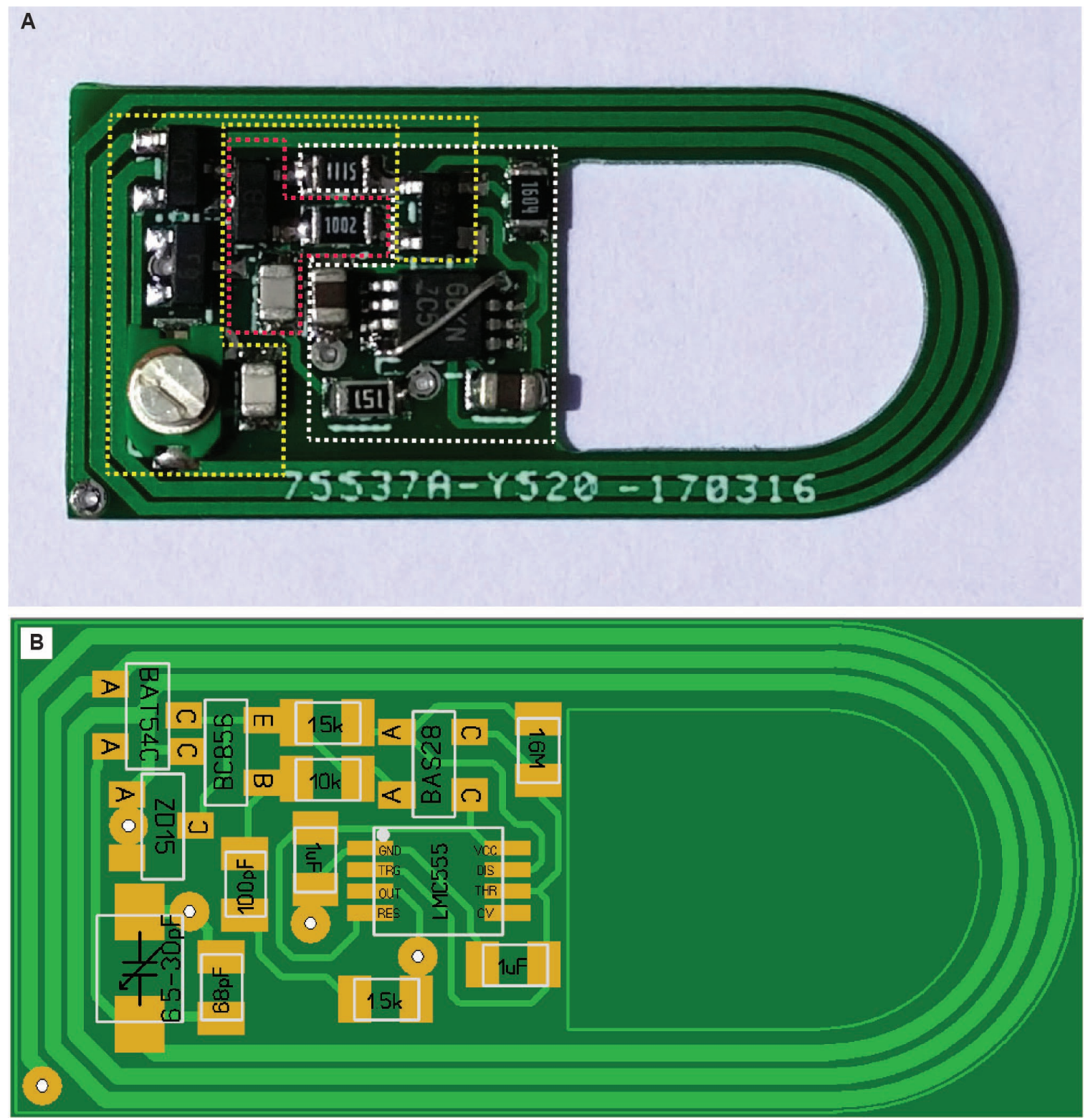

Fig. S6 Bioelectronic implant switchboard.

(A) Top view of the bioelectronic implant switchboard. Dashed frames correspond to functional elements described in Figure S5: power supply (yellow), time generator (white) and communication circuit (red). (B) Schematic view of the bioelectronics implant. Conductive paths are marked with lighter green. Components are marked with white frames. Orange rectangles represent connectors. Components are described in Table S8. 


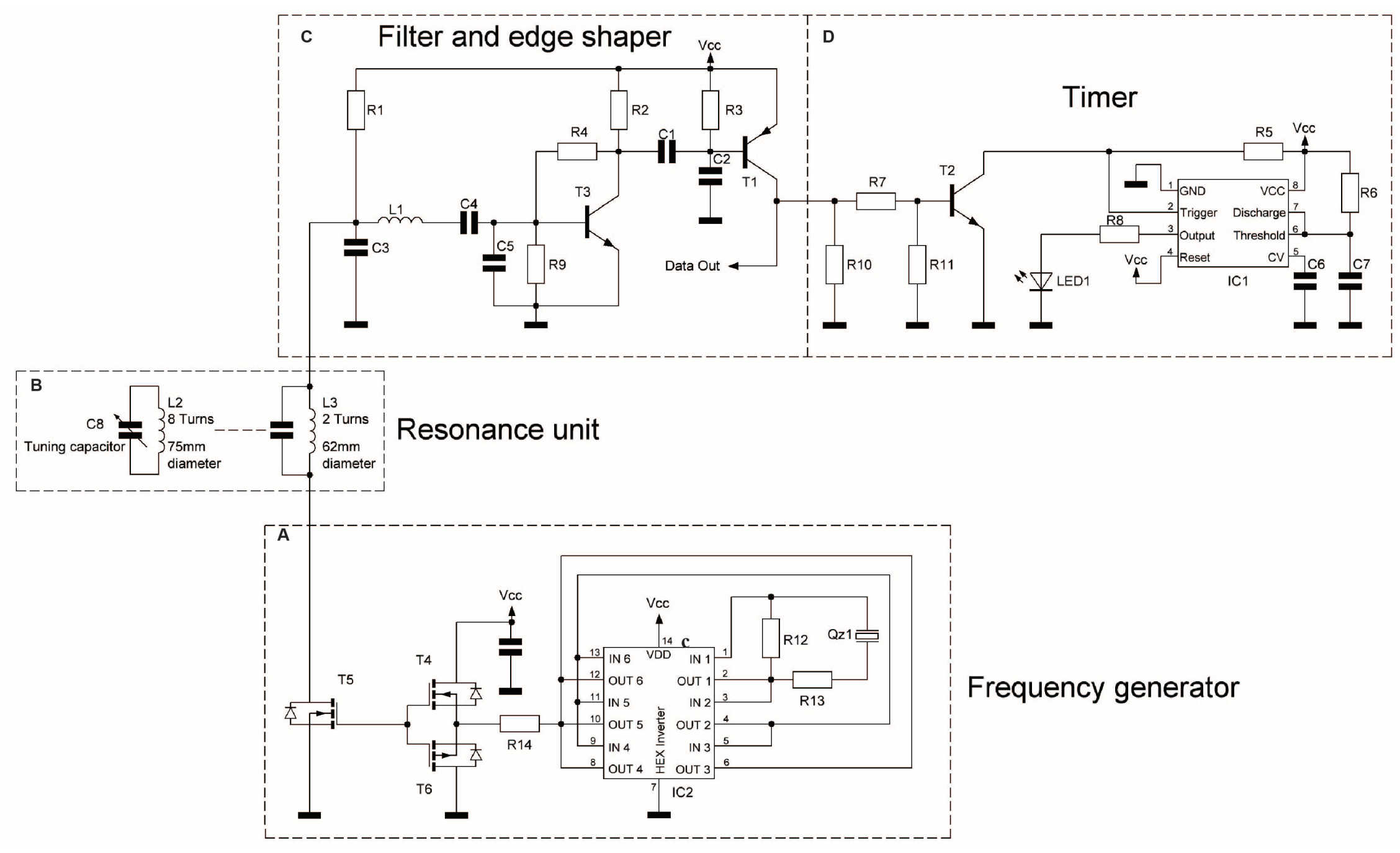




\section{Fig. S7 Electronic circuit of the field generator.}

Four main functional elements are marked with dashed frames: the frequency generator (A), the resonance coils $(\mathbf{B})$, the filter and edge shaper $(\mathbf{C})$, and the timer $(\mathbf{D})$. (A) Frequency generator. A crystal-based oscillating circuit (IC2) connected to a negative impedance converter (T4, T6) drives the output transistor (T5) of the frequency generator. (B) Resonance coils. The output transistor controls the coil (L3) current, which generates an alternating magnetic field. The second coil (L2) with an adjustable capacitor (C8) in parallel forms an oscillating circuit, which amplifies resonance of the main coil. (C) Filter and edge shaper. The current drawn by the resonance coil generates a proportional voltage drop by passing a resistor (R1). This voltage drop is filtered out by an LC network (L1, C4, C5) and amplified by a class A amplifier (T3). A decoupling capacitor (C1) forms a high-pass filter and drives a PNP transistor (T1). The high gain factor of the PNP transistor produces digital-like behavior of the data output (Data Out) for each fast change of the coil current and enables wireless communication from the implant to the field generator. (D) Timer. The data output triggers a timer circuit (IC1) that drives an LED, which enables function monitoring of the bioelectronics implant. 

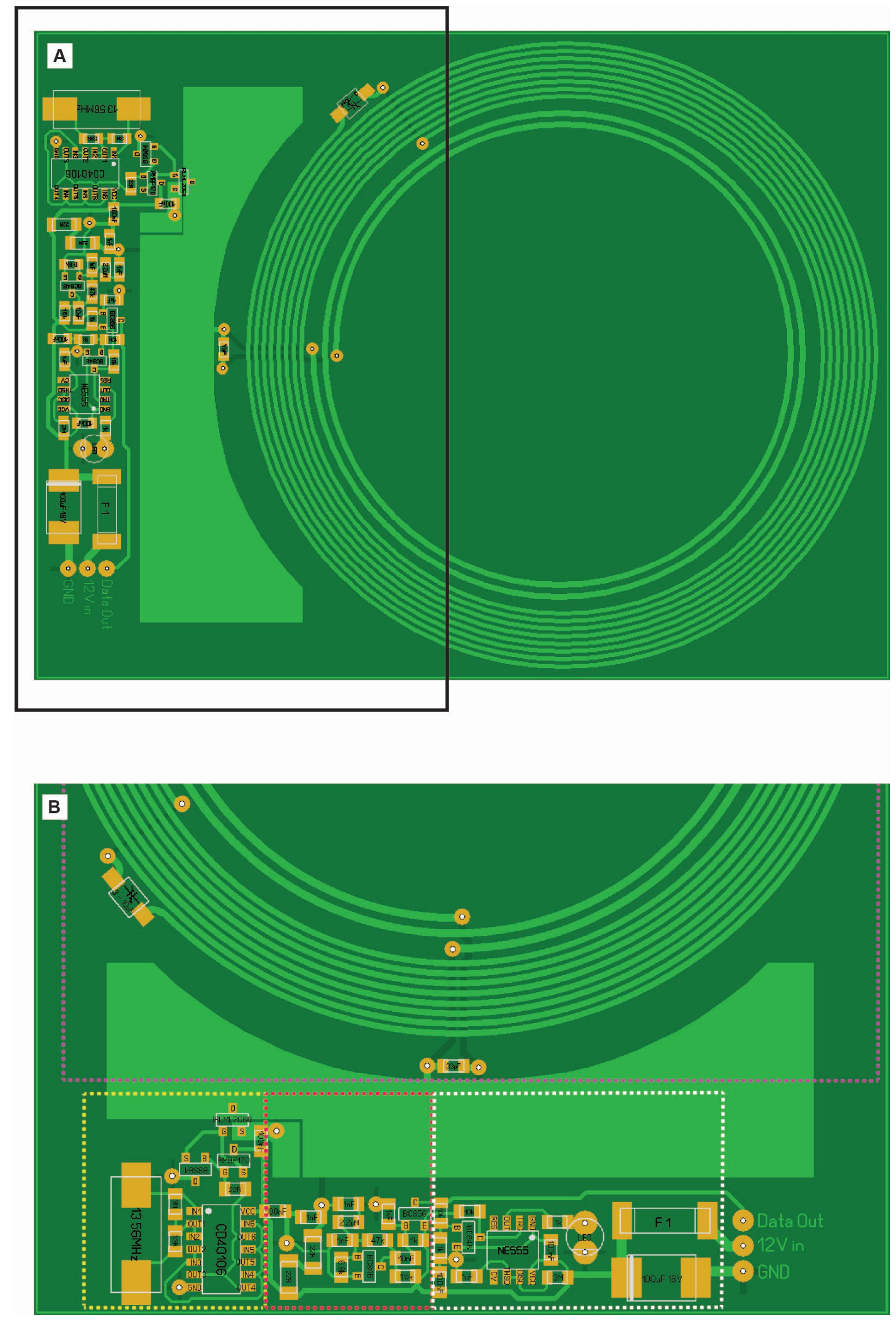
Fig. S8 Field generator switchboard.

(A) Schematic view of the field generator. Conductive paths are marked with lighter green. Components are marked with white frames. Orange rectangles represent connectors. (B) Enlarged view of the part enclosed with a black frame in (A). Dashed frames correspond to the functional elements described in Figure S7. frequency generator (yellow), the resonance coils (purple), the filter and edge shaper (red), and the timer (white). 


\section{A}

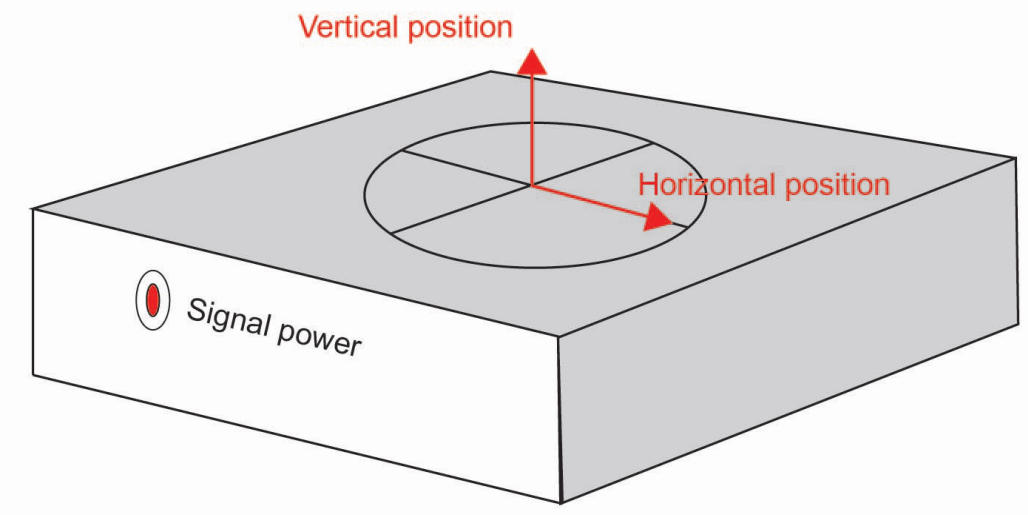

B

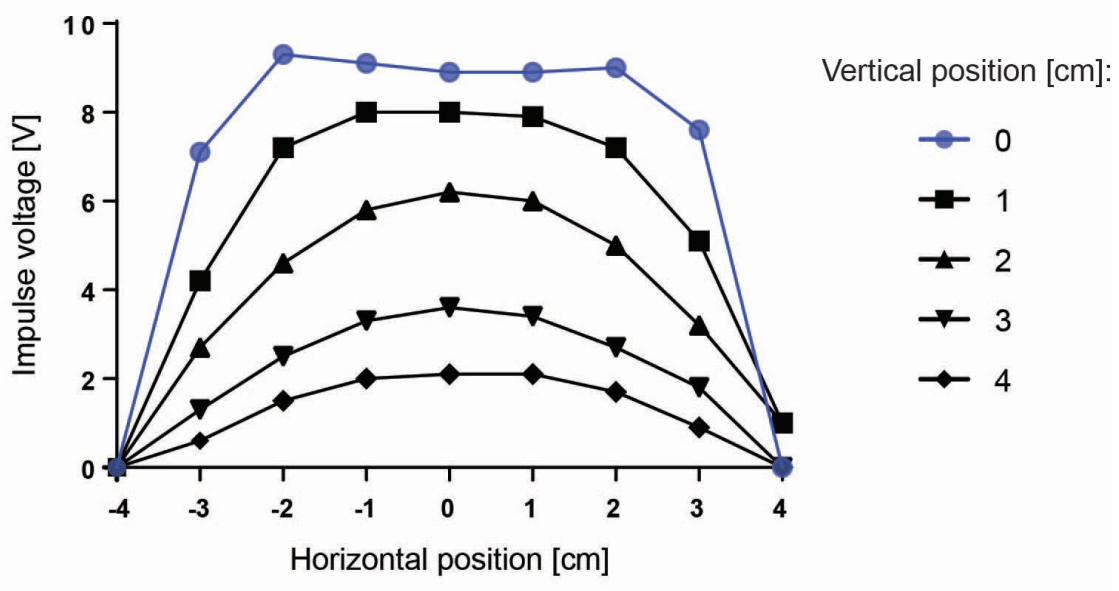

Fig. S9 Position-dependent coupling intensity between the field generator and the bioelectronic device.

(A) Schematic representation of the experimental design. The Y-axis indicates the vertical position of the implant. The $\mathrm{X}$-axis indicates the horizontal position of the implant measured from the middle point. (B) Dependence of the impulse voltage reached in the bioelectronic implant upon the horizontal $(0-8 \mathrm{~cm})$ and vertical $(0-4 \mathrm{~cm})$ positions. 


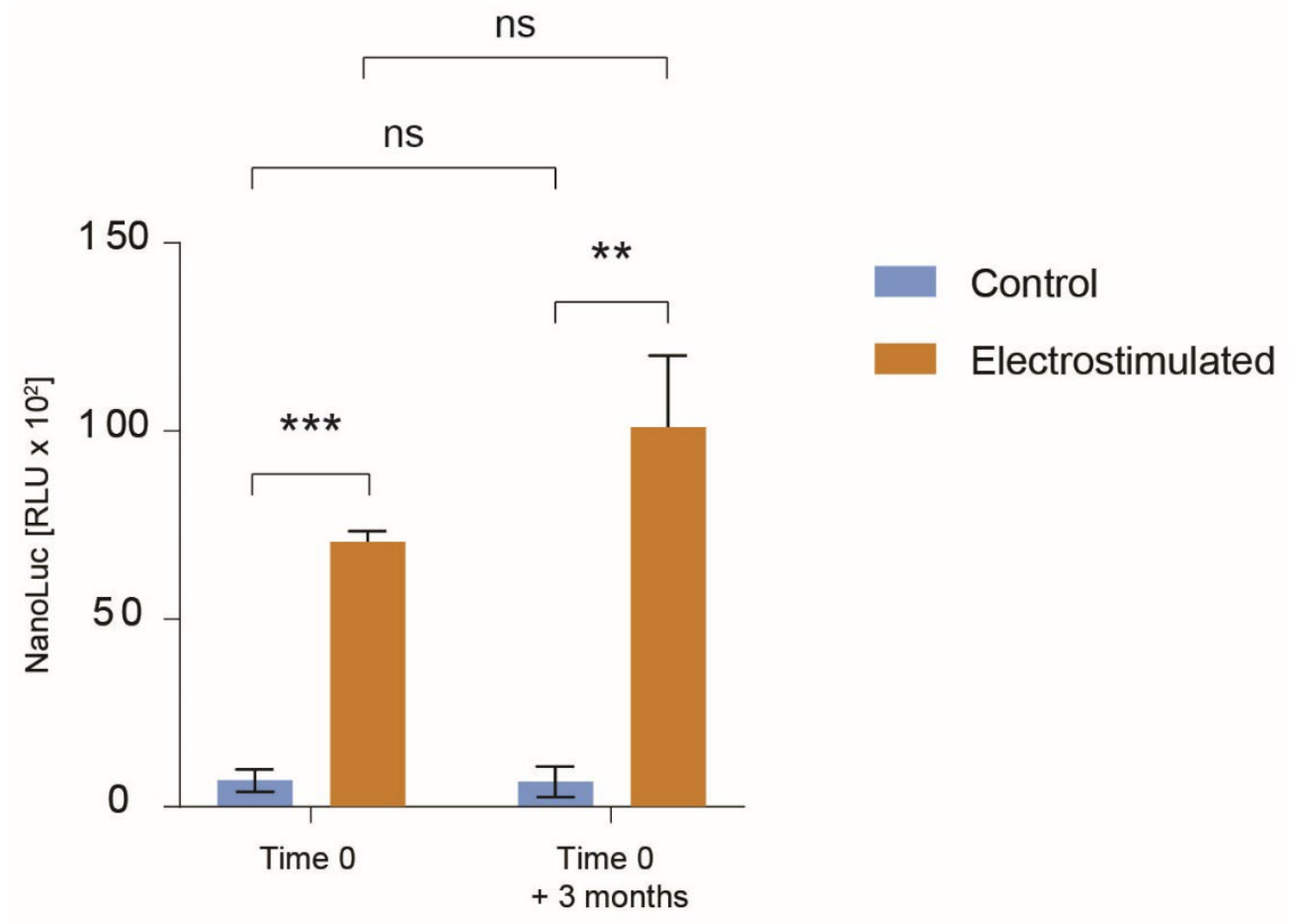

Fig. S10 Long-term electro-stimulation stability of the Electro $\beta$ cell line.

$2 \times 10^{5}$ Electro $\beta$ cells were either electro-stimulated for 20 minutes (orange bars) using 2 ms pulses at $5 \mathrm{~Hz}$ and $10 \mathrm{~V}$ or not electro-stimulated (blue bars) on day 1 and after a continuous cultivation period of 90 days. NanoLuc levels were quantified in the culture supernatants. Bars represent mean \pm SEM. $\mathrm{n}=3$. $\mathrm{ns}-$ not significant, ${ }^{*} \mathrm{p}<0.01, * * * \mathrm{p}<0.001$. 
A

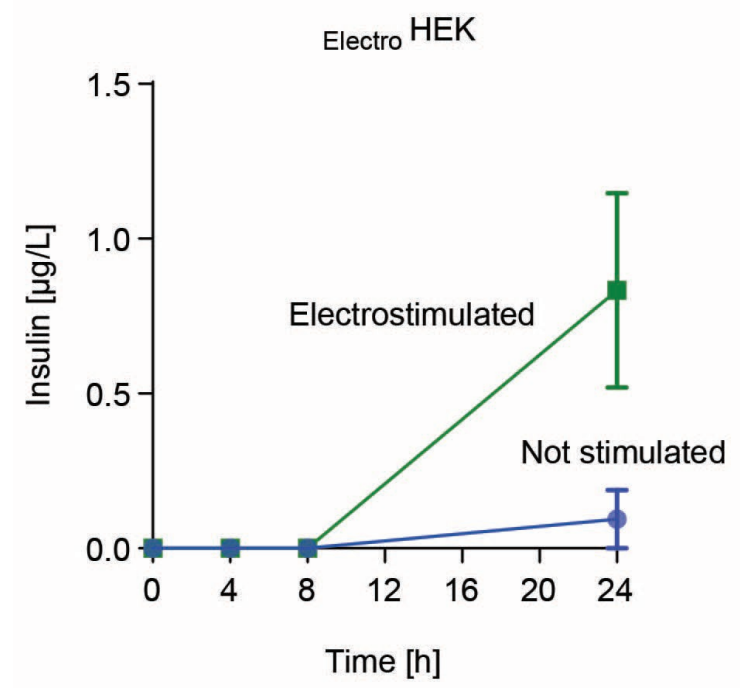

C

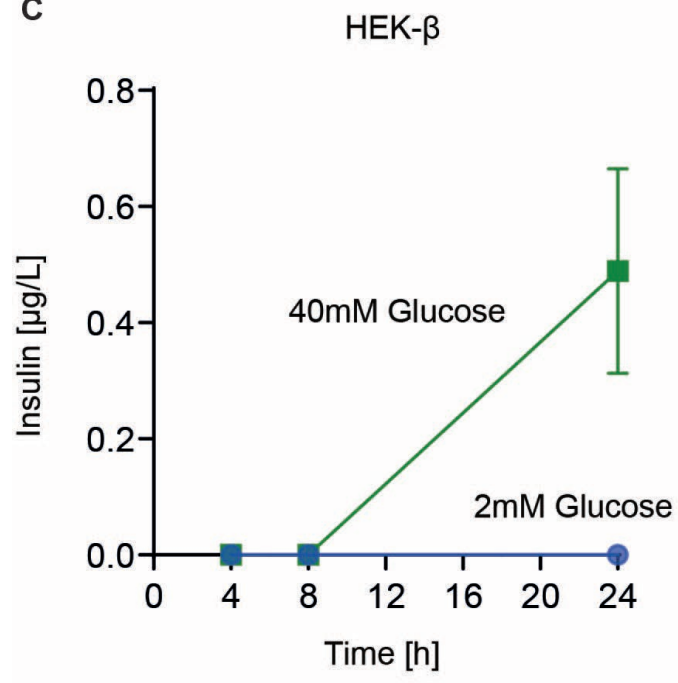

B

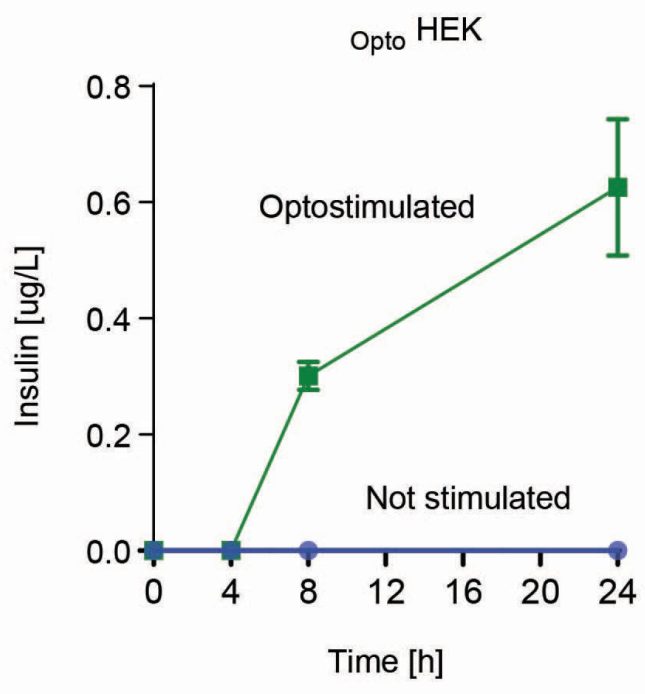

D

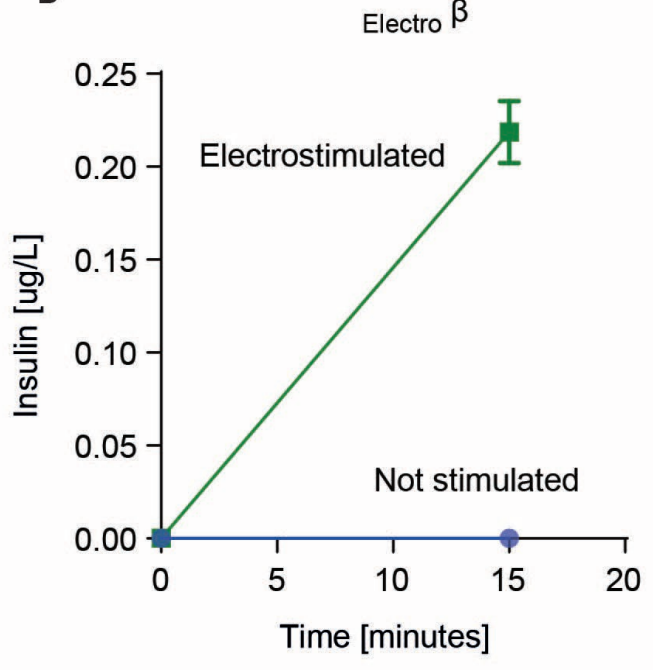

\section{Fig. S11 Comparative insulin-release kinetics.}

Comparative insulin-release kinetics of Electro $\beta$ (constitutive expression, vesicular secretion) and ElectroHEK, Opto HEK and HEK- $\beta$ ( P $_{\text {NFAT }}$-driven expression, secretory pathway). (A) ElectroHEK (4 hours electrostimulation), (B) OptoHEK (24 hours blue-light illumination) and (C) HEK- $\beta$ (40 mM glucose over 24 hours) were stimulated (green line) or non-stimulated (blue line) and insulin secretion was profiled in the culture supernatant. Likewise, (D) Electro $\beta$ were (15 minutes electrostimulation) stimulated (green line) or non-stimulated (blue line) and the immediate insulin release was monitored in the culture supernatant. 

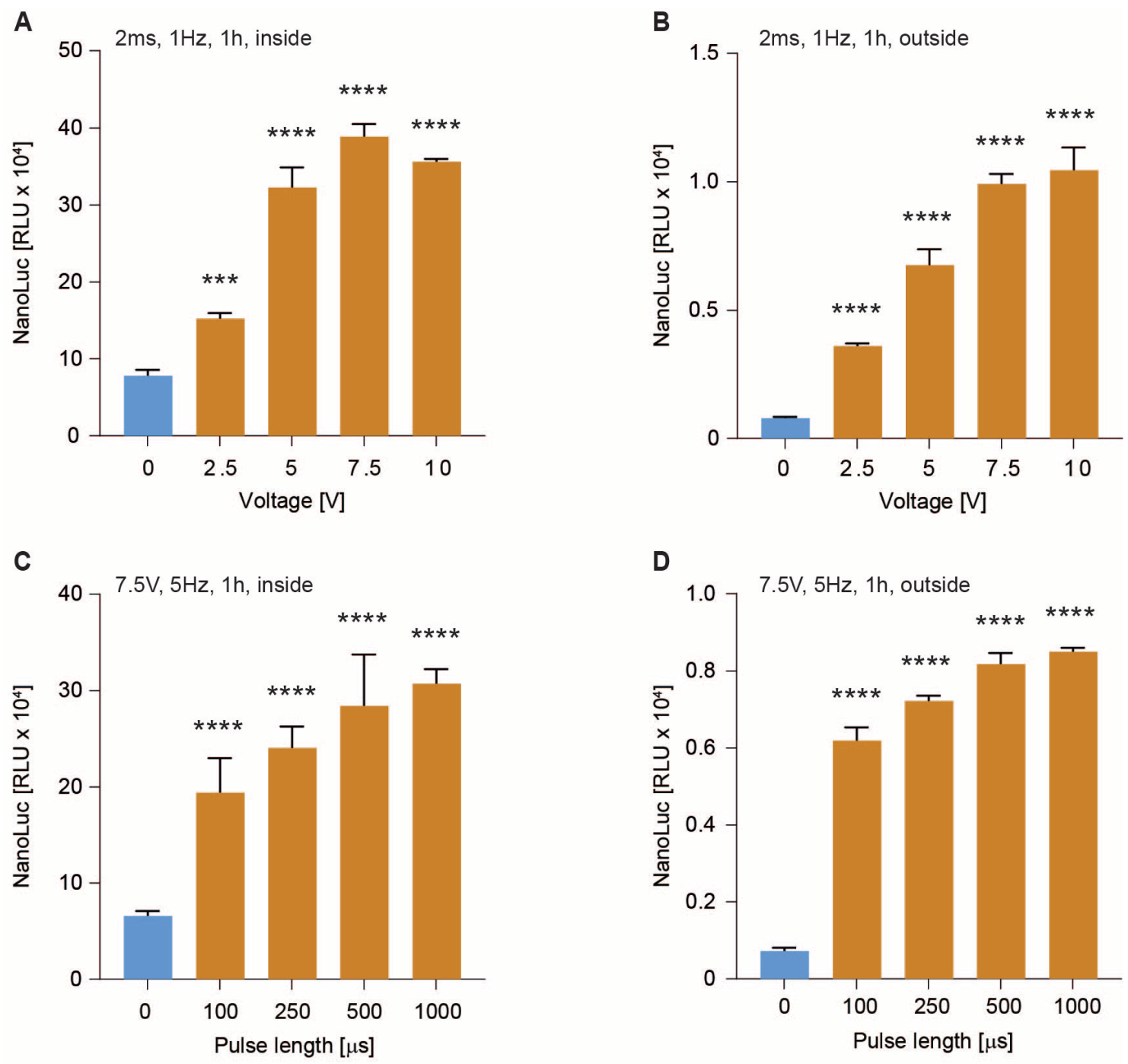

Fig. S12 Electrically inducible fast insulin secretion system.

(A, B) Voltage dependence. Electro $\beta$ cells were stimulated with $2 \mathrm{~ms}$ pulses at $1 \mathrm{~Hz}$ frequency and at the indicated voltage. NanoLuc was quantified from supernatant samples before (blue bars) and after electrical stimulation (orange bars) from above (A) and below (B) the cell layer. (C, D) Pulse length dependence. Electro $\beta$ cells were stimulated with $7.5 \mathrm{~V}$ pulses at $5 \mathrm{~Hz}$ frequency with the indicated pulse length. NanoLuc was quantified from supernatant samples before (blue bars) and after electrical stimulation (orange bars) from above (C) and below (D) the cell layer. The statistical significance of differences between the negative control and each of the stimulation conditions was calculated. Bars represent mean \pm SEM. $\mathrm{n}=3 .{ }^{* * *} \mathrm{p}<0.001$, $* * * * \mathrm{p}<0.0001$. 


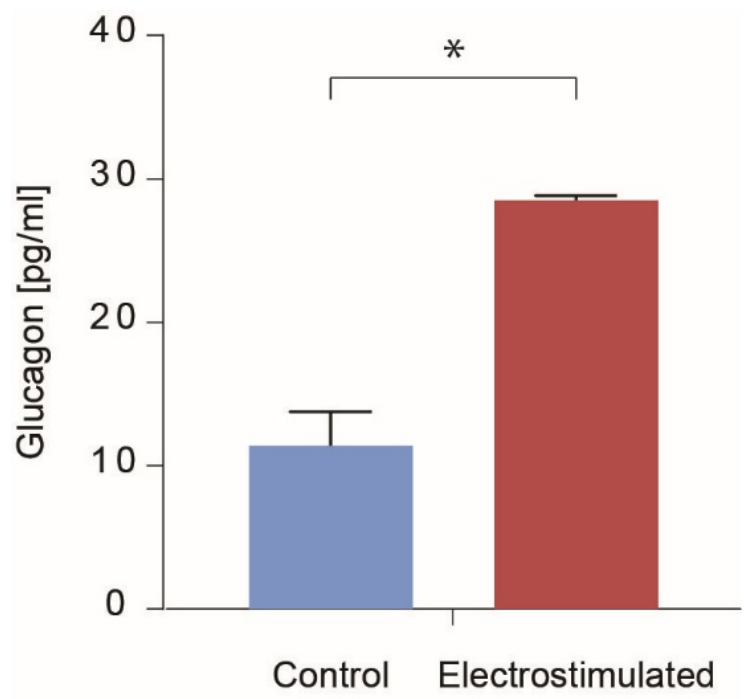

Fig. S13 Electro-stimulated glucagon secretion by pancreatic $\alpha$-cells.

$2 \times 10^{5}$ pancreatic $\alpha$-cells $(\alpha-\mathrm{TC} 1)$ cells were seeded into cell-culture inserts and electrostimulated with $2 \mathrm{~ms}$ pulses at $5 \mathrm{~Hz}$ and $10 \mathrm{~V}$ for 20 minutes (red bar). Then, glucagon levels were quantified in the culture supernatant. Bars represent mean \pm SEM. $n=3$. $* \mathrm{p}<0.05$. 


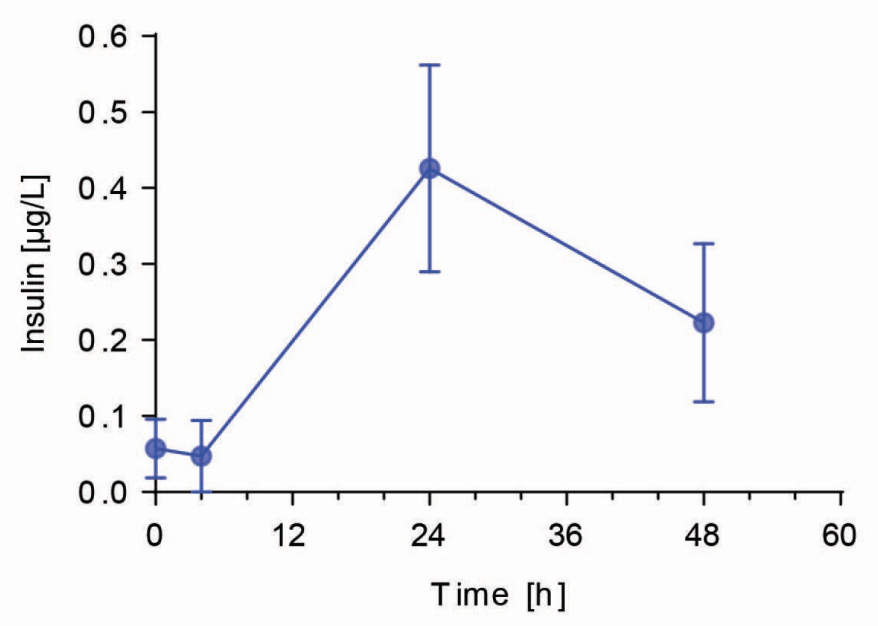

B Electro $\beta$ kinetics in vivo

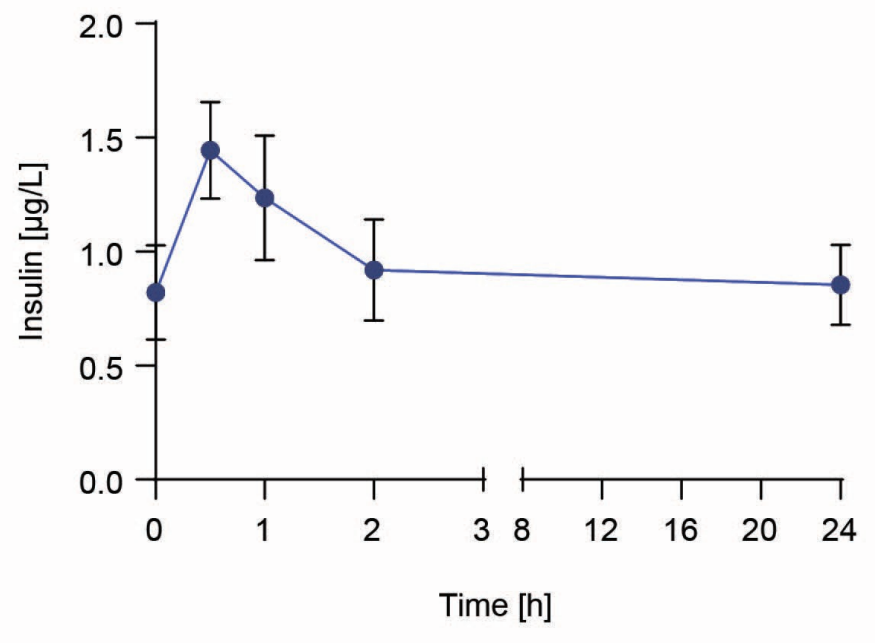

Fig. S14 In vivo kinetics of protein secretion.

(A) HEK- $\beta$ cell line secretion kinetics in vivo. HEK- $\beta$ cells were encapsulated into alginate beads and injected into hyperglycemic mice. Insulin was quantified from serum samples after 4, 24 and 48 hours. Data points represent mean \pm SEM. $n=7$. (B) Electro $\beta$ secretion kinetics in vivo. Electro $\beta$ cells inside the bioelectronic implant were electrostimulated for 30 minutes. Insulin levels in whole-blood samples were quantified before the stimulation, and after 30, 60, 120 minutes and 24 hours. 


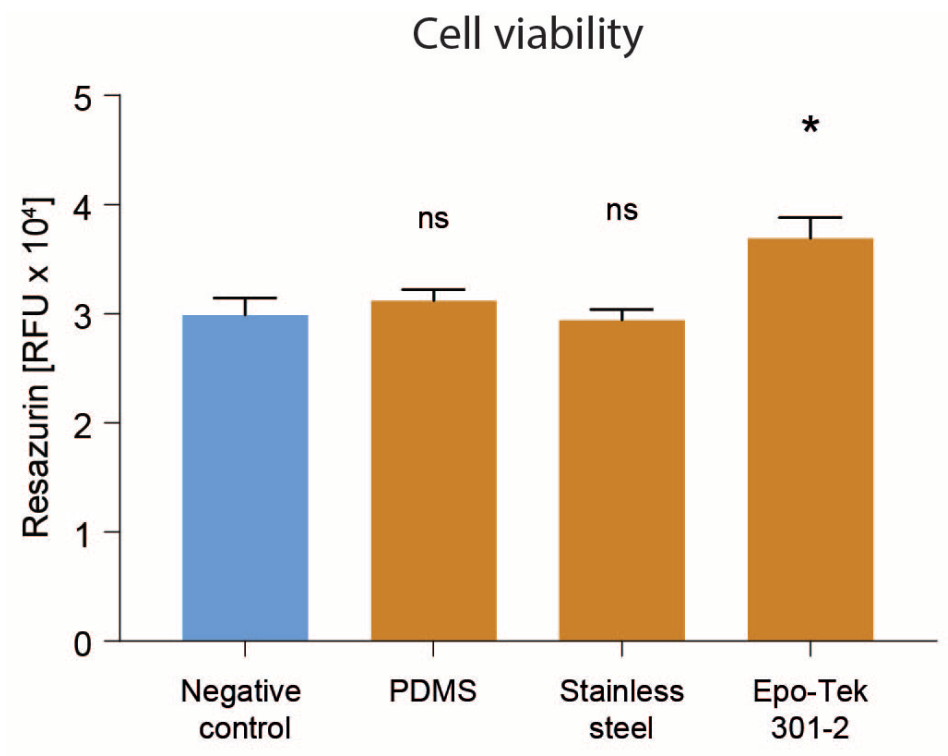

Fig. S15 Impact of materials used in the biomedical device on cell viability.

The viability of parental HEK-293T cells was measured after incubation for 24 hours with implant materials: solidified PDMS (biocompatible reference material), stainless steel (electrode material) and Epo-Tek 301-2 (implant material). Bars represent mean \pm SEM. $\mathrm{n}=3$. Statistical significance was calculated between cells only (negative control) and each of the implant materials. ns - not significant, ${ }^{*} \mathrm{p}<0.05$. 


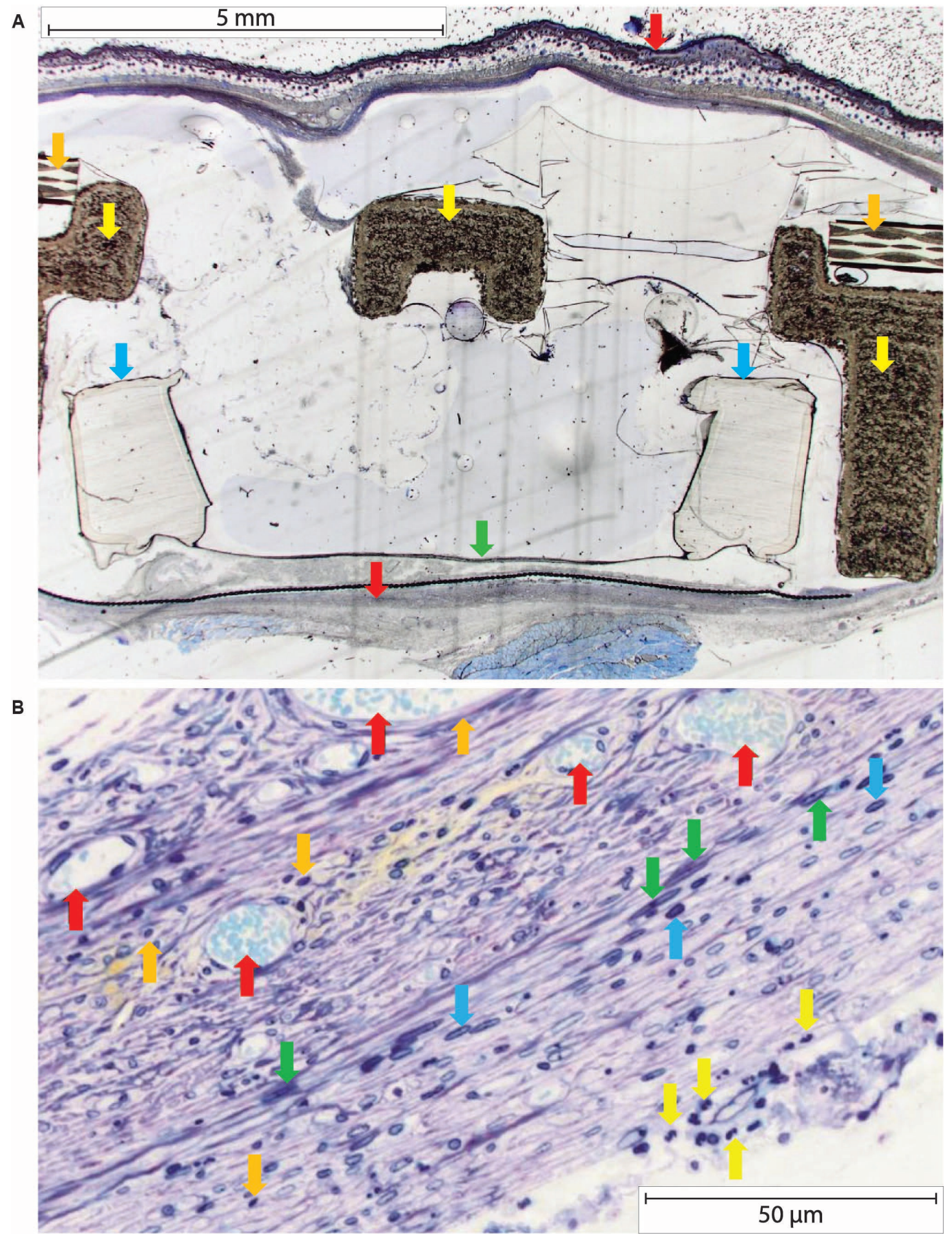

\section{Fig. S16 Biocompatibility.}

Histological sections of tissue-surrounded bioelectronic implant. Devices containing Electro $\beta$ cells were surgically placed on the dorsal side of mice for 21 days. Fibrotic capsule formation was examined by Paragon staining. (A) Cross section of the cell-containing chamber. Green arrow, porous membrane; red arrows, 3D-printed frame; orange arrows, 
electronic switchboard; blue arrows, cell insert frame; fibrotic tissue, yellow arrows (please note that, compared to the structural part of the biocompatible implant material of the bioelectronic device (Fig. S15), the fibrotic tissue formation at the porous membrane where the Electro $\beta$ cells interface with the host tissue, is less prominent. (B) Enlarged image of the fibrotic tissue formed at the implant material of the bioelectronic device. Red arrows - blood vessels, green arrows - fibroblasts, blue arrows - fibrocytes, yellow arrows - granulocytes, orange arrows - lymphocytes. 


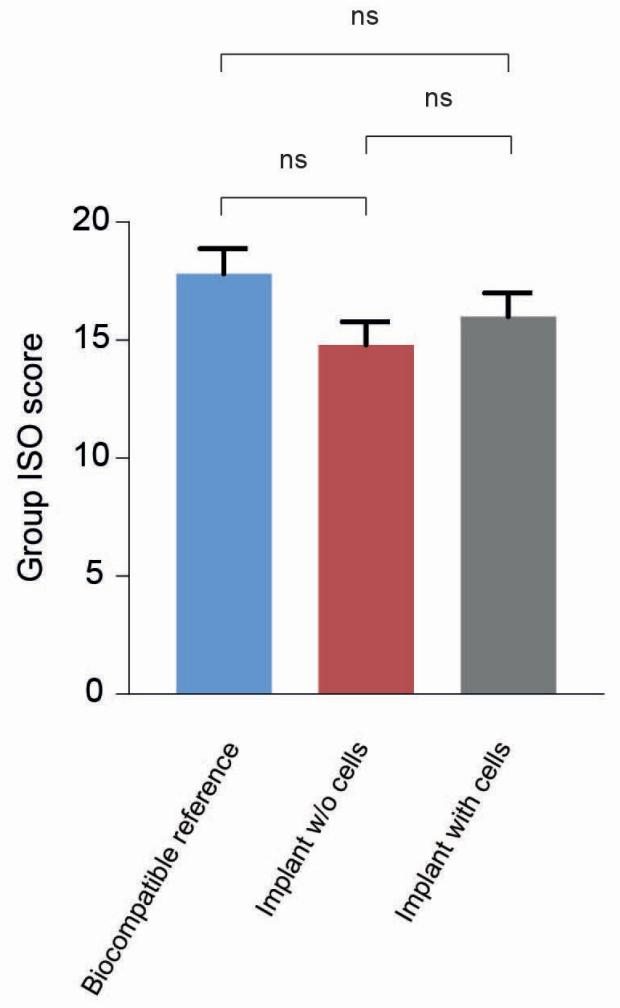

B

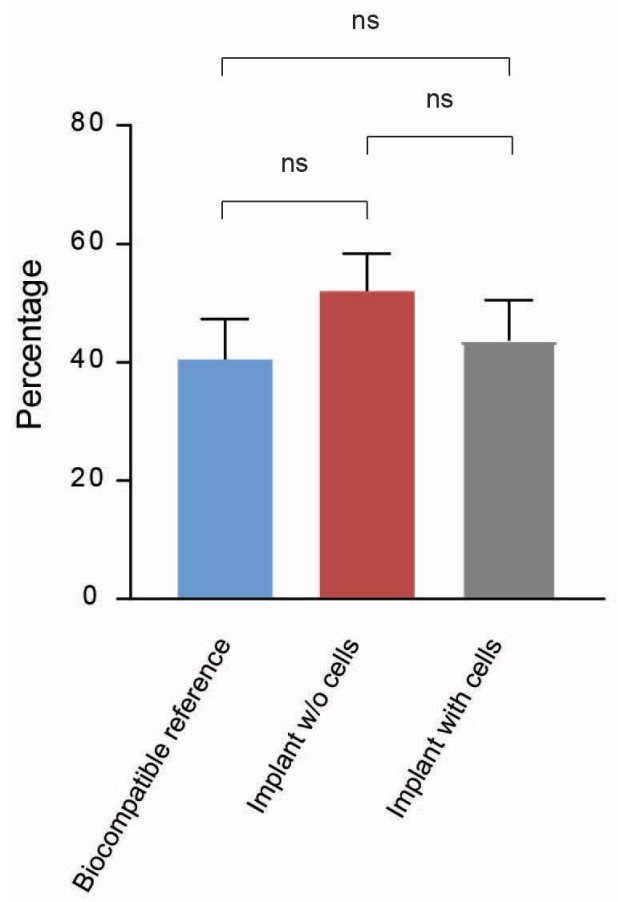

C

Anti-CD68

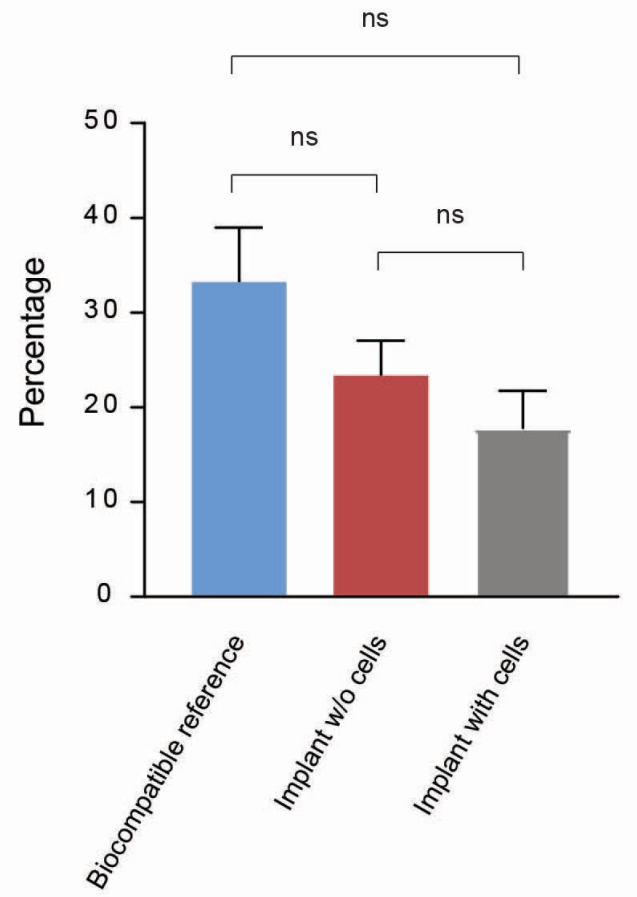


Fig. S17 Local immune response.

(A) Local effects on the immune response after implantation were scored according to ISO 10993. A higher score indicates greater local effects and lower biocompatibility. $(\mathbf{B}, \mathbf{C})$ Immunohistochemistry. Fragments of tissue adherent to the porous membrane of a bioelectronic implant were excised and immunostained. Graphs represent percentage of positively stained cells in experimental groups. (B) Anti-CD11b antibodies. CD11b is expressed on macrophages, neutrophils and natural killer cells. (C) Anti-CD68 antibodies. CD68 is expressed on activated macrophages. ns - not significant. 


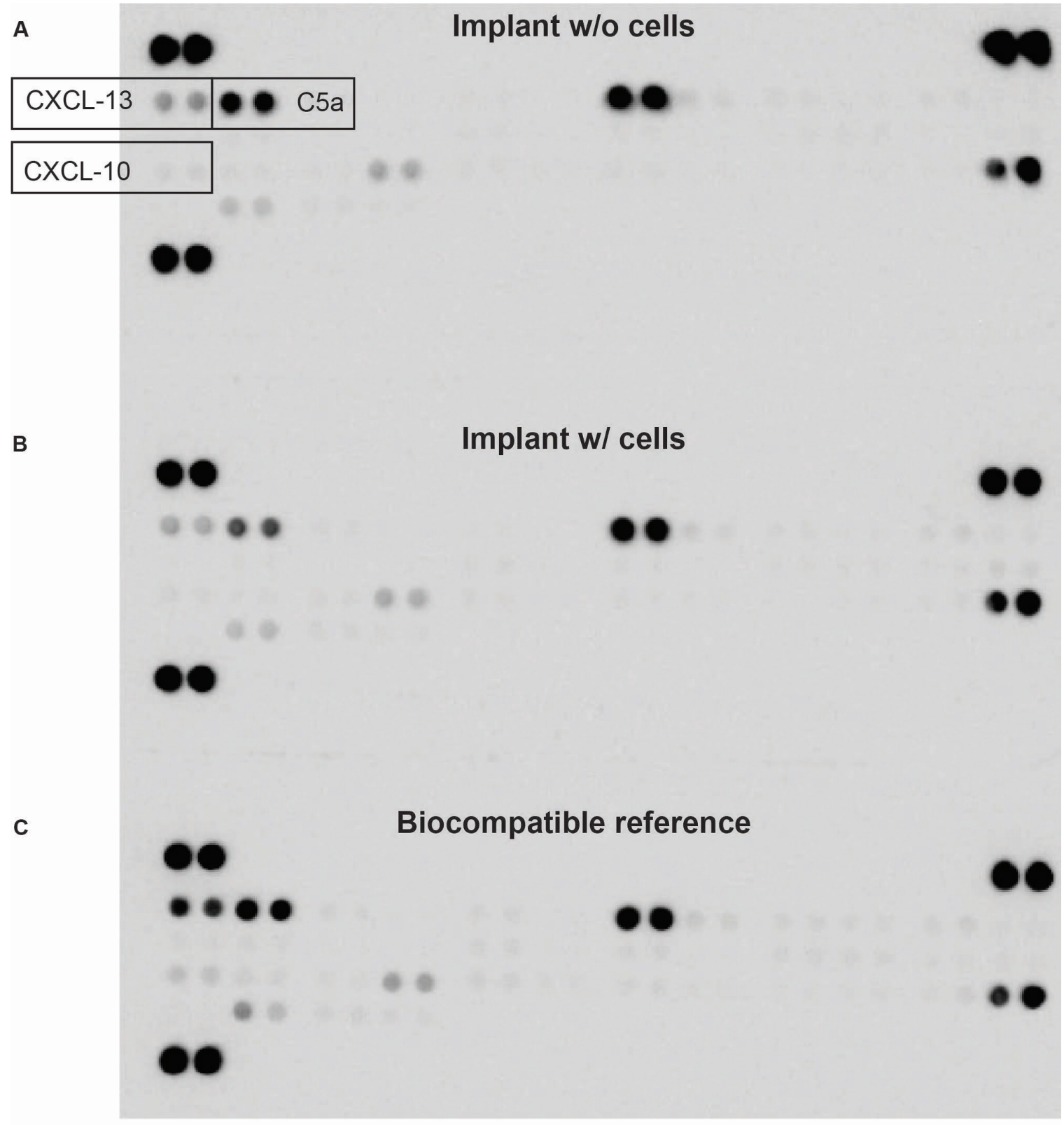

Fig. S18 Dot-blot-based cytokine profiling of treated mice.

Reference inflammatory cytokines CXCL-10, CXCL-13 and C5a were profiled in the serum of mice 3 weeks after the introduction of bioelectronic implants with (A) and without (B) cells, or biocompatible reference implants $(\mathbf{C})$. 


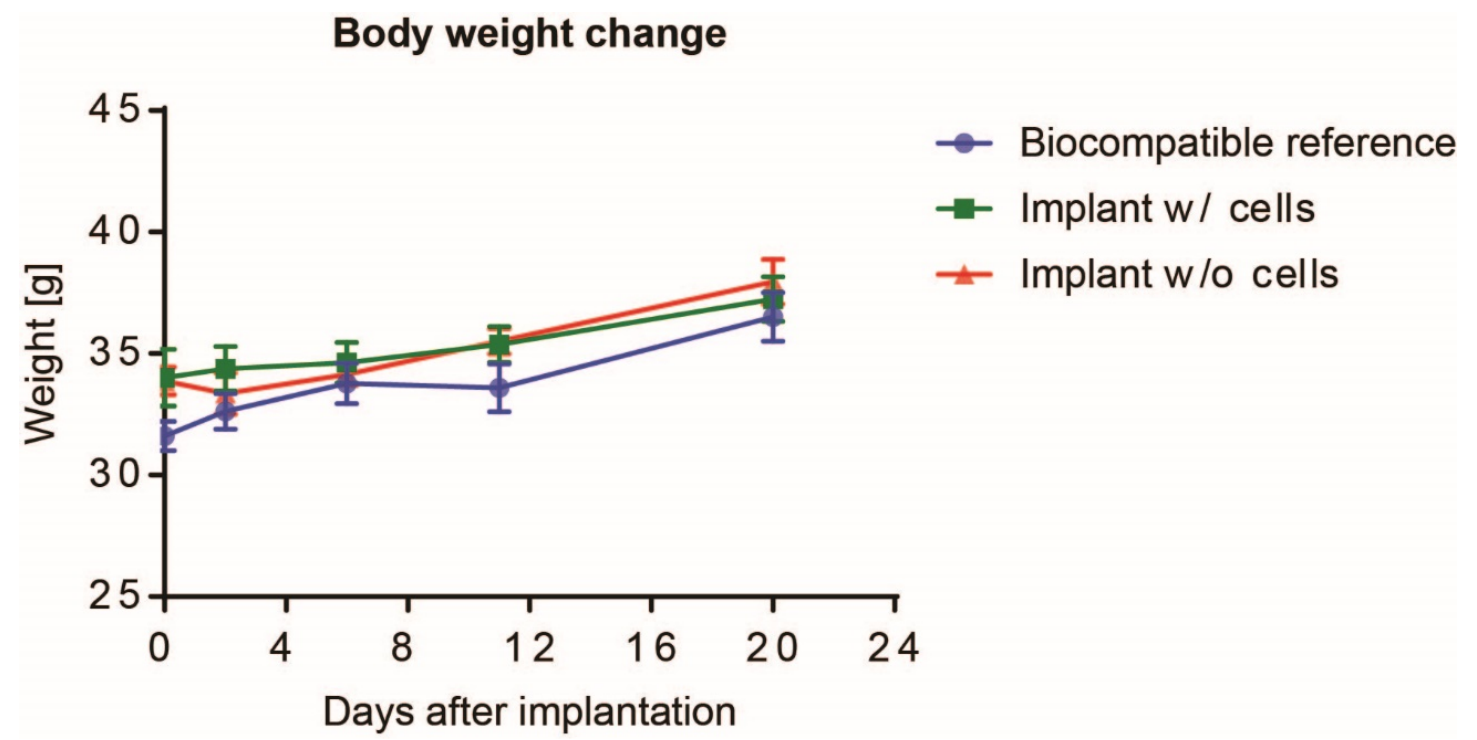

Fig. S19 Impact of bioelectronic implants on the body weight of mice.

The body weight of mice was profiled over three weeks after the introduction of bioelectronic implants with and without ElectroHEKs or biocompatible control implants. The weight of the implant $(2 \mathrm{~g})$ was subtracted from the body weight after implantation. Data points represent mean \pm SEM. $\mathrm{n}=8$. There were no significant differences between the groups after implantation. 
A

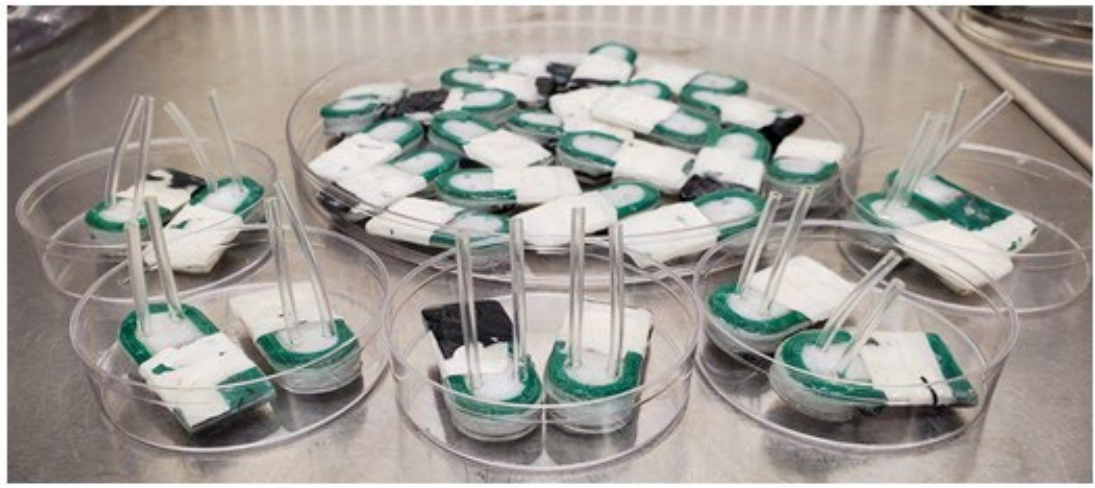

B

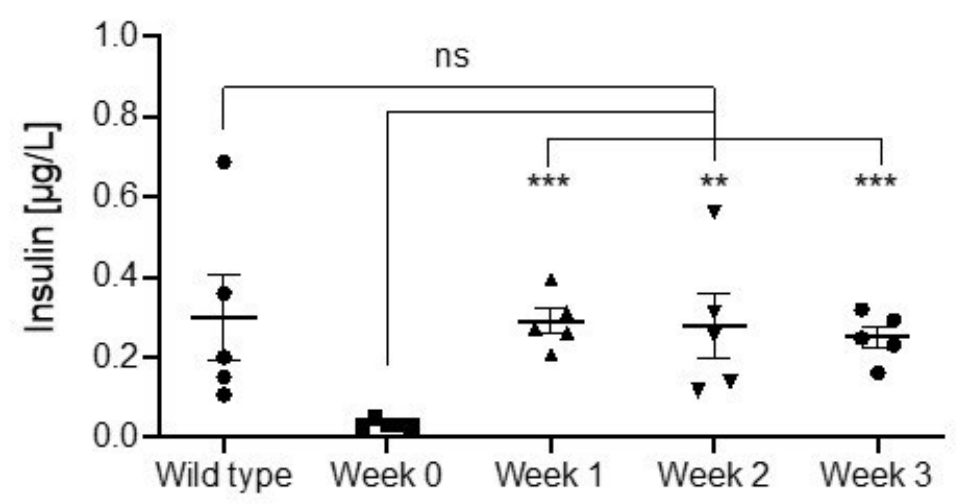

C

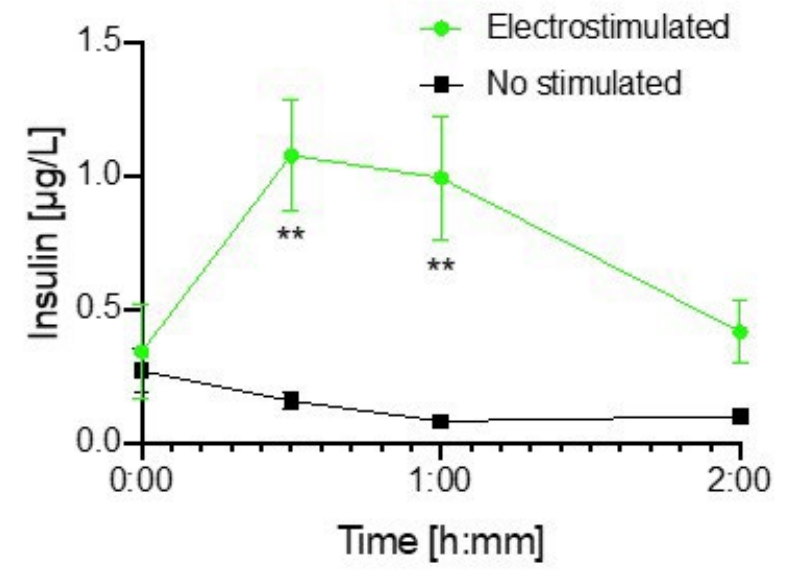

D

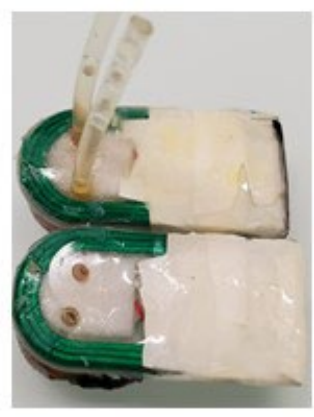

Fig. S20 Bioelectronic implants modified for long-term glycemic control in type-1diabetic mice.

(A) Picture of bioelectronic implants containing fill-in and exhaust tubes to allow repetitive in-situ exchange of Electro $\beta$-cell batches. (B) Validation of implant functionality over 3 weeks in type-1-diabetic mice. Bioelectronic devices shown in (A) were implanted into type-1 diabetic mice (T1DM), allowing weekly exchange of the Electro $\beta$-cell batches. 
Insulin levels were quantified once a week. Data represent mean $\pm S E M, n=5$ mice. Statistical significance of blood-insulin levels was calculated against blood-insulin levels before implantation and against homeostatic insulin levels of wild-type mice. (C) Electrostimulated insulin secretion kinetics of bioelectronic implants in treated type-1-diabetic mice after three weeks. Electro $\beta$-cell-containing bioelectronic implants were electrostimulated for 30 minutes and resulting blood-insulin levels were profiled. Data represent mean \pm SEM, $\mathrm{n}=5$ mice per group. (D) Picture of representative bioelectronic devices explanted from mice after termination of the experiment described in (B). 
Table S1. Temperature dependence of implant functionality

\begin{tabular}{|c|c|c|c|c|c|c|}
\hline $\begin{array}{c}\text { Supply Voltage } \\
{[\mathrm{V}]}\end{array}$ & $25^{\circ} \mathrm{C}$ & $30^{\circ} \mathrm{C}$ & $35^{\circ} \mathrm{C}$ & $40^{\circ} \mathrm{C}$ & $45^{\circ} \mathrm{C}$ & $50^{\circ} \mathrm{C}$ \\
\hline 3 & 2.32 & 2.32 & 2.32 & 2.32 & 2.32 & 2.31 \\
\hline 4 & 2.39 & 2.37 & 2.38 & 2.38 & 2.38 & 2.38 \\
\hline 5 & 2.46 & 2.44 & 2.45 & 2.44 & 2.45 & 2.45 \\
\hline 6 & 2.51 & 2.49 & 2.5 & 2.49 & 2.48 & 2.48 \\
\hline 7 & 2.55 & 2.53 & 2.52 & 2.52 & 2.51 & 2.51 \\
\hline 8 & 2.58 & 2.55 & 2.55 & 2.54 & 2.52 & 2.52 \\
\hline 9 & 2.62 & 2.6 & 2.59 & 2.58 & 2.57 & 2.56 \\
\hline 10 & 2.66 & 2.62 & 2.62 & 2.61 & 2.59 & 2.57 \\
\hline 11 & 2.69 & 2.63 & 2.63 & 2.61 & 2.6 & 2.58 \\
\hline 12 & 2.7 & 2.63 & 2.64 & 2.62 & 2.6 & 2.58 \\
\hline
\end{tabular}

The implant was equipped with a $1 \mathrm{kOhm}$ load at the impulse output, placed on a hot plate and covered with a $3 \mathrm{~cm}$ layer of polystyrene. The circuit was powered with an adjustable power supply. The output voltage was measured with a digital oscilloscope, LeCroy Wavesurfer, at the indicated temperature. 
Table S2. Quality control of bioelectronic devices

\begin{tabular}{|l|l|}
\hline Water immersion test $^{1}$ & 50 \\
\hline Batch size (no. of items) & 48 \\
\hline Implants containing functional electronics after 24 h of water immersion & $\mathbf{9 6}$ \\
\hline \% Functional & $\mathbf{5}$ \\
\hline Cell leakage test (mechanical integrity) & $\mathbf{0}$ \\
\hline Number of devices & $\mathbf{1 0}$ \\
\hline Number of devices with cell leakage detected & $\mathbf{1 0}$ \\
\hline Electronic functionality in $_{\text {vivo }}^{\mathbf{3}}$ & $\mathbf{1 0}$ \\
\hline Number of devices & $\mathbf{1 0}$ \\
\hline Functionality at week 1 after implantation & \\
\hline Functionality at week 2 after implantation & \\
\hline Functionality at week 3 after implantation & \\
\hline
\end{tabular}

${ }^{1} \mathrm{~A}$ batch of 50 implants was placed in $20 \mathrm{~cm}$ deep water for 24 hours. Electronic functionality of the implants was tested after 24 hours.

${ }^{2}$ Bioelectronic devices were filled with $2 \times 10^{5}$ cells and incubated in $60 \mathrm{~mm}$ cell culture dishes. After 12 hours, the cell-containing bioelectronic devices were transferred to fresh cell culture dishes, incubated for 5 days and carefully examined to determine whether or not cells were present outside the bioelectronic device.

${ }^{3}$ Functionality of bioelectronic devices used for experiment of Fig. S20B measured by a resonance-indicating diode. Please refer to Fig. 4 and Fig. S7 for details. 
Table S3. Systemic toxicity

\begin{tabular}{|c|c|c|c|}
\hline Group & $\begin{array}{l}\text { Animal } \\
\text { Number }\end{array}$ & Organ & Findings \\
\hline \multirow{10}{*}{$\begin{array}{l}\text { Biocompatible } \\
\text { reference item }\end{array}$} & \multirow{2}{*}{1} & Kidney & Pyelitis, chronic, focal, unilateral, minimal \\
\hline & & Liver & Hemopoietic cell foci, minimal \\
\hline & \multirow{2}{*}{5} & Kidney & Pyelitis, chronic, focal, unilateral, minimal \\
\hline & & Liver & No findings \\
\hline & \multirow{2}{*}{14} & Kidney & No findings \\
\hline & & Liver & Inflammatory cell foci, minimal \\
\hline & \multirow{2}{*}{18} & Kidney & Mononuclear cell foci, unilateral, minimal \\
\hline & & Liver & Hemopoietic cell foci, minimal \\
\hline & \multirow{2}{*}{19} & Kidney & Pyelitis, chronic, focal, biilateral, minimal \\
\hline & & Liver & No findings \\
\hline \multirow{10}{*}{$\begin{array}{l}\text { Implant without } \\
\text { cells }\end{array}$} & \multirow{2}{*}{3} & Kidney & Mononuclear cell foci, unilateral, minimal \\
\hline & & Liver & No findings \\
\hline & \multirow{2}{*}{4} & Kidney & Mononuclear cell foci, unilateral, minimal \\
\hline & & Liver & Inflammatory cell foci, minimal \\
\hline & \multirow[t]{2}{*}{12} & Kidney & $\begin{array}{l}\text { Mononuclear cell foci, unilateral, minimal } \\
\text { Pyelitis, chronic, focal, unilateral, minimal } \\
\text { Cast, hyaline, focal, unilateral, minimal }\end{array}$ \\
\hline & & Liver & Hemopoietic cell foci, minimal \\
\hline & \multirow{2}{*}{13} & Kidney & Pyelitis, chronic, focal, unilateral, minimal \\
\hline & & Liver & Hemopoietic cell foci, minimal \\
\hline & \multirow[t]{2}{*}{16} & Kidney & $\begin{array}{l}\text { Cyst, cortical, present } \\
\text { Urothelial hyperplasia, unilateral, minimal } \\
\text { Pyelitis, chronic, focal, unilateral, minimal }\end{array}$ \\
\hline & & Liver & No findings \\
\hline
\end{tabular}




\begin{tabular}{|c|c|c|c|}
\hline Group & $\begin{array}{l}\text { Animal } \\
\text { Number }\end{array}$ & Organ & Findings \\
\hline \multirow{10}{*}{ Implant with cells } & \multirow{2}{*}{ 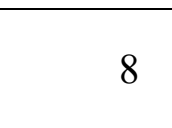 } & Kidney & No findings \\
\hline & & Liver & Inflammatory cell foci, Slight \\
\hline & \multirow[b]{2}{*}{9} & Kidney & Mononuclear cell foci, unilateral, minimal \\
\hline & & Liver & $\begin{array}{l}\text { Hemopoietic cell foci, minimal } \\
\text { Inflammatory cell foci, minimal }\end{array}$ \\
\hline & \multirow[t]{2}{*}{15} & Kidney & $\begin{array}{l}\text { Pyelitis, chronic, focal, unilateral, minimal } \\
\text { Cast, hyaline, focal, unilateral, minimal }\end{array}$ \\
\hline & & Liver & Hemopoietic cell foci, minimal \\
\hline & \multirow{2}{*}{21} & Kidney & Pyelitis, chronic, focal, unilateral, minimal \\
\hline & & Liver & Hemopoietic cell foci, minimal \\
\hline & \multirow{2}{*}{22} & Kidney & Mononuclear cell foci, unilateral, minimal \\
\hline & & Liver & Hemopoietic cell foci, minimal \\
\hline
\end{tabular}


Table S4. Hematology

\begin{tabular}{|c|c|c|c|c|c|c|}
\hline & \multicolumn{2}{|c|}{ Biocompatible control implant } & \multicolumn{2}{|r|}{$\begin{array}{l}\text { Implant with } \\
\text { cells }\end{array}$} & \multicolumn{2}{|c|}{ Implant without cells } \\
\hline & Mean & Standard deviation & Mean & Standard deviation & Mean & Standard deviation \\
\hline White blood cells $\left[10^{3} / \mathrm{mm}^{3}\right]$ & 11.08 & 3.33 & 13.18 & 4.17 & 13.90 & 3.76 \\
\hline Lymphocytes $\left[10^{3} / \mathrm{mm}^{3}\right]$ & 6.70 & 2.25 & 7.80 & 2.46 & 8.19 & 2.03 \\
\hline Monocytes $\left[10^{3} / \mathrm{mm}^{3}\right]$ & 0.55 & 0.18 & 0.73 & 0.32 & 0.71 & 0.22 \\
\hline Granulocytes $\left[10^{3} / \mathrm{mm}^{3}\right]$ & 3.83 & 0.99 & 4.65 & 1.82 & 5.00 & 2.04 \\
\hline Eosinophils $\left[10^{3} / \mathrm{mm}^{3}\right]$ & 1.43 & 0.65 & 1.09 & 0.64 & 1.06 & 0.78 \\
\hline Erythrocytes $\left[10^{6} / \mathrm{mm}^{3}\right]$ & 7.94 & 0.60 & 7.17 & 0.52 & 7.28 & 0.73 \\
\hline
\end{tabular}

Blood samples were taken from mice 21 days after implantation of one of the three items. White blood cells, lymphocytes, monocytes, granulocytes, eosinophils and erythrocytes were counted. $n=6$ for the biocompatible control implant group and $n=8$ for the other two groups. 
Table S5. Biocompatibility - single animal findings according to adapted ISO 10993-6:2016(E) scoring system

\begin{tabular}{|c|c|c|c|c|c|c|c|c|c|c|c|c|c|c|c|c|c|c|c|c|}
\hline \multirow[b]{3}{*}{ Animal: } & \multirow{2}{*}{\multicolumn{5}{|c|}{$\begin{array}{c}\text { Biocompatible reference } \\
\begin{array}{c}\text { Replica of Chamber } \\
\text { Section }\end{array}\end{array}$}} & \multirow{2}{*}{\multicolumn{5}{|c|}{$\begin{array}{c}\text { Implant without cells } \\
\begin{array}{c}\text { Chamber } \\
\text { Section }\end{array}\end{array}$}} & \multicolumn{10}{|c|}{ Implant with cells } \\
\hline & & & & & & & & & & & \multicolumn{5}{|c|}{ Chamber Section } & \multicolumn{5}{|c|}{ Switchboard Section } \\
\hline & 1 & 5 & 14 & 18 & 19 & 3 & 4 & 12 & 13 & 16 & $8 F$ & 9 & 15 & 21 & 22 & 8 & 9 & 15 & 21 & 22 \\
\hline Polymorphonuclear & 2 & 2 & 3 & 2 & 1 & 2 & 2 & 1 & 2 & 3 & 2 & 3 & 2 & 2 & 2 & 1 & 2 & 1 & 2 & 2 \\
\hline Lymphocytes & 1 & 2 & 2 & 2 & 2 & 1 & 2 & 2 & 1 & 1 & 2 & 2 & 2 & 1 & 1 & 2 & 1 & 2 & 1 & 1 \\
\hline Plasma cells & 0 & 0 & 0 & 0 & 1 & 0 & 0 & 0 & 0 & 0 & 0 & 0 & 0 & 0 & 0 & 0 & 0 & 0 & 0 & 0 \\
\hline Macrophages & 2 & 2 & 2 & 2 & 1 & 2 & 2 & 2 & 1 & 1 & 2 & 1 & 1 & 1 & 2 & 2 & 1 & 1 & 1 & 1 \\
\hline Giant cells & 0 & 0 & 0 & 0 & 0 & 0 & 0 & 0 & 0 & 0 & 0 & 0 & 0 & 0 & 0 & 0 & 0 & 0 & 0 & 0 \\
\hline Necrosis & 0 & 0 & 0 & 0 & 0 & 1 & 0 & 0 & 0 & 0 & 0 & 0 & 0 & 0 & 0 & 0 & 0 & 0 & 0 & 0 \\
\hline Subtotal (x2) & 10 & 12 & 14 & 12 & 10 & 12 & 12 & 10 & 8 & 10 & 12 & 12 & 10 & 8 & 10 & 10 & 8 & 8 & 8 & 8 \\
\hline Neovascularisation & 2 & 2 & 3 & 2 & 2 & 1 & 1 & 1 & 1 & 1 & 2 & 1 & 2 & 2 & 1 & 1 & 1 & 1 & 1 & 2 \\
\hline Fibrosis & 3 & 3 & 3 & 3 & 3 & 2 & 3 & 3 & 3 & 2 & 3 & 3 & 3 & 2 & 3 & 2 & 2 & 2 & 2 & 3 \\
\hline Fatty infiltrate & 0 & 0 & 0 & 0 & 0 & 0 & 0 & 0 & 0 & 0 & 0 & 0 & 0 & 0 & 0 & 0 & 0 & 0 & 0 & 0 \\
\hline $\begin{array}{l}\text { Detritus within } \\
\text { fibrous capsule }\end{array}$ & 1 & 1 & 1 & 2 & 0 & 2 & 1 & 0 & 0 & 1 & 2 & 1 & 1 & 1 & 1 & 1 & 1 & 0 & 1 & 1 \\
\hline Subtotal & 6 & 6 & 7 & 7 & 5 & 5 & 5 & 4 & 4 & 4 & 7 & 5 & 6 & 5 & 5 & 4 & 4 & 3 & 4 & 6 \\
\hline Total & 16 & 18 & 21 & 19 & 15 & 17 & 17 & 14 & 12 & 14 & 19 & 17 & 16 & 13 & 15 & 14 & 12 & 11 & 12 & 14 \\
\hline
\end{tabular}


Table S6. Energy consumption of optogenetic and electrogenetic implants

\begin{tabular}{|c|c|c|c|c|}
\hline Description & $\begin{array}{l}\text { Peak current } \\
\qquad[\mathrm{mA}]\end{array}$ & $\begin{array}{c}\text { Average current } \\
\qquad[\mathbf{m A}]\end{array}$ & $\begin{array}{c}\text { Predicted } \\
\text { theoretical battery } \\
\text { lifetime }[\mathrm{h}]\end{array}$ & Source \\
\hline Near infrared optogenetic implant & 28 & 14 & 143 & Folcher et al. (10) \\
\hline $\begin{array}{l}\text { Near infrared optogenetic implant } \\
\text { "HydroLED", }\end{array}$ & $350 *$ & 350 & 5.7 & Shao et al. (6) \\
\hline Electrogenetic implant & 13 & 0.027 & 75000 & This work \\
\hline
\end{tabular}

Average current was calculated assuming that no current is drawn between pulses. Predicted theoretical battery lifetime was calculated for a typical battery used for implantable cardiac pacemakers, which is $2 \mathrm{Ah}(52)$. The electrogenetic implant used in this work generates peak current of around $13 \mathrm{~mA}$ in $2 \mathrm{~ms}$ pulses at $1 \mathrm{~Hz}$ frequency. The optogenetic implant published by Folcher et al. (10) generates peak current of up to $28 \mathrm{~mA}$ for $30 \mathrm{~s}$ followed by $30 \mathrm{~s}$ of resting time.

*Authors did not measure the output current. The calculation was based on typical LED current value provided by the manufacturer. 
Table S7. Plasmids used and designed in this study

\begin{tabular}{|c|c|c|}
\hline Plasmid & Description and cloning strategy & Reference \\
\hline $\mathrm{pCa}_{\mathrm{v}} \alpha_{1} \mathrm{C}$ & Constitutive $\alpha_{1} \mathrm{C}$ expression vector ( $\mathrm{P}_{\mathrm{hCMV}}-\alpha_{1} \mathrm{C}-\mathrm{pA}$ ). (Addgene no. 26572). & $(60)$ \\
\hline $\mathrm{pCa}_{\mathrm{v}} \alpha_{1} \mathrm{D}_{\Delta 42}$ & Constitutive $\alpha_{1} \mathrm{D}_{\Delta 42}$ expression vector $\left(\mathrm{P}_{\mathrm{hCMV}}-\alpha_{1} \mathrm{D}_{\Delta 42}-\mathrm{pA}\right)$. (Addgene no. 49332). & $(61)$ \\
\hline $\mathrm{pCa}_{\mathrm{v}} \alpha_{1} \mathrm{D}_{42 \mathrm{~A}}$ & Constitutive $\alpha_{1} \mathrm{D}_{42 \mathrm{~A}}$ expression vector $\left(\mathrm{P}_{\mathrm{hCMV}}-\alpha_{1} \mathrm{D}_{42 \mathrm{~A}}-\mathrm{pA}\right)$. (Addgene no. 49333$)$. & $(61)$ \\
\hline $\mathrm{pCa}_{\mathrm{v}} \alpha_{2} \delta_{1}$ & Constitutive $\alpha_{2} / \delta_{1}$ expression vector $\left(\mathrm{P}_{\mathrm{hCMV}}-\alpha_{2} / \delta_{1}-\mathrm{pA}\right)$. (Addgene no. 26575). & $(62)$ \\
\hline $\begin{array}{l}\text { pcDNA3.1 } \\
(+)\end{array}$ & Constitutive mammalian expression vector containing a NeoR resistance gene ( $\left.\mathrm{P}_{\mathrm{hCMV}}-\mathrm{MCS}-\mathrm{pA}\right)$ & $\begin{array}{l}\text { Thermo } \\
\text { Fisher } \\
\text { Scientific, } \\
\text { CA }\end{array}$ \\
\hline $\begin{array}{l}\text { pCMV-T7- } \\
\text { SB100 }\end{array}$ & Constitutive SB100X expression vector ( $\mathrm{P}_{\mathrm{hCMV}}$-SB100X-pA). (Addgene no. 34879). & $(64)$ \\
\hline pEGFP-N1 & Constitutive EGFP expression vector ( $\mathrm{P}_{\mathrm{hCMv}}$-EGFP-pA). & $\begin{array}{l}\text { Clontech, } \\
\text { CA }\end{array}$ \\
\hline
\end{tabular}




\begin{tabular}{|c|c|c|}
\hline Plasmid & Description and cloning strategy & Reference \\
\hline $\begin{array}{l}\text { pGEM-T } \\
\text { Easy }\end{array}$ & Bacterial expression vector. & $\begin{array}{l}\text { Promega, } \\
\text { WI }\end{array}$ \\
\hline $\begin{array}{l}\text { pGEMTEZ } \\
-K_{\text {ir }} 2.1\end{array}$ & pGEM-T Easy containing $\mathrm{K}_{\mathrm{ir}} 2.1$. (Addgene no. 32641). & $(65)$ \\
\hline pMX57 & $\mathrm{P}_{\mathrm{NFAT3}}$-driven SEAP expression vector ( $\left.\mathrm{P}_{\mathrm{NFAT} 3}-\mathrm{SEAP}-\mathrm{pA}\right)$. & $(5)$ \\
\hline pSBbi-BP & 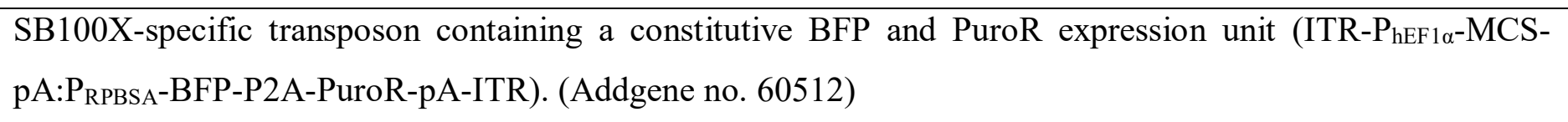 & $(68)$ \\
\hline $\begin{array}{l}\text { pSEAP2- } \\
\text { Control }\end{array}$ & Constitutive mammalian SEAP expression vector (PSV40-SEAP-pA) & $\begin{array}{l}\text { Clontech, } \\
\text { CA }\end{array}$ \\
\hline psPAX2 & Lentiviral packaging vector. (Addgene no. 12260) & $(69)$ \\
\hline pKK5 & Constitutive Kir2.1 expression vector ( $\left.\mathrm{P}_{\mathrm{hCMv}}-\mathrm{Kir} 2.1-\mathrm{pA}\right) . \mathrm{K}_{\mathrm{ir}} 2.1$ was excised from pGEMTEZ-K $\mathrm{K}_{\mathrm{ir}} 2.1$ using & This work \\
\hline
\end{tabular}




\begin{tabular}{|c|c|c|}
\hline Plasmid & Description and cloning strategy & Reference \\
\hline pKK55 & 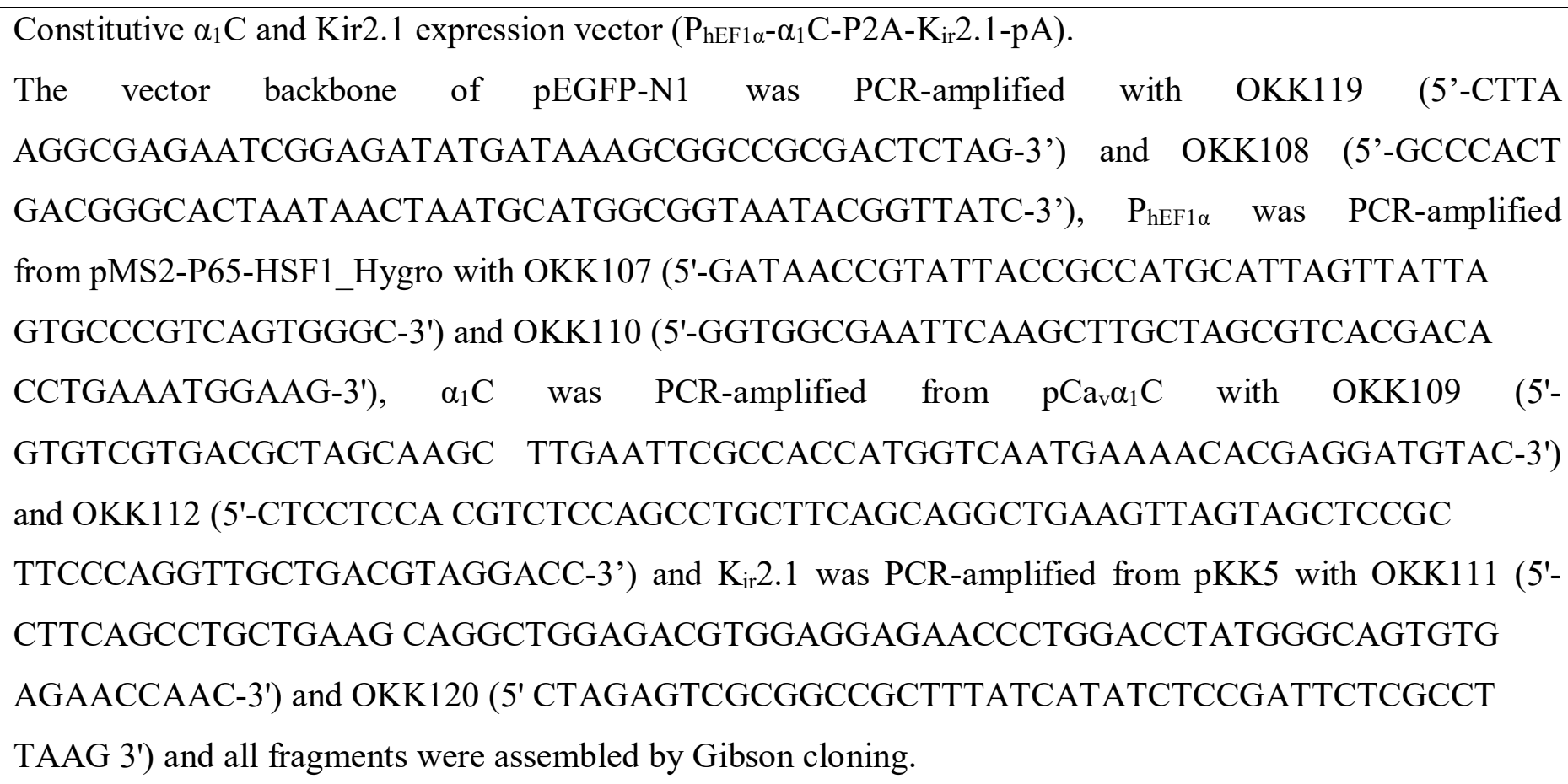 & This work \\
\hline pKK56 & 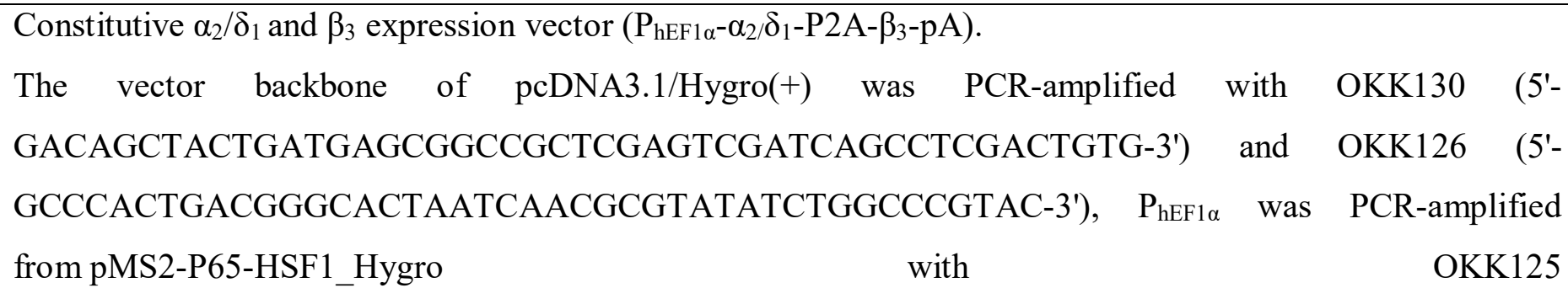 & This work \\
\hline
\end{tabular}




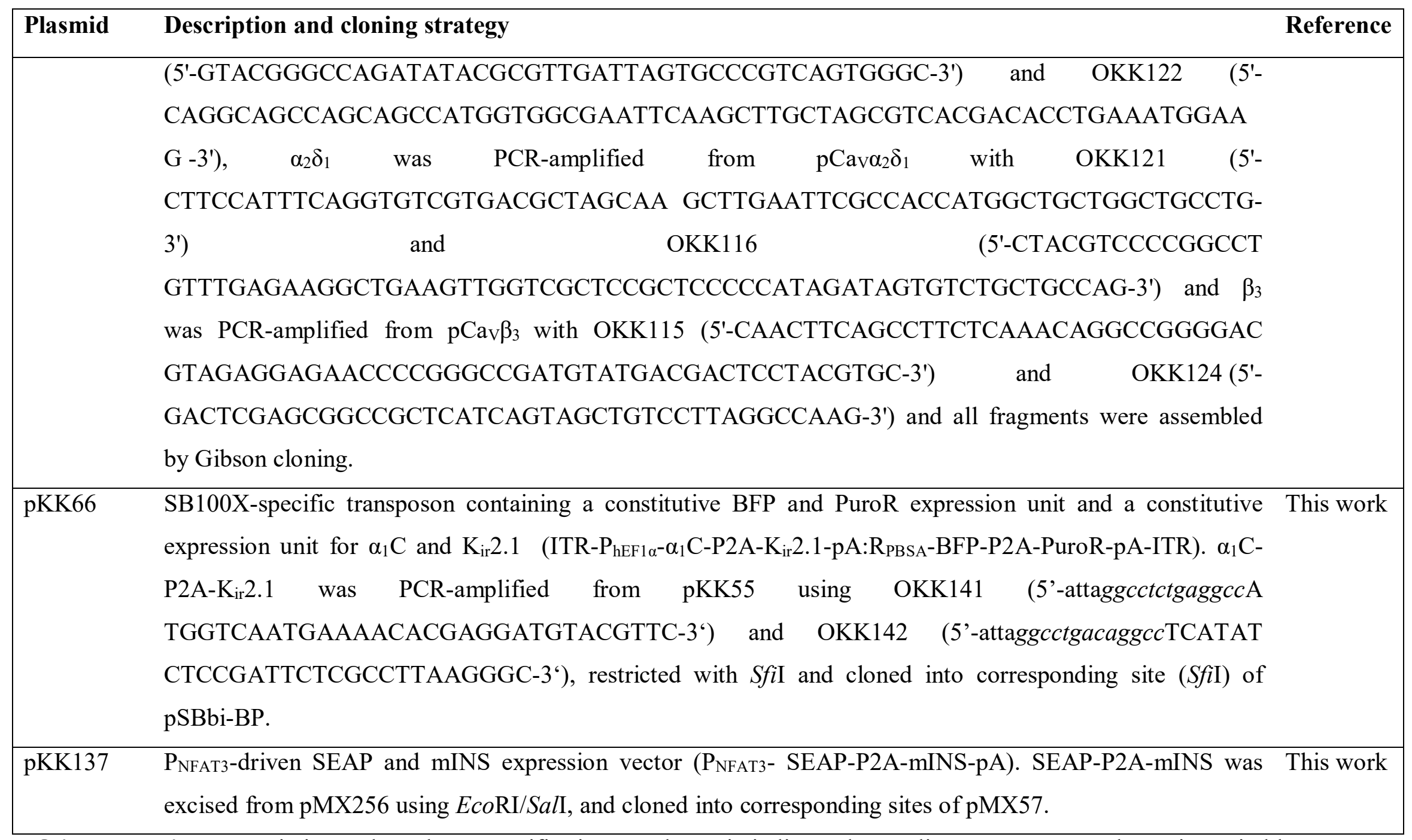

Oligonucleotides: Restriction endonuclease-specific sites are shown in italics and annealing sequences are shown in capital letters. 
Abbreviations: $\alpha_{1} \mathbf{C}, \alpha_{1} \mathrm{C}$ subunit of the murine L-type voltage-gated calcium channel $\mathrm{Ca}_{\mathrm{v}} 1.2 ; \boldsymbol{\alpha}_{1} \mathbf{D}_{42 \mathrm{~A}}, \alpha_{1} \mathrm{D}_{42 \mathrm{~A}}$ subunit of the murine L-type voltage-gated calcium channel $\mathrm{Ca}_{\mathrm{v}} 1.3 ; \boldsymbol{\alpha}_{\mathbf{1}} \mathbf{D}_{\Delta \mathbf{4 2}}, \alpha_{1} \mathrm{D}_{\Delta 42}$ subunit of the murine L-type voltage-gated channel Ca $1.3 ; \boldsymbol{\alpha}_{2} / \boldsymbol{\delta}_{1}, \boldsymbol{\alpha}_{2}$ and $\delta_{1}$ subunits of the murine L-type voltage-gated calcium channel $\mathrm{Ca}_{\mathrm{v}} 1.2 ; \beta_{3}, \beta_{3}$ subunit of the murine L-type voltage-gated calcium channel Ca $\mathrm{C}_{\mathrm{v}} 1.2$; BFP, blue fluorescent protein; BlastR, blasticidin resistance gene; Ca 1.2 , member 2 of the Ca 1 family of L-type voltage-gated calcium channels; Ca $\mathbf{C} \mathbf{1 . 3}$, member 3 of the $\mathrm{Ca}_{\mathrm{v}} 1$ family of L-type voltage-gated calcium channels; dTomato, dimeric red fluorescent protein variant; EGFP, enhanced green fluorescent protein; HygroR, hygromycin resistance gene; ITR, inverted terminal repeats of SB100X; $\mathbf{K}_{\mathbf{i r}} \mathbf{2 . 1}$, murine inwardly rectifying potassium channel; MCS, multiple cloning site; mINS, modified insulin variant for optimal expression in HEK-293 cells ; NanoLuc, Oplophorus gracilirostris luciferase; NeoR, neomycin resistance gene; NFAT, nuclear factor of activated T-cells; $\mathbf{p A}$, polyadenylation signal; $\boldsymbol{P 2 A}$; porcine teschovirus-1 2A self-cleaving peptide; PCR, polymerase chain reaction; $\mathbf{P}_{\mathbf{h C M V}}$, human cytomegalovirus immediate early promoter; $\mathbf{P}_{\mathbf{h E F} \mathbf{1} \alpha}$, human elongation factor 1 alpha promoter; $\mathbf{P}_{\mathbf{N F A T}}$, synthetic mammalian promoter containing five tandem repeats of a human IL-4 NFAT-binding site; ProinsulinNanoLuc, modified proinsulin with its C-peptide replaced by NanoLuc; $\mathbf{P}_{\mathbf{R P B S A}}$, constitutive synthetic mammalian promoter; $\mathbf{P}_{\text {SV40, }}$ simian virus 40 promoter; PuroR, puromycin resistance gene; SB100X, optimized Sleeping Beauty transposase; SEAP, human placental secreted alkaline phosphatase; VSV-G, vesicular stomatitis virus protein G; ZeoR, zeocin resistance gene. 
Table S8. Electronic components of the bioelectronic implant

\begin{tabular}{|c|c|c|c|}
\hline Designator & Description & Manufacturer & Manufacturer part number \\
\hline BAS28 & High-speed double diode & NXP & BAS28,215 \\
\hline BC856 & PNP Epitaxial Silicon Transistor & NXP & $\mathrm{BC} 856 \mathrm{~B}$ \\
\hline ZD15 & Voltage regulator diodes BZX84 & NXP & $\mathrm{BZX} 84 / \mathrm{C} 15$ \\
\hline BAT54C & Schottky barrier (double) diode & NXP & BAT54C \\
\hline LMC555 & CMOS Timer & Texas Instruments & LMC555CMM/NOPB \\
\hline $10 \mathrm{k}$ & Resistor $10 \mathrm{k}$ & Vishay & CRCW080510K0FKEA \\
\hline $1.5 \mathrm{k}$ & Resistor $1.5 \mathrm{k}$ & Vishay & CRCW08051K50FKEA \\
\hline $1.6 \mathrm{M}$ & Resistor $1.6 \mathrm{M}$ & Vishay & CRCW08051M60FKEA \\
\hline $100 \mathrm{pF}$ & Capacitor $100 \mathrm{pF}$ & Murata & GRM2165C1H101JA01D \\
\hline $68 \mathrm{pF}$ & Capacitor $68 \mathrm{pF}$ & RND Electronics & RND1500805N680J500 \\
\hline $1 \mathrm{uF}$ & Capacitor $1 \mathrm{uF}$ & RND Electronics & RND1500805B105K250 \\
\hline $6.5-30 \mathrm{pF}$ & Trimmer capacitor & Murata & TZC3P300A310R00 \\
\hline
\end{tabular}

Manufacturers: NXP Semiconductors, Eindhoven, Netherlands; Texas Instruments, Dallas, TX, USA; Vishay, Malvern, PA, USA; RND Electronics, Nänikon, Switzerland; Murata Manufacturing Co., Nagaokakyō, Japan. 